ISABEL CRISTINA ITALIANO

\title{
UM MODELO PARA MANUTENÇÃO DE ESQUEMA E DE DADOS EM DATA WAREHOUSES IMPLEMENTADOS EM PLATAFORMAS MÓVEIS
}

Tese apresentada à Escola Politécnica da Universidade de São Paulo para obtenção do Título de Doutor em Engenharia.

Área de Concentração:

Sistemas Digitais

Orientador:

Prof. Dr. Jorge Rady de Almeida Junior

São Paulo

Exemplar Original: 2007

Exemplar Revisado: 2007 
Este exemplar foi revisado e alterado em relação à versão original, sob responsabilidade única do autor e com a anuência de seu orientador.

São Paulo, 30 de junho de 2007

FICHA CATALOGRÁFICA

Italiano, Isabel Cristina

Um modelo para manutenção de esquema e de dados em data warehouses implementados em plataformas móveis / I.C. Italiano. -- São Paulo, 2007.

$143 \mathrm{p}$.

Tese (Doutorado) - Escola Politécnica da Universidade de São Paulo. Departamento de Engenharia de Computação e Sistemas Digitais.

1.Banco de dados 2.Banco de dados distribuídos 3.Sistemas de informação l.Universidade de São Paulo. Escola Politécnica. Departamento de Engenharia de Computação e Sistemas Digitais Il.t. 


\section{DEDICATÓRIA}

À minha filha Isabella, por sua compreensão nos incontáveis momentos em que fiquei ausente. 


\section{AGRADECIMENTOS}

Ao professor Jorge Rady de Almeida Junior por sua orientação, compreensão e paciência infinitas para com minhas limitações de tempo e disponibilidade.

Aos professores Jorge Luis Risco Becerra e João Eduardo Ferreira pelas importantes sugestões oferecidas para o direcionamento deste trabalho.

À minha família pelo apoio e estímulo que sempre recebi.

A todos os amigos que, direta ou indiretamente, contribuíram para que eu pudesse concluir mais esta etapa. 


\section{RESUMO}

O presente trabalho propõe uma arquitetura de utilização de Data Warehouses em computadores móveis, descreve os componentes desta arquitetura (dados e processos) que permite o sincronismo dos dados baseado em metadados e limitado ao escopo de acesso de cada usuário. As estruturas de dados e os processos que compõem a arquitetura proposta são reduzidos a problemas conhecidos e já solucionados, justificando sua viabilidade. Além disso, o presente trabalho também fornece diretrizes para avaliar a complexidade e o impacto causados por alterações de esquema no Data Warehouse central que devem ser refletidas nos data marts localizados nas plataformas móveis. A avaliação da complexidade e impacto das alterações nos esquemas do Data Warehouse pode auxiliar os administradores do ambiente a planejar a implementação destas alterações, propondo melhores alternativas no caso de alterações de esquema mais complexas e que causem um impacto maior no ambiente. A importância do trabalho está relacionada a casos reais de necessidade de evolução nas bases de dados analíticas (Data Warehouse) em computadores móveis, nos quais os usuários mantêm seu próprio subconjunto de dados do Data Warehouse para apoiar os processos de negócios.

Palavras-chave: Data Warehouse, Data Warehouse distribuído, Banco de dados, Metadados. 


\begin{abstract}
This work presents an architecture for using Data Warehouses in mobile computers and describes the architecture components (data and processes) that allow the data synchronism based on metadata and restricted to the scope of access for each user. The data structures and the processes composing the architecture are reduced to already known and solved problems, justifying its feasibility. Besides, this work also provides the guidelines to evaluate the complexity and impact caused by changes of schema in the central Data Warehouse that must be reflected in the data marts located in the mobile platforms. The analysis of the complexity and impact of the changes made to the schemas may help environment administrators to plan these changes and propose better alternatives when dealing with more complex schema changes causing a greater impact on the environment. The relevance of this work is related to real cases that require evolution of analytical databases (Data Warehouse) in mobile computers in which the users keep their own subset of Data Warehouse information to support their business processes.
\end{abstract}

Keywords: Data Warehouse, Distributed Data Warehouse, Distributed Databases, Metadata. 


\section{LISTA DE ILUSTRAÇÕES}

Figura 1-Modelo de Data Warehouse tradicional conectado às suas fontes de informação

Figura 2- Modelo simplificado da arquitetura do Data Warehouse em plataformas móveis, proposta por este trabalho.

Figura 3 - Modelo da arquitetura do Data Warehouse em plataformas móveis. proposta neste trabalho, mostrando a utilização dos componentes de metadados

Figura 4 - Exemplo de evolução de esquema baseado em metadados.

Figura 5 - Duas categorias de arquitetura de bases de dados, representando diferentes níveis de acoplamento (AMBLER; SADALAGE, 2006). .... .38

Figura 6 - O processo do database refactoring (AMBLER; SADALAGE, 2006).......41

Figura 7 - $O$ processo de implantação do database refactoring. 45

Figura 8 - Os principais componentes de um sistema de Data Warehouse. .50

Figura 9-MME - ambiente de gerenciamento de metadados proposto por Marco $\underline{(2004)}$ 55

Figura 10 - O metamodelo do CWM. 67

Figura 11 - Etapas do controle de segurança dos dados. .78

Figura 12 - Arquitetura de utilização de Data Warehouse em plataformas móveis visão geral das estruturas e processos.

Figura 13 - Principais fases para sincronismo do Data Warehouse central com as bases nas estações clientes

Figura 14 - Representação do nível de acoplamento das bases de dados do Data Warehouse central e das plataformas móveis.

Figura 15 - Implementação do modelo do estudo de caso na arquitetura proposta 109

Figura 16 - Modelo multidimensional de Vendas utilizado no estudo de caso 110 


\section{LISTA DE TABELAS}

Tabela 1 - Características dos processos de sincronização destacando as principais diferenças entre a primeira e segunda etapa........................................... 13

Tabela 2 - Resumo das opcões de sincronismo escolhidas para o presente trabalho.

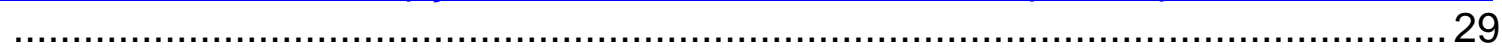

Tabela 3 - Categorias de database refactoring (AMBLER; SADALAGE, 2006).......39

Tabela 4 - Componentes do controle de segurança de acesso. ..............................74

Tabela 5 - Operações para avaliação de complexidade e impactos das alterações de esquema (continua) …….................................................................... 103

Tabela 6 - Representação das operações resultantes do estudo de caso (continua) 


\section{LISTA DE ABREVIATURAS E SIGLAS}

$\begin{array}{ll}\text { DW } & \text { Data Warehouse } \\ \text { DM } & \text { Data Mart } \\ \text { OLAP } & \text { On-Line Analytical Processing } \\ \text { SQL } & \text { Structured Query Language } \\ \text { MME } & \text { Managed Meta data Environment } \\ \text { ADW } & \text { Administrador do Data Warehouse } \\ \text { ETL } & \text { Extraction, Transformation and Load } \\ \text { CWM } & \text { Common Warehouse Metamodel }\end{array}$




\section{SUMÁRIO}

1 INTRODUÇÃO ............................................................................ 1

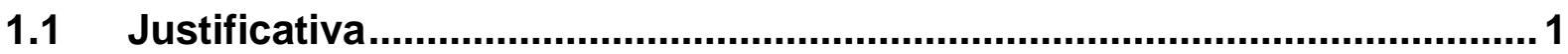

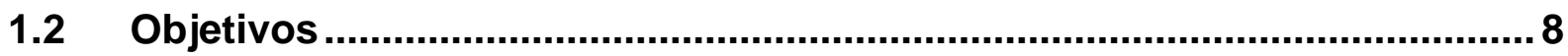

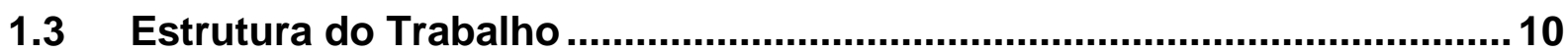

2 MODELOS DE SINCRONISMO DE DATA WAREHOUSE............. 11

2.1 Modelos de sincronismo para a primeira etapa de sincronização -

Transferência de dados para o DATA WAREHOUSE central.............................13

2.1.1 Sincronismo baseado em processos de carga periódicos ...............14

2.1.2 Sincronismo baseado em visões materializadas...............................19

2.2 Modelos de sincronismo para a segunda etapa de sincronização Transferência de dados para os data marts móveis............................................25

2.3 Resumo das opções de sincronismo escolhidas para a arquitetura

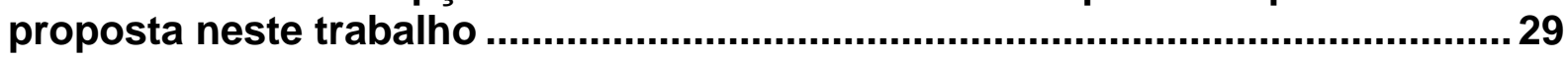

3 A MANUTENÇÃO DO ESQUEMA NO DATA WAREHOUSE ........ 30

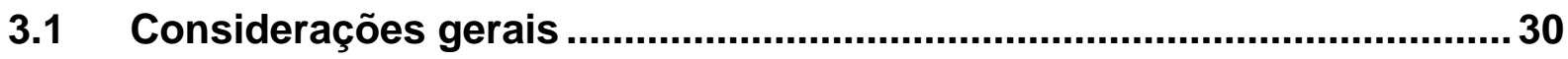

3.2 A evolução do esquema de bases de dados ............................................33





3.3.2 Classificação dos database refactorings........................................38

3.3.3 O processo de desenvolvimento do database refactoring ..............39

3.3.4 O processo de implantação do database refactoring em produção 43

3.4 A utilização dos conceitos sobre evolução de esquema para a arquitetura proposta neste trabalho.

4 A UTILIZAÇÃO DE METADADOS ............................................. 47

4.1 A importância dos metadados e suas aplicações ...................................... 47

4.2 Metadados em sistemas de Data Warehouse ..........................................49

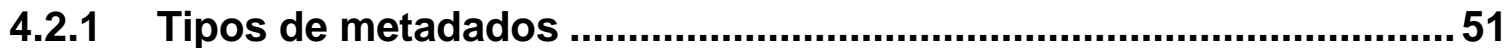

4.2.2 Arquiteturas de metadados..............................................................53




4.4 Esforços de padronização de metadados para Data Warehouse .............59

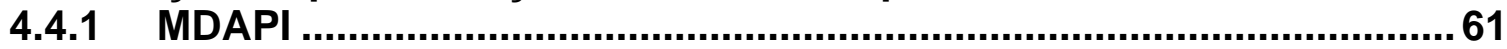

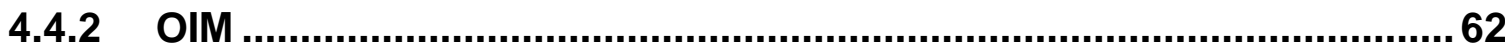

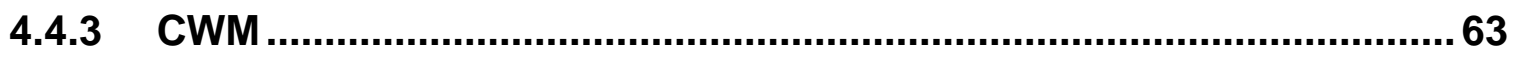

4.5 O padrão de metadados escolhido para a arquitetura proposta neste trabalho

4.5.1 O metamodelo do CWM .



4.5.3 Estudo de viabilidade de utilização do CWM ...................................70

5 SEGURANÇA DE ACESSO EM DATA WAREHOUSES .............. 72



5.2 A necessidade de metadados de segurança ...........................................74

5.3 Os componentes de segurança escolhidos para a arquitetura proposta

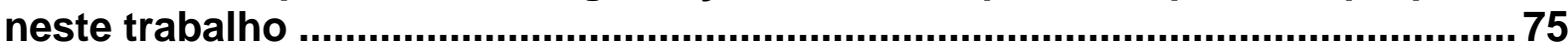

5.3.1 O cadastramento do perfil dos usuários .........................................76

5.3.2 Segurança na validação e preparação para a sincronização............77

5.3.3 Segurança durante a sincronização..................................................77

6 PROPOSTA DE ARQUITETURA PARA SINCRONISMO DE DATA WAREHOUSES EM PLATAFORMAS MÓVEIS................................... 79

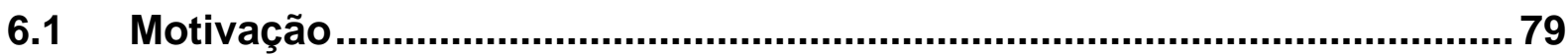

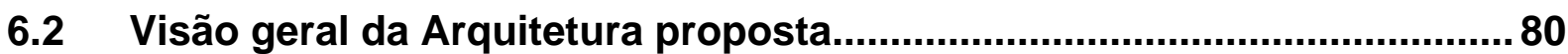

6.2.1 As estruturas de dados que compõem a arquitetura proposta ........82

6.2.2 Os processos que compõem o sincronismo entre o Data

Warehouse central e as bases de dados das plataformas móveis ...............86

6.3 A avaliação da complexidade e do impacto das alterações no esquema91 6.3.1 O cenário de manutenção de esquema.............................................94

6.3.2 O processo de análise da complexidade e do impacto das alterações no Data Warehouse central........................................................96

6.3.3 Resumo do modelo de avaliação de complexidade e impacto da

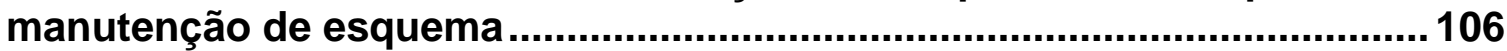

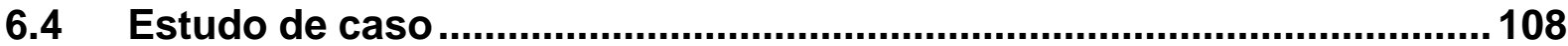

6.4.1 Representação na arquitetura proposta ....................................... 108

6.4.2 A segunda etapa do processo de sincronismo .............................113

6.4.3 O processo de manutenção de esquema ........................................115 


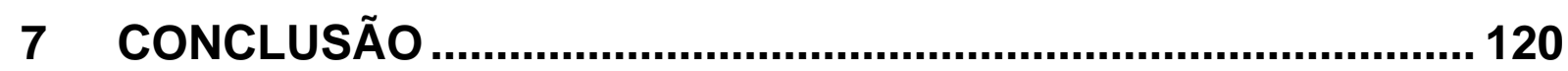

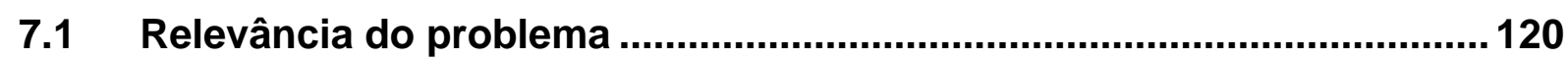

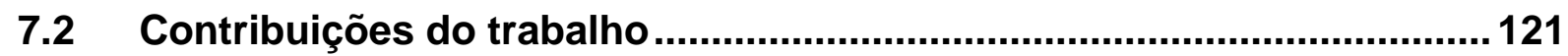

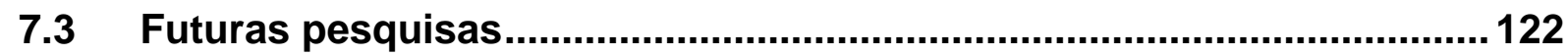

REFERÊNCIAS BIBLIOGRÁFICAS .......................................... 124 


\section{INTRODUÇÃO}

DATA WAREHOUSES ${ }^{1}$ são bases de dados integradas, construídas a partir de fontes distribuídas, autônomas e, muitas vezes, heterogêneas (ZHUGE et al., 1995), disponíveis para consultas e análises por meio de aplicações OLAP (On-Line Analytical Processing) e sistemas de apoio à decisão (GUPTA; JAGADISH; MUMICK, 1996).

A utilização dos Data Warehouses atualmente está bastante difundida, já que proporciona um alicerce sólido de integração de dados corporativos e históricos para a realização de análises gerenciais. A construção e implementação de um Data Warehouse têm por base a organização e armazenamento dos dados sob uma perspectiva de longo prazo. Assim, a partir dos dados históricos básicos, pode-se realizar análises de comportamento e tendências (INMON; HACKATHORN, 1997).

\subsection{JUSTIFICATIVA}

Por sua característica básica, que é a integração de dados provenientes de várias fontes diferentes, a etapa mais complexa na implementação de um Data Warehouse é o processo de carga. Estas várias fontes são as bases de dados de produção, que contêm os dados utilizados pelos vários sistemas transacionais de uma empresa. É importante lembrar que estas fontes de informação podem ser de natureza bastante diversa, desde informação bem estruturada, armazenada em bases de dados relacionais até informação não estruturada como páginas de Internet ou arquivos seqüenciais. Durante o processo de carga, os dados distribuídos pelos vários ambientes operacionais devem ser selecionados, trabalhados com o objetivo de padronização e eliminação de inconsistências, transferidos para o novo ambiente e finalmente carregados, sempre atendendo ao padrão de modelagem utilizada para o Data Warehouse.

\footnotetext{
${ }^{1} \mathrm{O}$ termo Data Warehouse, que pode ser traduzido para depósito ou armazém de dados, é sempre encontrado na literatura escrita em português na sua forma original, em inglês.
} 
Normalmente, este processo é feito periodicamente, sendo que sua freqüência depende de fatores relacionados ao modelo de negócios utilizado pela empresa e, normalmente, não é menor que 24 horas. Desta forma, os dados armazenados no Data Warehouse, após sofrerem a primeira carga, são incrementados por meio de cargas periódicas que devem refletir o ambiente operacional ao longo do tempo, tornando-o uma imensa base de dados para os sistemas de apoio à decisão. Uma vez armazenados no Data Warehouse, estes dados normalmente não sofrem atualizações, sendo, portanto, um ambiente apenas de carga e acesso.

Uma outra forma de implementar um Data Warehouse é defini-lo como um conjunto de visões materializadas que integram os dados a partir de múltiplas fontes heterogêneas de informação (IEEE DATA ENGINEERING BULLETIN, 1995).

Uma visão é uma relação derivada, definida em termos de relações base, que é computada todas as vezes que uma referência a ela é feita. Uma visão é dita materializada quando ela é realmente armazenada na base de dados em vez de ser computada a partir das relações base em resposta a consultas (QUASS et al., 1996). Um aspecto importante é que estas visões ficam obsoletas a partir do momento que ocorre uma atualização nos dados do ambiente origem. Para que voltem a refletir os dados é necessário que um processo de sincronismo das visões seja executado, e as atualizações realizadas nos dados do ambiente origem sejam implementadas também nas visões materializadas. Inúmeras pesquisas vêm desenvolvendo mecanismos com o objetivo de agilizar e garantir a correta e rápida propagação das atualizações ocorridas nas fontes de dados (AGRAWAL, 1997; QUASS et al., 1996; ZHUGE; GARCIA-MOLINA; WIENER, 1998; SALEM et al., 2000; GONÇALVES, 2002).

O uso das visões materializadas confere ao Data Warehouse características que possibilitam um modelo de sincronismo mais dinâmico, em vez do modelo estático implementado por meio de cargas periódicas.

O modelo de Data Warehouse descrito até este ponto, seja implementado com cargas periódicas ou atualização de visões materializadas, caracteriza um ambiente tradicional, sendo que as informações de origem (sistemas transacionais) e as informações destino (Data Warehouse) são componentes conectados. As aplicações analíticas executadas pelos usuários estão em estações cliente conectadas ao Data 
Warehouse que, por sua vez, se mantém conectado às bases de informações origem.

Desta forma, usuários podem ter à disposição acesso às aplicações analíticas e às informações armazenadas no Data Warehouse em computadores móveis.

Com isso, Stanoi et al. (1999) sugerem que o modelo tradicional de Data Warehouses, representado na Figura 1, precisa ser adaptado para um ambiente em que os consumidores de informação e até, eventualmente, os produtores estejam em plataformas móveis.

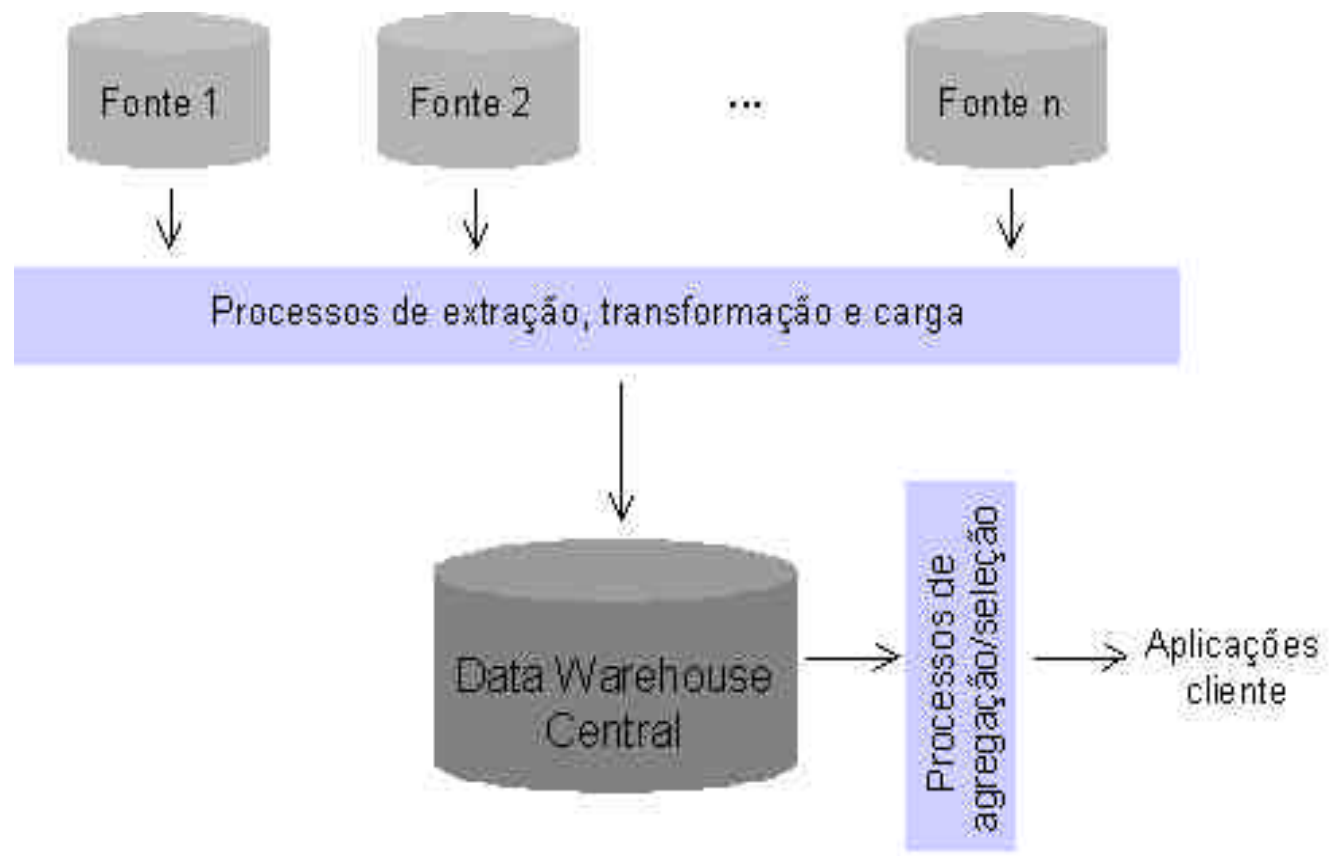

Figura 1- Modelo de Data Warehouse tradicional conectado às suas fontes de informação

Conforme Lee; Si e Va Leong (2000), um ambiente móvel difere de um ambiente convencional cliente-servidor principalmente em dois aspectos. Primeiro, a comunicação entre o cliente móvel e o servidor é realizada, normalmente, por meio de canais de rede sem fio. Segundo, uma rede sem fio está sujeita a quedas de desconexão constantes. Estas características geram alto custo no acesso e consultas à base de dados do servidor, a partir de um ambiente móvel. Assim, (LEE; SI; VA LEONG, 2000) propõe manter visões materializadas do Data Warehouse localmente armazenadas na plataforma móvel. Estas visões materializadas podem 
manter apenas as informações necessárias às análises do cliente móvel, reduzindo a dependência de acesso constante ao servidor.

Com base nesta proposta, o ambiente de Data Warehouse (ou data marts ${ }^{2}$ ) em plataformas móveis pode também ser visto como um conjunto de visões materializadas do Data Warehouse, da mesma forma que o modelo de Data Warehouse tradicional conectado é visto como um conjunto de visões materializadas das fontes de informação. Igualmente, as visões de dados das plataformas móveis tornam-se obsoletas, já que tais plataformas podem ficar desconectadas das fontes por longos períodos de tempo, enquanto que as fontes de informação são, freqüentemente, atualizadas. Assim, ao se reconectar às fontes, o Data Warehouse em uma plataforma móvel pode ser atualizado de forma similar aos processos de manutenção das visões dos Data Warehouses tradicionais, inclusive com os processos de manutenção incremental das visões, tema já bastante discutido nos ambientes de Data Warehouse tradicional.

Nesta abordagem, o ambiente de Data Warehouse em plataformas móveis adiciona complexidade ao modelo tradicional e requer a inclusão de novos componentes de dados e de processos. Uma visão simplificada da arquitetura proposta por este trabalho, que permita a implementação deste ambiente distribuído pode ser vista na Figura 2.

Nesta figura pode-se visualizar as plataformas móveis conectadas ao servidor do Data Warehouse central, no momento de sua sincronização, em que cada plataforma móvel solicita a execução dos processos de sincronismo. A conexão ao servidor de Data Warehouse pode ser efetuada conforme a periodicidade desejada pelo usuário e a o processo de sincronização na plataforma móvel estabelece qual o subconjunto de dados requerido.

As aplicações analíticas executadas nas plataformas móveis acessam diretamente os data marts locais, sem a necessidade de buscar dados no Data Warehouse central no momento da execução das consultas e análises.

Um aspecto importante a se destacar é que os data marts localizados nas plataformas móveis armazenam subconjuntos distintos do Data Warehouse central.

\footnotetext{
${ }^{2}$ Data marts são bases de dados que contêm partes ou segmentos do Data Warehouse.
} 
Estes subconjuntos são definidos em função do modelo de negócios e das necessidades de cada usuário. Isto significa que é necessário um controle sobre como e quais dados serão transportados do Data Warehouse central para os data marts.

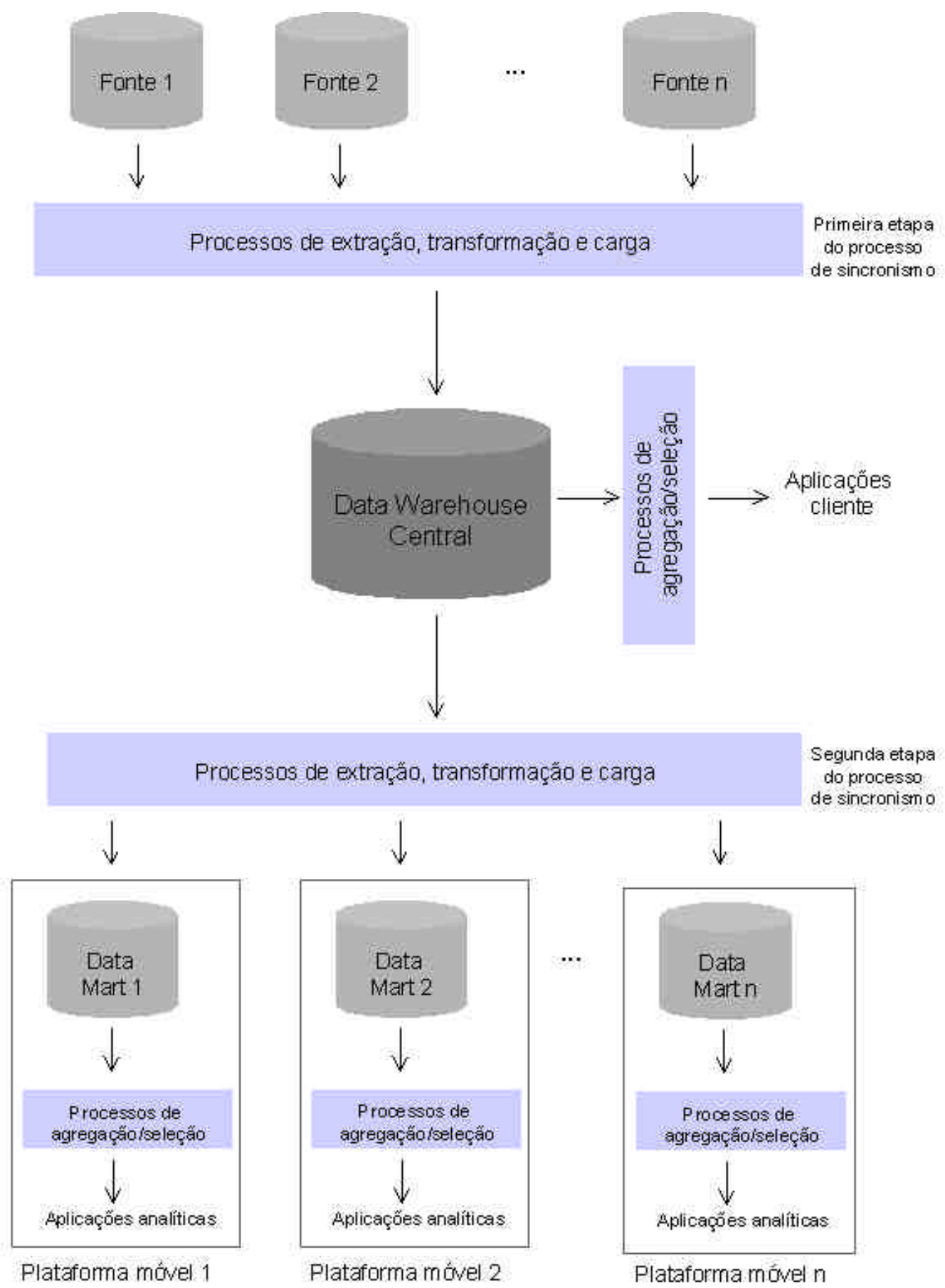

Figura 2- Modelo simplificado da arquitetura do Data Warehouse em plataformas móveis, proposta por este trabalho 
É neste contexto que surge a necessidade de se levar em conta a utilização de metadados. Conforme Stöhr; Muller e Rahm (1999), o gerenciamento dos metadados é essencial na administração, manutenção e uso dos Data Warehouses. Devido à complexidade crescente das arquiteturas propostas para ambientes de Data Warehouses é necessário um repositório que gerencie os metadados, isto é, informações sobre estrutura, conteúdo e interdependência dos componentes do Data Warehouse. Fan e Poulovassilis (2003) também destacam a importância do uso de metadados em ambientes de Data Warehouse, pois, tipicamente, os metadados devem gerenciar informações sobre dados (esquemas das bases de dados, propriedade dos dados, segurança de acesso aos dados etc.) e processos (regras para extração dos dados, transformações, mecanismos de sincronismo e eliminação de inconsistências das bases, linhagem dos dados migrados e convertidos etc.). Staudt; Vaduva e Vetterli (1999) fizeram um estudo sobre os esforços realizados para se definir um padrão para metadados de Data Warehouse e apresentaram algumas das implementações destes padrões em ferramentas disponíveis no mercado.

Os metadados devem fazer parte da arquitetura de um ambiente de Data Warehouse também em plataformas móveis, uma vez que os processos de sincronismo, bem como o subconjunto de dados a ser transportado fica sob 0 controle dos processos disparados pela plataforma móvel. Mais do que isso, os metadados devem controlar todos os processos e os dados envolvidos na arquitetura, sendo os responsáveis por estabelecer os parâmetros necessários à execução destes processos.

Desta forma, o presente trabalho estende a arquitetura representada na Figura 2, com o objetivo de incluir os componentes de metadados conforme o discutido acima. A arquitetura proposta, já incluindo os metadados, está representada na Figura 3. 


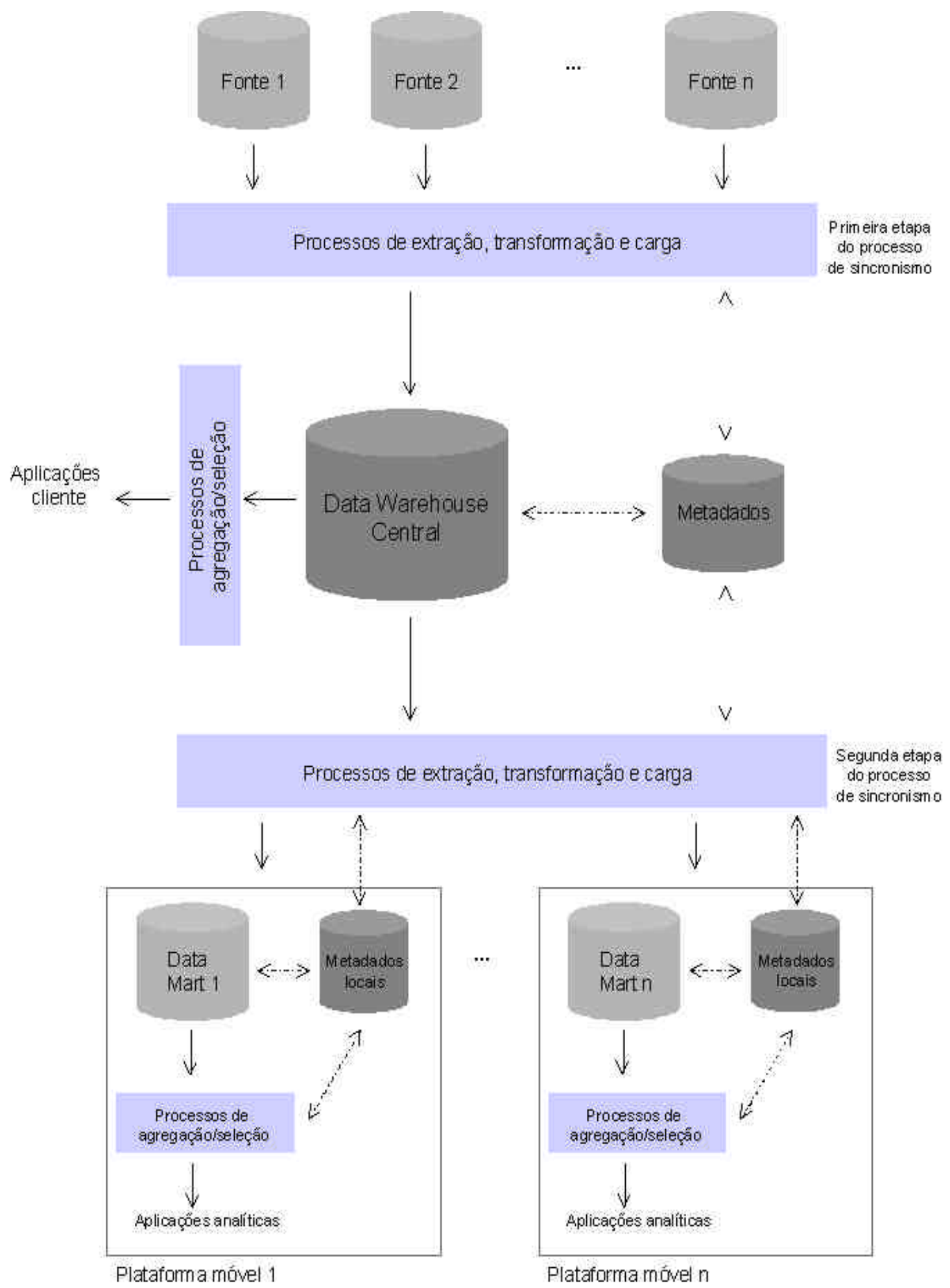

Figura 3 - Modelo da arquitetura do Data Warehouse em plataformas móveis, proposta neste trabalho, mostrando a utilização dos componentes de metadados 


\subsection{OBJETIVOS}

O principal objetivo deste trabalho, que é a definição de um modelo para manutenção de esquema e de dados em Data Warehouses implementados em plataformas móveis, baseia-se em um importante ponto crítico arquitetura de tais Data Warehouses, em plataformas móveis, que é o processo de sincronização de esquemas.

Uma vez que limitações como velocidade de acesso para sincronização, capacidade de processamento e de armazenamento são cada vez menos freqüentes, ganha importância o tratamento de outros problemas que podem surgir em função do dispositivo móvel não estar conectado permanentemente ao servidor. Algumas das principais questões a serem consideradas são:

- O esquema e as instâncias de dados podem ser alterados no servidor. Como é possível atualizar esta informação na plataforma cliente de forma simples e eficiente?

- Como é possível integrar novos fatos ao Data Warehouse armazenado na estação cliente?

- Quais porções do Data Warehouse central e dos metadados devem ser armazenadas nas estações cliente, sendo que cada um dos diferentes usuários necessitam de diferentes subconjuntos de informações?

- Como garantir que, mesmo utilizando processos automatizados, o usuário da estação cliente tenha acesso apenas a informações às quais está autorizado?

- Como definir uma arquitetura que possibilite que processos automatizados atendam processos de sincronismo com diferentes características e usuários?

Desta forma, inserido no objetivo acima descrito, este trabalho propõe uma arquitetura de utilização de Data Warehouses em plataformas móveis, apresentando soluções válidas e viáveis para as questões acima expostas. 
$\mathrm{Na}$ arquitetura proposta, os processos e componentes da arquitetura são discutidos e transformados em problemas conhecidos e já solucionados, justificando sua viabilidade.

O ambiente de Data Warehouse, por oferecer capacidade analítica estratégica, tática e operacional, com informações provenientes de vários sistemas é um ambiente em constante evolução. Da mesma forma que novos conjuntos de informação são adicionados diariamente ao Data Warehouse, seu esquema também sofre modificações freqüentes. A maioria dos trabalhos publicados propõe soluções para evolução e versionamento de esquema em um contexto diferente da arquitetura apresentada por este trabalho. Como a sincronização de esquema entre o ambiente do Data Warehouse central e as plataformas móveis pode demandar uma grande quantidade de recursos, é importante analisar qual sua complexidade e qual o impacto nos diversos objetos que compõem o sistema.

Portanto, este trabalho também propõe a análise da complexidade e do impacto das alterações de esquema para permitir o planejamento da manutenção do esquema nas plataformas móveis, garantindo que o processo possa ser automatizado, identificando as situações que podem necessitar de intervenção humana. Assim é apresentada uma forma de avaliação do impacto de possíveis alterações de esquemas no Data Warehouse central, as quais devem, em algum momento, serem refletidas no Data Warehouse da plataforma móvel.

Com a realização desta análise, também é possível oferecer alternativas no momento da sincronização de esquema, uma vez que existem situações em que a quantidade e complexidade das alterações podem justificar uma total reconstrução do ambiente analítico da plataforma móvel, com a remoção dos componentes seguida de uma carga completa do ambiente ou, em alguns casos, simplesmente permitir ao usuário adiar a execução do processo de sincronização de esquema, sincronizando apenas os dados naquele momento.

Assim, o trabalho aqui desenvolvido apresenta grande relevância para a implementação e manutenção de um Data Warehouse distribuído em plataformas móveis, descrevendo a arquitetura deste sistema e fornecendo diretrizes para a análise de impacto e de complexidade das alterações de esquema realizadas nas bases de dados. 
Com a proposta da arquitetura de um Data Warehouse com as características mencionadas acima, o detalhamento dos seus componentes e a avaliação de impacto e complexidade das alterações de esquema, este trabalho contribui para viabilizar a implementação de um sistema analítico que permita sincronizar dados e esquema de forma simplificada, confiável e que atenda os requisitos de negócios de inúmeras organizações.

A importância deste trabalho está baseada em casos reais da necessidade de sincronismo de bases analíticas em ambientes móveis, principalmente notebooks, em que os usuários solicitam portar seu próprio subconjunto de dados do Data Warehouse para análises e processos de negócio desconectados do servidor de Data Warehouse central.

\subsection{ESTRUTURA DO TRABALHO}

Nos próximos capítulos os principais componentes desta arquitetura e sua utilização são discutidos detalhadamente. No capítulo 2 são abordados os modelos de sincronismo de Data Warehouses tradicionais centralizados, bem como os modelos de sincronismo para dispositivos móveis. Os aspectos relacionados à manutenção de esquema em bancos de dados e, especialmente, em Data Warehouse, são apresentados no capítulo 3. A importância, utilização e padrões de metadados são apresentados a seguir, no capítulo 4 . No capítulo 5, descrevem-se os aspectos e modelos de segurança em sistemas de Data Warehouses. O foco do capítulo 6 está na apresentação da arquitetura proposta neste trabalho, detalhando-se seus componentes: estruturas de dados e processos. Ainda no capítulo 6, são descritas as diretrizes para a avaliação de complexidade e de impacto decorrentes das alterações de esquema. Ainda nesse capítulo é apresentado um estudo de caso, aplicando o modelo proposto. Por fim, no capítulo 7 são apresentadas as conclusões, os principais aspectos sobre a relevância do problema aqui abordado, além das contribuições deste trabalho e as futuras pesquisas decorrentes. 


\section{MODELOS DE SINCRONISMO DE DATA WAREHOUSE}

Por sua característica básica, que é a integração de dados provenientes de várias fontes diferentes, a etapa mais complexa na implementação de um Data Warehouse é o processo de carga. Neste processo, os dados distribuídos pelos vários ambientes operacionais (bases de dados de produção, que contêm os dados utilizados pelos vários sistemas transacionais de uma empresa) devem ser selecionados, trabalhados com o objetivo de padronização e eliminação de inconsistências, transferidos para o novo ambiente e, finalmente, carregados, sempre atendendo ao padrão da modelagem utilizada para o Data Warehouse. Este processo é feito periodicamente, sendo que sua freqüência depende de vários fatores relacionados ao modelo de negócios utilizado pela empresa e, normalmente, não é menor que 24 horas. Desta forma, pode-se dizer que os dados armazenados no Data Warehouse representam, para todos os propósitos práticos, uma longa série de fotografias, tiradas ao longo do tempo. Uma vez que os dados são armazenados no Data Warehouse, eles não mais sofrem, na grande maioria dos casos, atualizações, sendo, portanto, um ambiente apenas de carga e acesso.

Após sua criação e primeira carga, o Data Warehouse passa a sofrer cargas incrementais que devem refletir o ambiente operacional ao longo do tempo tornandoo uma imensa base de dados para os sistemas de apoio à decisão.

Com o objetivo de conferir ao Data Warehouse uma característica mais dinâmica e otimizar o acesso aos dados, vários estudos têm sido feitos indicando o uso de visões materializadas ${ }^{3}$ como alternativa viável (ZHUGE et al., 1995; IEEE DATA ENGINEERING BULLETIN, 1995; AGRAWAL, 1997; QUASS et al., 1996; ZHUGE; GARCIA-MOLINA; WIENER, 1998; SALEM et al., 2000; GUPTA; MUMICK, 1995; BLAKELEY; LARSON; TOMPA, 1986; SHMUELI; ITAI, 1984; CERI; WIDOM, 1991; HARRISON; DIETRICH, 1992; GUPTA; MUMICK; SUBRAHMANIAN, 1993, GUPTA, 1994; BARALIS; PARABOSCHI; TENIENTE, 1997; GUPTA; BLAKELEY, 1994; QUASS; WIDOM, 1997).

Uma visão é uma relação derivada, definida em termos de relações base, que é computada todas as vezes que uma referência a ela é feita. Uma visão é dita 
materializada quando ela é realmente armazenada na base de dados em vez de ser computada a partir das relações base em resposta a consultas (QUASS et al., 1996). Os Data Warehouses podem, portanto, ser vistos como um conjunto de visões materializadas que integram os dados a partir de múltiplas fontes de informação heterogêneas e, eventualmente, distribuídas (IEEE DATA ENGINEERING BULLETIN, 1995).

É possível, então, definir o Data Warehouse como um conjunto de visões materializadas baseadas nos dados dos ambientes transacionais, sendo que, conforme as fontes de dados nos ambientes transacionais vão sendo atualizadas, as visões materializadas passam, também, a refletir estas atualizações, por meio de algoritmos especialmente desenvolvidos para manutenção destas visões.

Tanto a abordagem de sincronização por meio de processos de carga periódicos quanto por meio de visões materializadas têm sido bastante utilizadas em ambientes de Data Warehouse tradicional, sendo o Data Warehouse tratado como fonte de consulta centralizada, com os usuários conectados à base de dados, conforme representado na Figura 1. Para atender o escopo deste trabalho, que pressupõe partes do Data Warehouse localizadas em plataformas móveis e desconectadas da base central, é necessária uma extensão a esses processos de sincronização, uma vez que, além da sincronização entre o Data Warehouse e suas fontes, é necessário também sincronizar os data marts localizados nas plataformas móveis. A Figura 3 mostra as duas etapas distintas dos processos de extração, transformação e carga de dados em arquiteturas em que o Data Warehouse central tem porções de seu conteúdo replicadas nas plataformas móveis.

É importante lembrar que estas duas etapas de sincronização (ambas compostas por processos de extração, transformação e carga de dados) apresentam certas diferenças. Na primeira etapa, das fontes de dados transacionais para o Data Warehouse, a origem e o destino estão permanentemente conectados e o processo pode ser realizado por meio de cargas periódicas (diárias, semanais ou mensais) ou em períodos de tempos menores e, se houver necessidade, até em tempo real (ITALIANO, 2002). Na segunda etapa, do Data Warehouse para os data marts em plataformas móveis, a origem e o destino não estão permanentemente conectados

\footnotetext{
${ }^{3}$ A expresssão visão materializada foi traduzida do inglês materialized views.
} 
e, portanto, o processo de sincronismo só pode ser realizado sob demanda, quando a origem e o destino estiverem conectados. Outra diferença importante está relacionada às modificações que o esquema de dados sofre. Caso o esquema de dados do Data Warehouse sofra alguma alteração, os esquemas dos data marts devem refletir esta alteração, acrescentando mais complexidade ao processo de sincronização. A Tabela 1 mostra um resumo das diferenças entre os processos de sincronização (extração, transformação e carga de dados) mencionados neste parágrafo, tendo como base as duas etapas de sincronização representadas na Figura 3.

Tabela 1 - Características dos processos de sincronização destacando as principais diferenças entre a primeira e segunda etapa.

\begin{tabular}{lcc}
\hline \multicolumn{1}{c}{ Aspecto } & $\begin{array}{c}\text { Primeira etapa de } \\
\text { sincronização }\end{array}$ & $\begin{array}{c}\text { Segunda etapa de } \\
\text { sincronização }\end{array}$ \\
\hline Origem dos dados & Sistemas transacionais & Data Warehouse central \\
\hline Destino dos dados & Data Warehouse central & $\begin{array}{c}\text { Data mart na plataforma } \\
\text { móvel }\end{array}$ \\
\hline $\begin{array}{l}\text { Forma de acionamento do } \\
\text { sincronismo }\end{array}$ & $\begin{array}{c}\text { Processos periódicos } \\
\text { automáticos }\end{array}$ & Sob demanda \\
\hline Freqüência do sincronismo & $\begin{array}{c}\text { Pré-estabelecida, sendo } \\
\text { desde tempo real até período } \\
\text { de tempo (diário, semanal, } \\
\text { mensal ou outro) }\end{array}$ & $\begin{array}{l}\text { Variável, de acordo com } \\
\text { necessidade do usuário. }\end{array}$ \\
\hline Processos & Sincronismo de dados & Sincronismo de dados \\
\hline
\end{tabular}

\subsection{MODELOS DE SINCRONISMO PARA A PRIMEIRA ETAPA DE SINCRONIZAÇÃO - TRANSFERÊNCIA DE DADOS PARA O DATA WAREHOUSE CENTRAL}

Nesta seção são apresentadas as principais alternativas para os processos da primeira etapa de sincronização, representados na Figura 3 e na Tabela 1. Nestes processos, a origem das informações é o conjunto de sistemas transacionais e o destino é o Data Warehouse central. Nesta etapa, apenas os dados são objeto de sincronismo, uma vez que alterações no esquema do Data Warehouse central são feitas diretamente na base de dados que armazena o Data Warehouse. 


\subsubsection{Sincronismo baseado em processos de carga periódicos}

Uma das principais leis do data warehousing, conforme Adamson e Venerable (1998), é sobre a complexidade dos processos de carga, que permitem implementar o sincronismo entre os dados que estão nos sistemas transacionais e o Data Warehouse. $O$ autor nos diz que a parte mais complexa na construção de um Data Warehouse é a carga dos dados. Vários aspectos contribuem para aumentar a complexidade desta tarefa: baixa qualidade e falta de dados adequados, péssima documentação dos sistemas, múltiplas, redundantes e conflitantes fontes de dados. Muitas características complexas dos dados ficam "escondidas", vindo à tona somente no momento do processo de carga do Data Warehouse. A utilização de ferramentas que automatizam este processo pode facilitar o trabalho, porém a complexidade semântica que envolve o processo de transformação dos dados não pode ser minimizada. O processo de carga é, na grande maioria das vezes, redundante e desnecessariamente complicado, tornando-se um ponto crítico para a introdução de erros.

A complexidade desta etapa surge devido à diversidade e abrangência das tarefas envolvidas, recuperando, convertendo e migrando os dados a partir das diversas fontes, executando sua transformação de modo a garantir que a base de dados resultante compreenda sempre informações precisas, integradas, válidas e disponíveis em tempo hábil.

O processo de extração apresenta várias dificuldades operacionais como, por exemplo, encontrar uma janela de tempo adequada para a execução do conjunto de programas necessários para o processo, normalmente em batch, principalmente se a atualização do Data Warehouse for diária. Outro problema a ser enfrentado referese ao ponto de sincronismo entre os vários sistemas transacionais, que são atualizados em diferentes intervalos de tempo e que servirão de entrada para este processo de extração.

Uma vez que a periodicidade do processo de carga esteja definida, é necessário escolher um método para identificar e capturar as informações que foram atualizadas nas bases de origem desde a execução da última carga. Existem algumas opções que podem ser empregadas para esta tarefa e, de acordo com Kelly (1994), as mais importantes são: 
- Utilização de Logs: a maioria dos gerenciadores de bancos de dados mantém logs ou journals que podem ser utilizados para identificar as alterações ocorridas nas bases de dados. Estas alterações, uma vez identificadas, devem ser escritas em um arquivo diferente que será utilizado para migrar as alterações para o ambiente de Data Warehouse. Esta alternativa produz bons resultados se as atualizações a serem capturadas são obtidas de forma simples e direta. Porém, se os dados necessários para a atualização do Data Warehouse estiverem em um número considerável de arquivos ou bases de dados separados, dificultando o sincronismo dos logs, este processo começa a aumentar em complexidade. Adicionalmente, pode-se citar os problemas relativos às alterações necessárias no programas de carga devido a novas versões dos gerenciadores de bancos de dados que podem levar a modificações na estrutura dos logs.

- Comparação das informações: apesar de conceitualmente simples, é uma opção de execução bastante trabalhosa. Esta opção consiste em desenvolver um programa que leia os dados nas bases fonte e no Data Warehouse, identificando as alterações ocorridas desde a última execução da carga. Este método é caro, no que se refere aos recursos de máquina necessários para comparar os dados e pode ser demorado, dependendo do tamanho das bases pesquisadas e dos recursos disponíveis para seu processamento.

- Reengenharia dos sistemas aplicativos transacionais: esta opção não se mostra muito atrativa, já que requer que as aplicações em produção sejam alteradas com o objetivo de armazenar, em arquivos destinados para este fim, as modificações ocorridas nos dados fonte. Ocorre, porém, que a maioria das aplicações não pode sofrer facilmente um processo de reengenharia e esta opção, em muitas situações, só poderia ser aplicada nas novas aplicações que estivessem sendo desenvolvidas. Neste caso, as necessidades do Data Warehouse passariam a fazer parte da especificação da aplicação.

Após sua captura, os dados devem passar por uma etapa de transformação, já que, simplesmente obter os dados do ambiente fonte e passá-los para o Data 
Warehouse não é suficiente. É necessário, com o objetivo de otimizar o potencial do Data Warehouse, transformar as entidades obtidas em novas composições de entidades que são requeridas para processo de geração de informação relevante para o usuário. Outro aspecto relacionado à transformação dos dados é sua reformatação física. Os ambientes de origem e o Data Warehouse podem estar em ambientes computacionais heterogêneos, sendo que, muitas vezes, surgem problemas relacionados ao formato dos dados. Por exemplo, um problema bastante comum refere-se às diferenças entre os formatos de arquivos em EBCDIC, encontrados nos ambientes IBM e os formatos ASCII utilizados pela maioria das outras plataformas.

Além da transformação, os dados passam por um processo de enriquecimento, que é, normalmente, um produto da integração de dados e ocorre, por exemplo, quando um atributo adicional é acrescentado a uma entidade. Se um dado externo está sendo acrescentado ao Data Warehouse, uma entidade Cliente, por exemplo, pode ser "enriquecida" com este novo atributo que foi selecionado de fontes econômicas, demográficas, financeiras, etc. Estas fontes podem ser valiosas para 0 "enriquecimento" das informações, porém mais valiosas ainda, podem ser as próprias aplicações do Data Warehouse cujos atributos podem ser derivados dos padrões de comportamento analisados.

Uma outra etapa necessária para a migração dos dados envolve um mecanismo de transporte partindo do ambiente operacional para o Data Warehouse. Estes dois ambientes podem estar localizados em plataformas distintas, além da possibilidade de estarem fisicamente remotas, levando a uma maior dificuldade na transferência dos dados. A implementação do mecanismo de transporte pode envolver uma avaliação de todas as opções disponíveis, já que diferentes fabricantes podem oferecer diferentes opções proprietárias de custos, capacidades e limitações bastante distintas. Ao considerar a velocidade da transferência, deve-se levar em conta cada aspecto envolvido no processo, seja na plataforma de origem ou na plataforma destino. Esta análise é particularmente importante para determinar, no contexto considerado, o tempo disponível para a execução desta etapa nas plataformas envolvidas.

Na seqüência do processo de carga um fator muito importante está relacionado à garantia da integridade dos dados que estão sendo adicionados ao Data 
Warehouse. Este controle de integridade deve ser implementado de forma a garantir dois aspectos. O primeiro deles é a garantia de que os dados que foram extraídos dos sistemas de origem são exatamente os mesmos que estão sendo carregados no Data Warehouse. O segundo aspecto deve garantir que os dados que estão sendo carregados estão consistentes com os dados que foram pedidos para as bases de origem em um determinado instante no tempo.

Como último passo do processo, encontra-se a etapa de carga dos dados que depende do volume de dados envolvido no processo. Pode ser que o tempo necessário para a carga dos dados adicionado ao tempo requerido para transferi-los, cause um impacto negativo perante os usuários, do ponto de vista da disponibilidade do Data Warehouse. Portanto, devem ser considerados todos os aspectos que possam dificultar este processo. Um destes aspectos é a quantidade de índices criados nas tabelas do Data Warehouse. Uma grande quantidade de índices adequados vai agilizar a execução das consultas, objetivo primário de um Data Warehouse, porém este alto nível de indexação pode diminuir sensivelmente a velocidade do processo de carga.

Pode-se perceber, após uma análise das etapas necessárias ao processo de carga, a alta complexidade desta tarefa que, se não for definida com bastante cuidado, pode levar à introdução de erros, comprometendo todo o processo de tomada de decisão executado pelos usuários. Além disso, qualquer alteração na arquitetura dos sistemas transacionais e nas bases de origem deve ser detalhadamente verificada, já que pode causar alterações em várias etapas do processo de carga.

Normalmente, os processos de sincronismo são implementados por meio de um conjunto de passos, executados com periodicidade, no mínimo, diária. Para um grande conjunto de aplicações em Data Warehouse, esta periodicidade é satisfatória. Porém, para determinadas aplicações, que requerem a propagação dos dados da base transacional para o Data Warehouse, de forma imediata, é necessária uma forma mais dinâmica para implementar este sincronismo. Outro aspecto a considerar é que, durante o processo de sincronismo descrito nos parágrafos anteriores, o Data Warehouse fica indisponível para consultas. Se forem considerado as características de uma economia globalizada, na qual empresas localizadas em diferentes países possam utilizar o mesmo Data Warehouse para os processos de tomada de decisão, este período de indisponibilidade é inaceitável. 
Muitas vezes pode ser necessário buscar uma implementação mais dinâmica do sincronismo do Data Warehouse, que minimize os problemas apresentados. Para isto, uma alternativa é definir o Data Warehouse como um conjunto de visões materializadas que integram os dados a partir de múltiplas fontes heterogêneas, e eventualmente distribuídas, de informação (IEEE DATA ENGINEERING BULLETIN, 1995).

Além de definir o próprio Data Warehouse como um conjunto de visões materializadas baseadas nos dados dos ambientes operacionais (QUASS et al., 1996); (GUPTA; BLAKELEY, 1994), estas visões também podem ser utilizadas com o objetivo de otimizar consultas complexas (QUASS, 1997), sendo que, para isto, deve-se definir um conjunto compartilhado de visões, criteriosamente escolhidas a partir de uma análise das consultas mais freqüentes executadas no Data Warehouse. Estas visões, ao serem materializadas, agilizariam o acesso aos dados necessários para a realização das consultas no Data Warehouse (YANG; KARLAPALEM; LI, 1996), aspecto crítico e diferencial nas aplicações em que a quantidade de consultas é alta e as visões são complexas ou são definidas sobre dados em bases remotas.

Estes dois temas têm apresentado grande relevância, já que a utilização dos Data Warehouses vem aumentando significativamente e inclui aspectos como otimização das consultas, replicação dos dados e a construção e otimização das ferramentas de apoio à decisão e OLAP. Vários trabalhos vêm sendo realizados envolvendo a utilização das visões materializadas em sistemas de Data Warehouse, com o objetivo de conferir a estas enormes bases de dados, melhor integração das informações, facilidades no processo de carga e otimização das consultas efetuadas. Para o escopo do presente trabalho, será considerada apenas a utilização de visões materializadas no sentido de se implementar o Data Warehouse como um conjunto destas visões, tendo como origem os dados dos sistemas transacionais. 


\subsubsection{Sincronismo baseado em visões materializadas}

Com o uso das visões, o Data Warehouse pode manter-se atualizado e sincronizado com as bases de dados transacionais originais, em intervalos de tempo bem menores, já que não dependerá do processo de carga periódico para isto. Tipicamente, uma visão é mantida imediatamente, como parte da transação que atualiza as tabelas bases, quando da inserção ou eliminação de alguma linha destas tabelas. Esta forma de atualizar as visões causa, porém, uma sobrecarga ao processo de atualização das tabelas base. Uma outra opção é protelar esta manutenção por certo período de tempo e ativá-la em intervalos predefinidos ou sob demanda. É importante, no processo de atualização das visões, levar em conta dois fatores básicos: minimizar o tempo em que a visão fica "bloqueada" para acesso (durante sua manutenção) e minimizar a sobrecarga imposta às transações de atualização das tabelas base, considerando que este processo passa por, basicamente, duas etapas. A primeira etapa consiste da definição das alterações que devem ser aplicadas nas visões e a segunda, na aplicação destas atualizações.

O uso de visões de materializadas traz vários aspectos que devem ser cuidadosamente analisados e resolvidos, entre eles:

1. A seleção das visões mais adequadas, levando-se em conta uma análise dos custos de manutenção e os benefícios de cada visão e os algoritmos disponíveis;

2. Aspectos da materialização e utilização das visões para responder às consultas;

3. Os mecanismos que permitem a propagação correta, quando da atualização das fontes de dados base, para vários tipos de visões, preferencialmente de forma on-line;

4. A manutenção das visões de forma dinâmica e incremental;

5. A criação de algoritmos que permitam a manutenção das visões de maneira autônoma, utilizando o conceito de self maintainable views ${ }^{4}$.

${ }^{4}$ A expressão self maintainable views, que se refere a visões que possuem a capacidade de auto manutenção, será utilizada em sua forma original, em inglês. 
Uma visão materializada oferece acesso rápido aos dados, sendo que esta velocidade pode ser crítica em aplicações em que a quantidade de consultas é alta e a complexidade das visões leva à impossibilidade de recálculo da visão em todo acesso.

No entanto, as visões materializadas também ficam desatualizadas quando as bases de dados de origem são modificadas. Neste caso, é necessária a execução de um processo de manutenção sendo que, na maioria dos casos, constitui desperdício de recursos proceder o seu recálculo a partir do zero (GUPTA; MUMICK, 1995). Isto porque apenas uma parte da visão muda em resposta às alterações das bases originais e, portanto, é possível alterar o conteúdo da visão materializada, de forma incremental. De fato, isto é apenas heurística. Se houver, por exemplo, a eliminação da maioria das linhas na relação base, será mais eficaz recalcular a visão que depende desta relação, do que apenas aplicar as alterações. Vários trabalhos descrevem algoritmos que permitem a manutenção incremental das visões materializadas, com diferentes domínios de aplicabilidade, como (SHMUELI; ITAI, 1984; CERI; WIDOM, 1991; HARRISON; DIETRICH, 1992; GUPTA; MUMICK; SUBRAHMANIAN, 1993).

O trabalho de Gupta e Mumick (1995) propõe uma classificação do problema de manutenção das visões, em quatro aspectos, ao longo dos quais, este problema pode ser analisado, a saber:

- Dimensão da Informação: Refere-se à quantidade de informação disponível para a manutenção da visão. $\mathrm{Na}$ análise sob esta dimensão, pergunta-se se o acesso é possível a toda ou apenas parte das relações base e se existe acesso à visão materializada, se são conhecidas regras de integridade e chaves. A quantidade de informação utilizada é ortogonal à "incrementabilidade" da manutenção da visão. "Incrementabilidade" se refere à capacidade de se computar ou calcular apenas aquela parte da visão que foi alterada. Nesta dimensão, portanto, analisam-se os dados utilizados para computaremse as alterações na visão.

- Dimensão da Modificação: Nesta dimensão são analisadas as modificações que o algoritmo de manutenção da visão pode tratar. Questiona-se, então, se inserções ou eliminações de tuplas nas 
tabelas base são suportadas pelo algoritmo, se as atualizações nas tuplas são tratadas diretamente ou se são modeladas como eliminações seguidas por inserções e aspectos relacionados às alterações na definição da visão.

- Dimensão da Linguagem: Esta dimensão está relacionada a questões sobre a forma com que a visão está expressa, ou seja, foi definida como uma consulta do tipo select-project-join (também conhecida como visão SPJ ou como consulta conjuntiva) ou baseada em algum outro subconjunto da álgebra relacional, se utiliza a SQL ou um subconjunto da SQL, se a visão possui duplicidades e se utiliza agregação e recursão.

- Dimensão das Instâncias: Esta dimensão divide-se em dois tipos: informações relativas às instâncias da base de dados e às instâncias da modificação. É importante saber se o algoritmo de manutenção da visão funciona para todas as instâncias da base de dados ou apenas para algumas e se funciona para todas as instâncias da modificação ou apenas para algumas.

O processo de manutenção incremental das visões depende da quantidade de informações disponíveis. Conforme descritos por Gupta e Mumick (1995), vários trabalhos foram desenvolvidos apresentando algoritmos para a manutenção das visões em função da quantidade de informações disponíveis e do tipo de visão.

Segue abaixo uma breve descrição dos vários algoritmos definidos nestes trabalhos, agrupados pela quantidade de informação disponível e pelo tipo de visão que pode ser tratada.

1. Utilizando informação completa: A maioria dos trabalhos em manutenção de visões assume que todas as relações base e as visões materializadas estão disponíveis para 0 processo de manutenção, considerando características como agregações, duplicidades, recursão e outer join. As técnicas diferem quanto à linguagem de definição utilizada, quanto ao uso das chaves e regras de integridade e quanto à capacidade de tratar inserções e eliminações de forma separada ou em apenas um passo. As atualizações são modeladas e tratadas como uma eliminação seguida de 
uma inserção. Todas as técnicas funcionam para todas as instâncias da base de dados tanto para inserções como para eliminações de tuplas.

1.1. Visões não recursivas: as técnicas apropriadas neste caso incluem o algoritmo de counting apresentado por Gupta; Mumick e Subrahmanian (1993), além de outros algoritmos que também utilizam contadores, como (SHMUELI; ITAI, 1984) que cria estruturas com ponteiros que partem da tupla de origem para suas tuplas derivadas. Blakeley; Larson e Tompa (1986) utilizam os contadores, exatamente como o algoritmo counting, porém apenas para visões do tipo SPJ, computando inserções e eliminações, separadamente. $O$ algoritmo de manutenção por diferenciação algébrica, introduzido por Paige (1984) e utilizado posteriormente em (QIAN; WIEDERHOLD, 1991) para manutenção de visões, diferencia expressões algébricas para derivar a expressão relacional que determina a alteração em uma visão SPJ. Este tipo de algoritmo gera duas expressões para cada visão: uma para definir as inserções na visão e outro, para definir as eliminações. O algoritmo Ceri-Widom (CERI; WIDOM, 1991) define regras de produção para manter as visões SQL que não possuam duplicidades, agregações e negação e aquelas em que os atributos das visões determinam funcionalmente, a chave da relação base que está sendo atualizada.

1.2. Visões com outer-join: a manutenção de visões com outer-join é discutida em (GUPTA; BLAKELEY, 1994), cujo algoritmo redefine a visão, obtendo duas instruções (uma com left-outer-join e outra com right-outer-join) para calcular as alterações a serem implementadas.

1.3. Visões recursivas: Os algoritmos citados nesta seção aplicam-se também a visões não recursivas. O primeiro deles é o algoritmo Dred, apresentado no trabalho de Gupta; Mumick e Subrahmanian (1993). Vários outros algoritmos se aplicam a este tipo de visão, estando entre eles: o algoritmo PF (Propagation/Filtration) definido por Harrison e Dietrich (1992), que é muito similar ao DRed, sendo que, para visões não recursivas, o DRed funciona melhor; o algoritmo Kuchenhoff (KUECHENHOFF, 1991) que cria regras para calcular a diferença 
entre estados consecutivos da base de dados e o algoritmo Urpi-Olive (URPI; OLIVE, 1992) que cria regras de transição mostrando como cada modificação na relação base se traduz em uma modificação em cada relação derivada.

2. Utilizando informação parcial: As visões podem ser mantidas, utilizandose somente um subconjunto das relações envolvidas na definição da visão. De forma diferente da utilização da informação completa, quando a manutenção utiliza apenas informação parcial, nem sempre é possível realizar o processo de manutenção da visão. A manutenção vai depender de aspectos como o tipo de modificação, ou seja, se é uma inserção, uma eliminação ou atualização. Portanto, neste caso, os algoritmos devem se preocupar se a visão pode ser mantida e então, como efetuar a manutenção, sendo que em alguns casos, mesmo que não exista 0 algoritmo para eliminação seguido de inserção, é possível existir o algoritmo para atualização.

2.1. Nenhuma informação disponível: Muitos trabalhos têm sido feitos para determinar quando uma modificação na base não acarreta alteração na visão. Esta situação é conhecida como "o problema da atualização irrelevante". Os trabalhos (BLAKELEY; LARSON; TOMPA, 1986); (BLAKELEY; COBURUNM; LARSON, 1989); (ELKAN, 1990); (LEVY; SAGIV, 1993) determinam atualizações irrelevantes em várias condições diferentes.

2.2. Utilizando a visão materializada: Self-Maintenance. As visões podem ser mantidas utilizando-se apenas a visão materializada e as regras implementadas por meio das chaves. Estas visões são tratadas por Gupta e Blakeley (1994), que apresenta vários resultados em selfmaintenance em visões do tipo SPJ e com outer-join, respondendo a inserções, eliminações e atualizações. Este trabalho define uma visão self-maintainable com respeito ao tipo de modificação, não considerando as visões com self-joins ou outer-joins, as visões que não usam informações das chaves e as que não consideram a capacidade de auto-manutenção com respeito a todas as instâncias de modificações. 


\section{Utilizando a visão materializada e algumas relações base: Referência} parcial. O problema da manutenção com referência parcial é manter a visão, considerando apenas um subconjunto das relações base e a visão materializada. Dois subproblemas interessantes surgem desta abordagem: o primeiro é quando estão disponíveis a visão e todas as relações base, com exceção da relação que sofreu a modificação e o segundo, quando estão disponíveis a visão e a relação modificada. Vários trabalhos, como (JAGADISH; MUMICK; SILBERSCHATZ, 1995; GUPTA, 1994; GUPTA; BLAKELEY, 1994), tratam de variações desta situação.

A manutenção dinâmica das visões materializadas, de maneira similar à definição do processo de carga estático, não é uma tarefa simples. Muitas das etapas envolvidas na carga implementada por meio de processos periódicos estão presentes na manutenção mais dinâmica, por meio do uso de visões materializadas, diluídas nos processos de atualização de cada visão materializada.

Existem algumas opções relacionadas ao momento em que as visões são atualizadas. Basicamente, a atualização pode ser imediata, ou seja, no momento em que os dados base são atualizados, ou protelada, sendo que, neste caso, devem ser considerados os aspectos necessários para minimizar o tempo que as visões ficam indisponíveis para o acesso por parte dos usuários.

Normalmente, as bases de dados fonte, para o Data Warehouse, podem ser sistemas legados ou sistemas que, de uma forma geral, não conhecem as visões materializadas implementadas no ambiente analítico. As aplicações no ambiente fonte devem informar ao Data Warehouse quando ocorre uma atualização, por exemplo, a contratação de um novo funcionário ou um paciente que pagou sua conta hospitalar. Entretanto, estas aplicações não têm condições de determinar quais são os dados necessários para implementar as atualizações nas visões materializadas do Data Warehouse. Quando a informação sobre uma atualização chega ao Data Warehouse, é necessário buscar dados adicionais, nas bases fonte, para atualizar as visões corretamente e de forma incremental. Por esta razão, o Data Warehouse deverá emitir algumas consultas para as bases fonte após a ocorrência da atualização. Existem trabalhos já realizados, citados em parágrafos anteriores, que implementam vários algoritmos distintos para garantir que as visões materializadas no Data Warehouse sejam atualizadas de forma correta, garantindo a 
consistência das visões, no menor tempo possível. A escolha do algoritmo mais adequado depende de uma série de fatores como: o tipo da visão implementada, sua dependência das bases de dados fonte durante o processo de atualização, incluindo sua capacidade de se auto manter sem a necessidade de acesso às bases originais, a distribuição dos ambientes fonte e do Data Warehouse e a concorrência no momento da atualização.

\subsection{MODELOS DE SINCRONISMO PARA A SEGUNDA ETAPA DE SINCRONIZAÇÃO - TRANSFERÊNCIA DE DADOS PARA OS DATA MARTS MÓVEIS}

Nesta seção são apresentadas as principais alternativas para os processos da segunda etapa de sincronização, representados na Figura 3 e na Tabela 1. Nestes processos, a origem das informações é o Data Warehouse central, localizado no servidor e o destino são os Data Warehouses ou data marts armazenados nos clientes em plataformas móveis. Nesta etapa, tanto os dados quanto o esquema são objeto de sincronismo, uma vez que tanto as alterações nos dados quanto no esquema do Data Warehouse central devem ser repassados às bases nas estações cliente.

Conforme Schlesinger et al. (2001), a arquitetura do Data Warehouse central e das plataformas móveis é equivalente a uma arquitetura cliente servidor, sendo que o cliente é um computador não permanentemente conectado ao servidor, que requer sincronização de seus dados com o Data Warehouse localizado no servidor. Assume-se que os dados no servidor são alterados com determinada freqüência, por meio dos processos previstos na primeira etapa de sincronização, e que é possível detectar as alterações efetuadas para que sejam transferidas para as bases nas estações cliente.

O trabalho de Schlesinger et al. (2001) propõe três opções de arquitetura para o Data Warehouse cliente-servidor, que são apresentadas a seguir. 
$\mathrm{Na}$ primeira arquitetura, a cada sincronização, é transferido para o cliente todo 0 conjunto de informações que compõe a sua base local, dependendo do perfil do cliente. As principais etapas são:

- Um processo gera o conjunto de informações que deve ser transferido para os clientes e que é, temporariamente, armazenado no servidor;

- Cada conjunto de informações contém apenas dados de interesse de um cliente ou de um conjunto de clientes com o mesmo perfil;

- Após estabelecer a conexão entre o cliente e o servidor, todos os dados do cliente são removidos e, após a remoção, o conjunto de informações correspondente, previamente armazenado no servidor, é transferido para o cliente e diretamente carregado na base de dados local.

A vantagem desta arquitetura é utilizar o poder de processamento do servidor para gerar o conjunto de informações que serão carregadas no cliente. O único processo necessário, no cliente, consiste em carregar as informações na base de dados local. A desvantagem é transferir grandes volumes de dados, cada vez que a sincronização é realizada.

A segunda arquitetura implementa a computação dos dados modificados e sua transferência é feita cada vez que o processo de sincronização é solicitado. As principais etapas são:

- Após estabelecer a conexão entre o cliente e o servidor, é iniciado, no servidor, o processo para detectar as alterações relevantes para o cliente em questão;

- O conjunto de alterações é transferido para o cliente, onde a base de dados local é atualizada conforme as informações recebidas.

A vantagem desta arquitetura é transferir do servidor para o cliente apenas as alterações do Data Warehouse central, localizado no servidor. A desvantagem é a sobrecarga no servidor, para identificar e produzir o conjunto de alterações, a cada vez que o processo de sincronização é executado.

A terceira arquitetura proposta por Schlesinger et al. (2001) é uma combinação das duas anteriores, utilizando as vantagens de cada uma delas. Nesta arquitetura, são preparados, previamente, os conjuntos de dados no Data Warehouse central, de 
acordo com o perfil dos clientes, e armazenados, temporariamente, no servidor, como na primeira arquitetura apresentada, porém, cada conjunto contém apenas os dados que foram alterados desde o último processo de sincronização, como na segunda arquitetura apresentada. As principais etapas são:

- Um processo detecta as alterações relevantes para cada cliente e gera o conjunto de informações que deve ser transferido. Este conjunto de informações é armazenado no servidor;

- Após estabelecer a conexão entre o cliente e o servidor, o conjunto de informações correspondente, previamente armazenado no servidor, é transferido para o cliente e a base de dados local é atualizada com as informações recebidas (o cliente pode estar desconectado durante o processo de atualização de sua base local).

A grande vantagem desta arquitetura é a redução do custo de comunicação devido à redução da quantidade de dados transferidos e do tempo de conexão.

Para a segunda etapa de sincronização, que envolve o Data Warehouse central e as bases dos clientes, localizadas nos dispositivos móveis, uma abordagem similar ao da primeira etapa de sincronização (quando os dados são transferidos dos sistemas transacionais de origem para o Data Warehouse central) pode ser adotada, no que se refere à sincronização de dados. $\mathrm{O}$ ambiente de Data Warehouse localizado nas plataformas móveis pode também ser visto como um conjunto de visões materializadas do Data Warehouse central e, igualmente, estas visões de dados se tornam obsoletas, já que a plataforma móvel pode ficar desconectada das fontes por longos períodos de tempo, enquanto que o Data Warehouse central é freqüentemente atualizado. Assim, ao se reconectar ao servidor, o Data Warehouse em uma plataforma móvel pode ser atualizado de forma similar aos processos de manutenção das visões, inclusive com os processos de manutenção incremental das visões mencionados na seção 2.1.2, deste trabalho. Este tema, que já se mostrou viável e bastante discutido na manutenção do Data Warehouse central (ZHUGE et al., 1995; IEEE DATA ENGINEERING BULLETIN, 1995; ITALIANO, 2002; AGRAWAL et al., 1997; QUASS et al., 1996; ZHUGE; GARCIA-MOLINA; WIENER, 1998; SALEM et al., 2000; GONÇALVES, 2002), é adequado também ao ambiente de Data Warehouse cliente-servidor. Além disso, se aplica tanto para o sincronismo dos dados que compõem os Data Warehouses, como para o sincronismo dos dados 
que compõem os metadados, componente importante para a arquitetura proposta no presente trabalho.

Vários autores propõem arquiteturas e algoritmos que permitem sincronizar o Data Warehouse central com as bases móveis, localizadas nas estações clientes.

O trabalho de Chan; Va Leong e Si (2000) apresentam uma forma de atualização do Data Warehouse na plataforma móvel como visões materializadas, de forma eficiente e minimizando a janela de tempo necessária para a manutenção por meio de um método chamado summary-delta table que permite manter visões com agregados.

Sampaio; Dias e Baptista (2003) propõe uma alternativa mais ampla apresentando uma abordagem híbrida, utilizando visões materializadas no contexto do Data Warehouse em plataforma móvel que possibilita atualizar, de forma incremental, visões materializadas de grande volume ou reconstruir visões materializadas menores.

Lee; Si e Va Leong (2000) propõem uma abordagem pull-based, em que o cliente móvel solicita ao servidor a sincronização de suas visões materializadas, também de forma incremental. $\mathrm{Na}$ abordagem pull-based, como o cliente móvel solicita, periodicamente, ao servidor (Data Warehouse central) atualizações de seu Data Warehouse local, o servidor não precisa manter controle sobre as bases locais em cada plataforma móvel. A freqüência destas atualizações depende do modelo de negócios implementado.

Dentro do escopo do presente trabalho, tendo como base os vários trabalhos mencionados acima, será utilizada a abordagem pull-based, por atender, adequadamente, às necessidades do modelo de negócios, em que a estação cliente solicita ao servidor a sincronização de sua base de dados, no momento mais oportuno. Além disso, a abordagem híbrida proposta por Sampaio; Dias e Baptista (2003) é também adequada para a arquitetura proposta no presente trabalho, já que possibilita carga incremental das visões materializadas maiores e reconstrução das menores, de forma a otimizar os recursos necessários para os processos de sincronismo. 


\subsection{RESUMO DAS OPÇÕES DE SINCRONISMO ESCOLHIDAS PARA A ARQUITETURA PROPOSTA NESTE TRABALHO}

Os aspectos apresentados nas seções anteriores descrevem e implementam soluções viáveis e transformam as questões relacionadas ao sincronismo de dados em Data Warehouse em soluções já conhecidas e de eficiência comprovada. Assim, com base nestas soluções, são escolhidas as opções para compor a arquitetura de sincronismo proposta no presente trabalho. Um resumo das opções escolhidas está representado na Tabela 2.

Tabela 2 - Resumo das opções de sincronismo escolhidas para o presente trabalho.

Aspecto

Alternativa escolhida para este trabalho

Ambiente origem Data Warehouse central

Ambiente destino Data Warehouse na plataforma cliente móvel

Acionamento do sincronismo A partir da estação cliente (pull based)

Freqüência do sincronismo Variável, de acordo com necessidade do usuário

Implementação no DW móvel Visões materializadas do DW central

Sincronismo dos dados e metadados Algoritmos de carga incremental

A arquitetura escolhida para o presente trabalho é apresentada e descrita detalhadamente, no capítulo 6 . 


\section{A MANUTENÇÃO DO ESQUEMA NO DATA WAREHOUSE}

Assim como o conteúdo do Data Warehouse evolui, quando novos fatos ou elementos das dimensões são acrescentados, da mesma forma o esquema dos dados também sofre modificações ao longo do tempo. Novos modelos de negócios passam a ser representados no Data Warehouse para incrementar as análises dos usuários, assim como os modelos de negócios já representados sofrem modificações, devido a novos requisitos das análises, do ambiente da corporação ou do ambiente exterior a ela. Estas modificações podem requerer que novos objetos sejam criados ou alterados, como, por exemplo, tabelas, atributos, chaves, índices, visões, entre outros.

Diferentemente do sincronismo de dados, o processo de sincronização do esquema dos dados entre o Data Warehouse central e o Data Warehouse na estação cliente é um processo pouco discutido e muito mais complexo.

\subsection{CONSIDERAÇÕES GERAIS}

Em uma análise inicial sobre o tema, espera-se que as alterações no esquema sejam identificadas no Data Warehouse central e repassadas à estação cliente. Deve-se destacar que, em função da criação de novos objetos, os dados armazenados nestas estruturas também devem compor o processo de sincronização.

Algumas situações são simples de se implementar por meio de cargas incrementais, como a criação de uma nova chave ou índice, mas determinados processos, devido à sua complexidade, são mais difíceis, como, por exemplo, a criação de um novo atributo e sua conseqüente carga de valores.

Como todo o controle dos objetos e seus esquemas é mantido no conjunto de metadados central, uma etapa do processo de sincronismo deve identificar a alteração do esquema e preparar o novo esquema a ser implementado na estação cliente. 
Para exemplificar a manutenção de esquema, a Figura 4 representa uma situação na qual o esquema de uma determinada estrutura de dados (conjunto de tabelas) presente no Data Warehouse central e representado por $E_{C e n t r a l}$, será modificado. $O$ esquema da estrutura correspondente, na estação cliente, está representado como $E_{\text {Local1. }}$.

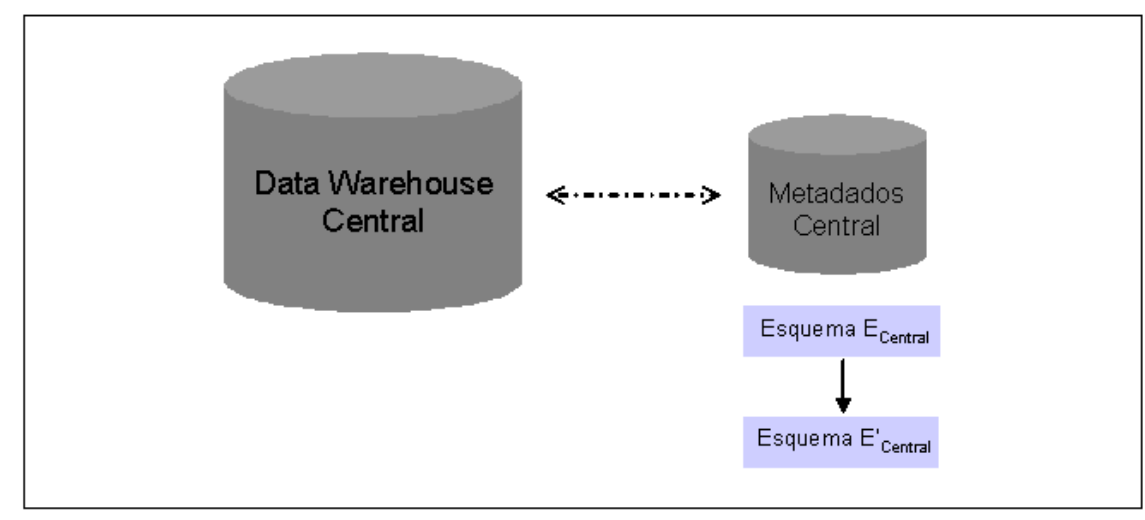

Ambiente Central

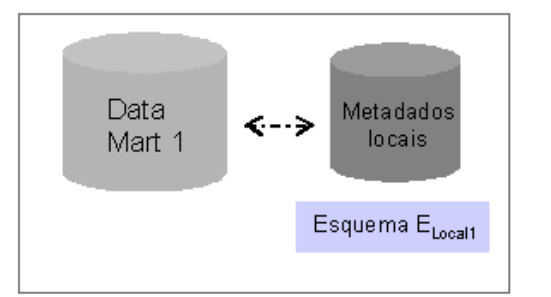

Plataforma móvel 1

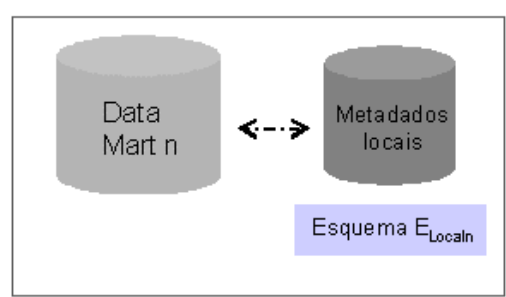

Plataforma móvel n

Figura 4 - Exemplo de evolução de esquema baseado em metadados

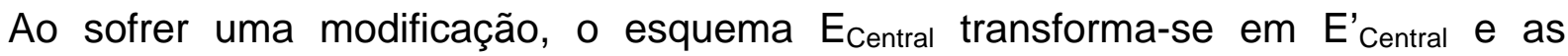
alterações devem ser, conseqüentemente, implementadas na estação cliente.

O conjunto de tabelas que devem ser alteradas na estação cliente é representado por? $\mathrm{E}_{\text {Central, }}$ onde:

$$
\text { ? } \mathrm{E}_{\text {Central }}=\mathrm{E}_{\text {Central }} \mathrm{n} \mathrm{E}_{\text {Central }}^{\prime}
$$

Assim, duas situações devem ser avaliadas:

1. Se: $\quad$ ? $E_{\text {Central }} n E_{\text {Local1 }}=\varnothing$, então a manutenção será incremental, sendo que novas tabelas serão adicionadas ao Data Warehouse local; 
2. Se: ? $\quad$ Eentral $\mathrm{n} \mathrm{E}_{\text {Local1 }} ? \varnothing$, então será necessária a manutenção em tabelas já existentes no Data Warehouse da estação cliente.

A implementação da situação 1, acima, é relativamente simples, pois requer apenas a criação de novas tabelas e carga de seus conteúdos.

A situação dois, mais complexa para se implementar, vai requerer alteração das estruturas já existentes e tratamento especial, dependendo do tipo de alteração necessária.

Dentro do contexto do presente trabalho, o controle das modificações ocorridas no esquema do Data Warehouse central é de extrema importância, já que requer a conseqüente manutenção das bases de dados locais, nas plataformas móveis. Desta forma, é necessária uma avaliação das alterações de esquema ocorridas na base central que serão repassadas para as bases locais, pois dependendo da complexidade da manutenção, a sincronização dos esquemas entre o Data Warehouse central e os data marts locais pode requerer uma grande quantidade de recursos.

Assim, este trabalho apresenta diretrizes para avaliação nas manutenções de esquema ocorridas no Data Warehouse central, analisando sua complexidade e os objetos impactados, para:

- Planejar a manutenção do esquema;

- Garantir que o processo possa ser automatizado ou identificar a necessidade de uma reengenharia, utilizando intervenção e inteligência humanas;

- Possibilitar a escolha de alternativas no momento da sincronização do esquema com as bases locais, nas plataformas móveis;

- Permitir ao usuário postergar a execução do processo, caso não disponha de recursos de tempo suficientes, naquele momento.

$\mathrm{Na}$ próxima seção são apresentados os dois principais conceitos relativos à manutenção do esquema do Data Warehouse, que são a evolução e o versionamento do esquema de bases de dados. 


\subsection{A EVOLUÇÃO DO ESQUEMA DE BASES DE DADOS}

Muito já se discutiu sobre a evolução e versionamento do esquema de bases de dados. Nesta seção, são citados alguns dos trabalhos considerados mais importantes para o contexto abordado pelo presente trabalho.

Noy e Klein (2004), em um trabalho que compara ontologias com esquemas de bases de dados e discute aspectos da evolução de esquemas, definem o principal objetivo da evolução e versionamento de esquema, como sendo: preservar a integridade dos dados armazenados.

As principais preocupações abordadas pelos trabalhos desenvolvidos sobre evolução e versionamento de esquemas referem-se a aspectos sobre como o novo esquema afeta a visão dos dados antigos, como as consultas baseadas no esquema antigo podem ser executadas sobre os novos dados e como os dados antigos podem ser vistos utilizando o novo esquema.

Muitos destes trabalhos discutem evolução de esquemas e versionamento de esquemas em conjunto. Vale diferenciar estes dois aspectos, destacando que os autores consideram a evolução de um esquema como um caso especial do versionamento de esquema sendo que apenas a versão atual do esquema é mantida (FRANCONI; GRANDI; MANDREOLI, 2001).

Conforme Franconi; Grandi e Mandreoli (2001), uma base de dados que possibilite evolução de esquema permite modificações do esquema sem a perda dos dados existentes e uma base que possibilite versionamento de esquema permite consultas sobre todos os dados, em qualquer uma das versões do esquema, conforme a necessidade e preferência das aplicações.

Dentre os problemas tratados por vários trabalhos publicados, existem dois que são fundamentais. O primeiro se refere à semântica da mudança, estando relacionado aos efeitos da mudança causados no próprio esquema e envolve a verificação e manutenção da consistência do esquema após as modificações. O segundo problema refere-se à propagação da mudança, estando relacionado aos efeitos causados nas instâncias de dados envolvidas e trata da consistência dos dados existentes no esquema modificado. Neste caso ainda deve-se popular a nova versão com os dados existentes na versão anterior. 
Vários trabalhos tratam do aspecto referente à semântica da mudança tanto em bases de dados relacionais (RODDICK; SNODGRASS, 1995; CASTRO; GRANDI; SCALAS, 1997), quanto em bases orientadas a objeto. Existem duas abordagens principais referentes a este tema.

A primeira delas é baseada na adoção de invariantes, que definem a consistência de um esquema e regras que devem ser seguidas para manter as invariantes satisfeitas após cada alteração no esquema. As invariantes e as regras referem-se a elementos específicos do modelo e, portanto, são dependentes do modelo utilizado. Esta abordagem é utilizada em importantes trabalhos como Banerjee et al. (1987) e Ferrandina et al.(1995).

A segunda abordagem, proposta por Peters e Özsu (1997), é baseada na introdução de axiomas (oferecidos como um mecanismo de inferência) e formaliza a evolução dinâmica de esquema que possibilita o gerenciamento das alterações no esquema em um sistema em operação.

Para atender o segundo problema na manutenção de esquemas, referente à propagação da mudança, várias soluções já foram propostas e implementadas em sistemas reais (BANERJEE et al., 1987; FERRANDINA et al., 1995; MONK; SOMMERVILE, 1992; PENNEY; STEIN, 1987). Em todos os casos, mecanismos de default ou funções de conversão podem ser utilizados para as atualizações nos objetos.

Franconi; Grandi e Mandreoli (2001) trata da evolução e do versionamento de esquemas em bancos de dados orientados a objeto, representando as mudanças no esquema por meio de uma notação que parte do esquema inicial e representa todas as alterações realizadas ao longo do tempo. Também é apresentado um conjunto de técnicas para verificação de consistência e classificação que podem ser aplicadas automaticamente sobre qualquer esquema resultante de uma modificação.

Ambler e Sadalage (2006) apresentam um conjunto de técnicas que permitem evoluir o esquema de uma base de dados, chamada de database refactoring que, por definição em Ambler (2003), "é uma alteração simples do esquema de uma base de dados que otimiza seu projeto, enquanto preserva tanto sua semântica comportamental quanto sua semântica informacional". Ambler e Sadalage (2006) destacam que preservar a semântica informacional, implica em garantir que os 
clientes (usuários) da informação não devem ser afetados pela melhoria, ou seja, a semântica informacional está relacionada à forma com que os usuários "vêem" a informação. Preservar a semântica comportamental tem por objetivo manter a mesma funcionalidade existente antes da alteração, de forma que quaisquer códigos que utilizem os aspectos alterados na base de dados devem ser refeitos para garantir a mesma funcionalidade existente antes da alteração.

As técnicas e metodologia apresentadas por Ambler e Sadalage (2006) têm por objetivo corrigir e melhorar, de forma segura e simples, a qualidade da base de dados ao longo do tempo além de apoiar a implementação de modernas técnicas de desenvolvimento evolucionário (iterativo e incremental) como RUP, XP e AUP.

Os autores destacam que os database refactorings são pequenas alterações ao esquema da base de dados que melhoram seu projeto, preservando a semântica comportamental e informacional. Uma pequena transformação no esquema, com o objetivo de estendê-lo, como, por exemplo, a adição de uma nova coluna ou tabela, não é um database refactoring, uma vez que esta alteração estende o projeto da base. Um grande número de pequenas alterações aplicadas, simultaneamente, no esquema, como, por exemplo, renomear dez colunas, também não é considerado um database refactoring por não ser uma única e pequena alteração.

Apesar de não tratar a evolução do esquema da base de dados com o objetivo de estendê-lo, necessidade comum em um ambientes de Data Warehouse, ainda assim, os conceitos e metodologia apresentados por Ambler e Sadalage (2006) podem ser bastante úteis, para o presente trabalho. Tanto a classificação proposta por Ambler e Sadalage (2006) quanto sua metodologia de implantação, que inclui o importante conceito de período de transição, são utilizadas para avaliar, classificar e aplicar as alterações dentro do contexto deste trabalho, na evolução de esquema em ambientes de Data Warehouse em plataformas móveis.

Por esta razão, os conceitos e a metodologia do database refactoring de Ambler e Sadalage (2006) são descritos, mais detalhadamente, nas próximas seções. 


\subsection{DATABASE REFACTORING}

\subsubsection{Conceitos}

Fowler (1999) descreve a técnica de programação chamada refactoring, que é uma forma disciplinada para reestruturar o código em pequenos passos. Esta prática permite evoluir o código lentamente ao longo do tempo, para obter uma abordagem evolucionária (iterativa e incremental) de programação. Em um refactoring não são adicionadas nem retiradas funcionalidades, sendo realizada apenas uma melhoria na qualidade do código. Programadores que utilizam a técnica XP (Extreme Programming), consideram 0 refactoring como a principal prática de desenvolvimento. Ambler e Sadalage (2006) mencionam que, quando existir uma nova funcionalidade a ser adicionada ao código, a primeira questão é saber se este código está implementado da melhor forma (melhor projeto possível). Caso a resposta seja positiva, o código deve ser implementado. Caso a resposta seja negativa, primeiramente o código deve passar por um refactoring para ter a melhor implementação (estar no melhor projeto possível) e, somente após isto, a funcionalidade deve ser implementada. Apesar de parecer bastante trabalhoso, Ambler e Sadalage (2006) garantem que, na prática, ao se iniciar com código de alta qualidade, utilizando a prática de refactoring para garanti-la, esta abordagem funciona muito bem.

De forma similar aos conceitos introduzidos por Fowler (1999) na programação, Ambler (2003) define um database refactoring como uma simples alteração ao esquema da base de dados para melhorar seu projeto, enquanto mantém a semântica comportamental e informacional, ou seja, não se pode adicionar novas funcionalidades ou eliminar funcionalidades existentes, nem tampouco adicionar novos dados ou alterar o significado dos dados existentes.

Os database refactorings são mais complexos que os refactorings de código, pois estes apenas precisam se preocupar em manter a semântica comportamental (pelo menos sob o ponto de vista de caixa preta), enquanto que um database refactoring precisa também garantir a semântica informacional. 
O database refactoring é apresentado por Ambler e Sadalage (2006) em um contexto mais amplo, sendo a principal técnica, dentro de um conjunto de técnicas que compõem a abordagem evolucionária de desenvolvimento de bases de dados. Estas técnicas são apresentadas abaixo:

1. Database refactoring - permite evoluir o esquema de uma base de dados pouco a pouco para melhorar a qualidade de seu projeto, sem alterar a semântica;

2. Modelagem de dados evolucionária - permite modelar os aspectos de dados de um sistema, de forma iterativa e incremental, assim como todos os outros aspectos de um sistema, para garantir que o esquema da base de dados evolua, simultaneamente, ao código da aplicação;

3. Testes de regressão na base de dados - garante que o esquema da base de dados realmente funciona;

4. Gerenciamento de configuração de artefatos da base de dados - os modelos de dados, dados de teste, bases de dados de testes são importantes artefatos do projeto e devem ser gerenciados como qualquer outro artefato;

5. Ambientes de desenvolvimento - os devesenvolvedores necessitam ter seus próprios ambientes de trabalho, de forma a poder modificar porções do sistema antes de integrar estas porções ao projeto. Cada desenvolvedor deve ter um ambiente isolado, no qual seja possível construir, testar e/ou executar as alterações sem interferir no trabalho de outros elementos do projeto.

A implementação dos database refactorings pode se complicar, dependendo do nível de acoplamento implementado na base de dados. Dois diferentes níveis de acoplamento estão representados na Figura 5.

O nível de acoplamento é uma métrica que avalia a dependência entre dois itens, sendo que, quanto mais acoplados são os itens, maior é a chance que uma modificação em um deles requeira uma alteração no outro. Uma arquitetura de base de dados com uma única aplicação (Figura 5, A) que interage com a base de dados é a situação mais simples (aplicações standalone), permitindo o refactoring de ambos em paralelo e a implementação de ambos, simultaneamente. A segunda 
arquitetura (Figura 5, B), é bem mais complexa, pois existem vários programas externos interagindo com a base de dados, alguns dos quais podem estar além de nosso controle. Nesta situação não se pode assumir que as alterações em todos os programas externos podem ser implementadas de uma vez e será necessário possibilitar um período de transição (chamado no texto original de deprecation period), durante o qual tanto o esquema antigo quanto o esquema novo serão suportados em paralelo.



Figura 5 - Duas categorias de arquitetura de bases de dados, representando diferentes níveis de acoplamento (AMBLER; SADALAGE, 2006).

\subsubsection{Classificação dos database refactorings}

Ambler e Sadalage (2006) destacam como um aspecto importante o fato de um database refactoring ser um subconjunto das transformações que uma base de dados pode sofrer. Uma transformação na base de dados pode ou não alterar a semântica, enquanto que um database refactoring não altera a semântica. 
Uma grande contribuição do trabalho de Ambler e Sadalage (2006) é a classificação dos database refactorings em seis categorias. Uma visão geral destas categorias está representada na Tabela 3.

Tabela 3 - Categorias de database refactoring (AMBLER; SADALAGE, 2006).

\begin{tabular}{|c|c|c|}
\hline Categoria & Descrição & Exemplo(s) \\
\hline Estrutural & $\begin{array}{l}\text { Uma mudança na definição de uma } \\
\text { ou mais tabelas ou visões }\end{array}$ & $\begin{array}{l}\text { Mover uma coluna de uma tabela para } \\
\text { outra ou dividir uma coluna utilizada } \\
\text { para múltiplos propósitos em diferentes } \\
\text { colunas separadas, uma para cada } \\
\text { propósito }\end{array}$ \\
\hline $\begin{array}{l}\text { Qualidade de } \\
\text { dados }\end{array}$ & $\begin{array}{l}\text { Uma mudança que melhora a } \\
\text { qualidade da informação contida em } \\
\text { uma base de dados }\end{array}$ & $\begin{array}{l}\text { Alterar a definição de uma coluna de } \\
\text { modo a não permitir valores nulos para } \\
\text { garantir que sempre haverá um valor } \\
\text { armazenado ou aplicar um formato } \\
\text { comum a uma coluna para garantir } \\
\text { consistência }\end{array}$ \\
\hline $\begin{array}{l}\text { Integridade } \\
\text { referencial }\end{array}$ & $\begin{array}{l}\text { Uma mudança que garante que a } \\
\text { linha referenciada existe em uma } \\
\text { outra tabela e/ou que garante que } \\
\text { uma linha que não é mais } \\
\text { necessária é removida } \\
\text { apropriadamente }\end{array}$ & $\begin{array}{l}\text { Adicionar um trigger para permitir } \\
\text { eliminação em cascata entre duas } \\
\text { entidades, cujo código estava, } \\
\text { anteriormente, implementado fora do } \\
\text { banco de dados }\end{array}$ \\
\hline Arquitetural & $\begin{array}{l}\text { Uma mudança que melhora, de } \\
\text { forma geral, a interação dos } \\
\text { programas externos com a base de } \\
\text { dados }\end{array}$ & $\begin{array}{l}\text { Substituir uma operação Java existente } \\
\text { em uma biblioteca de código } \\
\text { compartilhado por uma stored } \\
\text { procedure no banco de dados. Manter } \\
\text { o código como uma stored procedure o } \\
\text { torna disponível para aplicações não } \\
\text { escritas em Java }\end{array}$ \\
\hline Método & $\begin{array}{l}\text { Uma mudança em um método (uma } \\
\text { stored procedure ou trigger) que } \\
\text { melhora sua qualidade. Vários } \\
\text { refactorings de código são } \\
\text { aplicáveis aos métodos dos bancos } \\
\text { de dados }\end{array}$ & $\begin{array}{l}\text { Renomear uma stored procedure para } \\
\text { tornar mais fácil seu entendimento }\end{array}$ \\
\hline $\begin{array}{l}\text { Transformação } \\
\text { não-refactoring }\end{array}$ & $\begin{array}{l}\text { Uma mudança no esquema da base } \\
\text { de dados que altera sua semântica }\end{array}$ & $\begin{array}{l}\text { Adicionar uma nova coluna em uma } \\
\text { tabela existente }\end{array}$ \\
\hline
\end{tabular}

\subsubsection{O processo de desenvolvimento do database refactoring}

Ambler e Sadalage (2006) propõem um ambiente de desenvolvimento no qual, tanto a aplicação, quanto o esquema da base de dados estão presentes, permitindo 0 desenvolvimento e o teste de unidade relativo a uma modificação. Cada equipe do 
projeto tem uma coleção de ambientes de desenvolvimento e um ambiente de desenvolvimento para a integração das alterações desenvolvidas. Com isso, em caso de erros, o impacto é relativamente baixo, uma vez que impacta apenas o trabalho de cada equipe.

A necessidade de se desenvolver um database refactoring parte, tipicamente, de uma necessidade de se implementar um novo requisito ou de se corrigir algum defeito na aplicação. Um exemplo, citado pelos autores, é a necessidade de se estender uma aplicação para aceitar um endereço de outro país, em adição ao que já é aceito na aplicação. Com isso, é necessário modificar a coluna que armazena o código de endereçamento postal, para permitir armazenamento de códigos com diferentes estruturas.

Ao se deparar com semelhante necessidade, o administrador de banco de dados e 0 desenvolvedor devem passar por uma série de etapas (todas ou em parte) para desenvolver o database refactoring.

A Figura 6 mostra o processo para o database refactoring, que deve ser realizado iterativamente. A seguir, cada uma destas etapas é detalhada:

1. Verificar se o database refactoring é necessário - nesta etapa, deve-se considerar se realmente faz sentido a alteração em questão, se existe uma regra de negócio que requer a alteração e se o esforço em se implementar a alteração justifica a mudança, avaliada em função do nível de acoplamento desta parte da base de dados;

2. Escolher o database refactoring mais adequado - uma vez que é possível aplicar um grande número de refactorings, deve-se avaliar qual o database refactoring mais adequado para o caso em questão. 0 problema pode estar identificado corretamente, porém é necessário cuidado ao escolher a solução, uma vez que esta já pode estar implementada em alguma outra parte da base de dados;

3. Elaborar a transição do esquema original da base de dados - se múltiplas aplicações acessam a base de dados, pode não ser possível alterar e implementar todos os programas simultaneamente. Assim, pode ser necessário um período de transição para a porção original do esquema que está sendo alterado. Durante este período de transição, é necessário 
oferecer possibilidade de uso do esquema original e também do novo esquema em paralelo, para que os desenvolvedores tenham tempo para implementar as alterações nas outras aplicações que acessam a base de dados. Ambler e Sadalage (2006) mencionam que durante este período de transição, é necessário assumir que algumas aplicações utilizarão o esquema original, enquanto que outras usarão o novo esquema. Além disso, uma aplicação apenas poderá utilizar uma das versões do esquema e não ambas simultaneamente. Nem todos os database refactorings requerem períodos de transição;

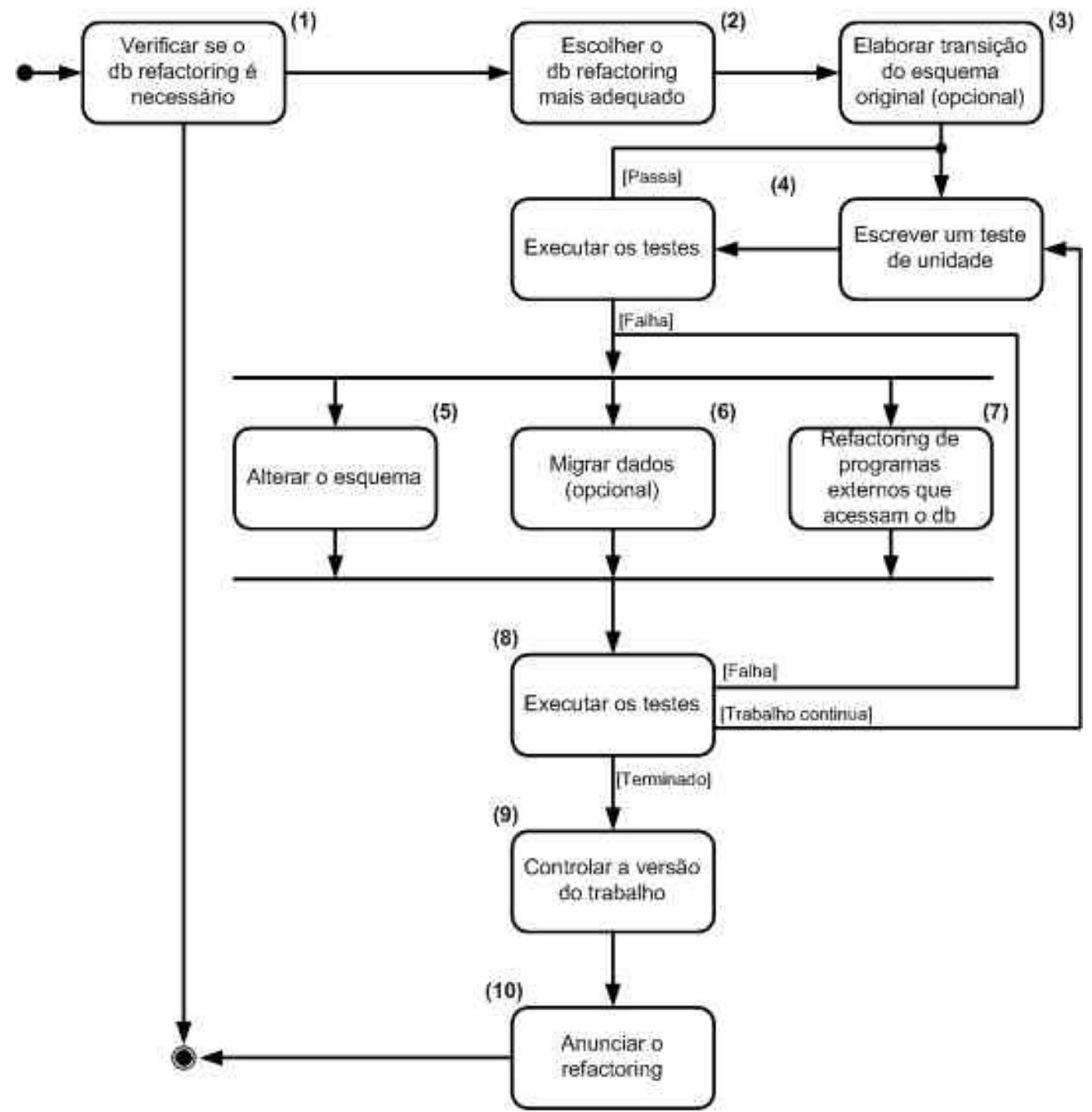

Figura 6 - 0 processo do database refactoring (AMBLER; SADALAGE, 2006) 
4. Testes - um conjunto de testes deve ser elaborado e executado até que o database refactoring seja completamente implementado. O esquema deve ser testado em todos os aspectos relativos à alteração, como stored procedures e triggers, regras de integridade referencial, definições de visões, valores defaults e regras de domínio. Dependendo da alteração, pode ser necessário migrar ou realizar uma eliminação de inconsistências sobre os dados armazenados (descrito na etapa 6). Desta forma, os procedimentos que foram escritos para a migração ou eliminação de inconsistências dos dados devem ser devidamente testados. Por fim, os programas externos que têm acesso à base de dados e foram alterados (descrito na etapa 7) também devem ser testados;

5. Alterar o esquema da base de dados - nesta etapa será necessário criar scripts para implementar cada database refactoring na base de dados;

6. Migrar dados - muitos dos database refactorings requerem algum tipo de tratamento nos dados já armazenados na base. Em alguns casos é necessário mover dados de um local a outro, em casos de refactoring que envolvem qualidade de dados, é necessário realizar uma eliminação de inconsistências nos valores armazenados. Desta forma, pode ser necessária a criação de procedimentos para realizar estas atividades;

7. Refactoring de programas externos que acessam a base de dados quando o esquema da base de dados sofre alterações, é necessário alterar também os programas externos que acessam a parte alterada do esquema. Os métodos para alteração destes programas estão além do escopo deste trabalho e não serão detalhados. Ambler e Sadalage (2006) citam vários autores e metodologias para se executar esta tarefa de modo otimizado;

8. Testes - equivalente ao descrito na etapa 4;

9. Controlar a versão do trabalho - após concluído o desenvolvimento de um database refactoring é necessário controlar versões dos artefatos envolvidos, como scripts, geração e dados de teste, casos de teste, documentação e modelos; 
10. Anunciar o database refactoring - uma vez que a base de dados é um recurso compartilhado, mesmo que o nível de acoplamento seja baixo, é necessário comunicar às partes interessadas, equipes internas e externas, que o database refactoring foi realizado.

\subsubsection{O processo de implantação do database refactoring em produção}

Uma vez que as alterações já estão desenvolvidas e devidamente testadas, Ambler e Sadalage (2006) sugerem que, por se tratar de um ambiente bem mais complexo, em que o impacto de um erro pode afetar inclusive outros ambientes, as alterações sejam implantadas com base em um processo rigoroso.

Para isso, os autores recomendam que sejam adotadas as seguintes estratégias:

- Implantação nos vários ambientes isolados e controlados - partindo-se dos ambientes de desenvolvimento de cada elemento da equipe e, posteriormente, no ambiente de integração, as alterações serão colocadas em um ambiente de pré-produção, que possibilita a validação do sistema com outros sistemas da organização. Além disso, também é recomendável sua implantação em um ambiente de demonstração, para que os usuários possam também avaliar os resultados;

- Aplicação de pacotes de database refactorings - devido à forma de trabalho das equipes de desenvolvimento, as alterações podem ser implementadas em curtos períodos de tempo. Se várias alterações forem sendo implementadas, normalmente, não existe justificativa para se implantar em produção cada uma delas, separadamente. Tipicamente, as alterações podem ser implantadas em produção em períodos de poucos meses, assim, os database refactorings podem ser agrupados e implementados em pacotes;

- Programar janelas de implantação - uma janela de implantação é um ponto específico no tempo no qual é permitido implantar um sistema em produção. Estas janelas, tipicamente, coincidem com horários de menor atividade no sistema. Isto ajuda a organizar o tempo da equipe 
de operação e permite estabelecer datas para os usuários receberem as novas funcionalidades;

- Implantar o sistema - os database refactorings são implantados como parte de um processo que envolve um ou mais sistemas. Apesar de existirem situações em que o nível de acoplamento é baixo, envolvendo apenas uma aplicação e uma base de dados, deve-se considerar o caso em que vários sistemas e vários conjuntos de dados estão presentes. Ambler e Sadalage (2006) sugerem as seguintes tarefas para a implantação. Estas tarefas estão representadas na Figura 7.

1. Backup da base de dados - para que seja possível desfazer uma implantação;

2. Executar testes de regressão - estes testes são necessários para garantir que nada foi alterado, de forma incorreta, após a conclusão dos testes em pré-produção. Além disso, é importante verificar se existe algum efeito colateral não esperado no ambiente de produção;

3. Implantar as aplicações alteradas - seguir os procedimentos existentes na organização para esta tarefa;

4. Implantar os database refactorings - é necessário executar os procedimentos que alteram o esquema e os procedimentos de migração dos dados;

5. Executar testes de regressão - após a implantação dos database refactorings é necessário verificar se o sistema está funcionando, apropriadamente, em produção;

6. Desfazer alterações, se necessário - em caso de erros graves surgirem em ambiente de produção, será necessário desfazer todas as alterações efetuadas, utilizando as cópias de segurança geradas na tarefa 1, acima descrita. Para minimizar a ocorrência deste tipo de situação, a implantação em produção pode ser incremental; 
7. Anunciar os resultados da implantação - com o objetivo de gerenciar a expectativa dos usuários, é importante comunicar ou sucesso ou insucesso da implantação.

- Remover o esquema de transição - a implantação só pode ser considerada concluída quando o esquema de transição for retirado da produção, o que pode levar bastante tempo. É importante lembrar que todos os procedimentos existentes para garantir o acesso tanto ao esquema antigo quanto ao novo esquema devem ser retirados, primeiramente, no ambiente de pré-produção e acompanhados de um conjunto de testes que garantam seu correto funcionamento.



Figura 7 - 0 processo de implantação do database refactoring 


\subsection{A UTILIZAÇÃO DOS CONCEITOS SOBRE EVOLUÇÃO DE ESQUEMA PARA A ARQUITETURA PROPOSTA NESTE TRABALHO}

O gerenciamento da evolução do esquema da base de dados é um dos principais pontos considerado na arquitetura de uso do Data Warehouse em plataformas móveis apresentada neste trabalho. Assim, o presente trabalho busca descrever um conjunto de processos que permita classificar, avaliar e aplicar as mudanças na evolução do esquema realizadas no Data Warehouse central, que devem ser propagadas para as bases de dados das estações de trabalho, tanto no que se refere à semântica quanto à propagação da mudança, ou seja, o esquema propriamente dito e os dados armazenados.

O contexto no qual estas mudanças de esquema irão ocorrer está detalhado no capítulo 6, em uma arquitetura que representa todos os principais componentes e processos relativos a uma solução de Data Warehouse em plataformas móveis.

O trabalho de Ambler e Sadalage (2006) é utilizado no presente trabalho como base para a avaliação da complexidade e do impacto das alterações de esquema ocorridas no Data Warehouse central e que devem ser replicadas nos data marts das plataformas móveis. 


\section{A UTILIZAÇÃO DE METADADOS}

De acordo com Staudt; Vaduva e Vetterli (1999), o principal propósito dos metadados é fornecer documentação consistente sobre a estrutura, o processo de desenvolvimento e o uso de um sistema computadorizado. O gerenciamento dos metadados auxilia no entendimento sobre que informação a organização tem, onde esta informação está localizada e qual seu valor para o usuário.

Historicamente, metadados são definidos como "dados sobre os dados" e mais especificamente, no escopo deste trabalho, pode-se dizer que os metadados fornecem informações sobre os dados e o processamento destes dados (FAN; POULOVASSILIS, 2003).

\subsection{A IMPORTÂNCIA DOS METADADOS E SUAS APLICAÇÕES}

Como já mencionado, o principal objetivo dos metadados é fornecer documentação consistente sobre a estrutura, o processo de desenvolvimento e o uso de um sistema computadorizado e, de forma, resumida, oferecer informações sobre os dados e o processamento dos mesmos.

A disponibilidade dos metadados auxilia no entendimento do sistema e apóia, de forma eficiente, o trabalho de todos os "atores" envolvidos no desenvolvimento, exploração, manutenção e administração de um sistema: administradores de dados, desenvolvedores de aplicação, administradores e auditores do sistema e usuários finais.

Com a criação e o uso dos metadados as seguintes tarefas e objetivos podem ser alcançados (STAUDT; VADUVA; VETTERLI, 1999):

- Melhorar a interação com o sistema - quer a interação com o sistema seja feita por meio de simples consultas, quer seja realizada por meio de complexas tarefas de análise, metadados são úteis, pois disponibilizam informação sobre os componentes do sistema e como utilizá-los, explicam conceitos e terminologias relacionadas ao modelo de negócios, além de fornecer informações sobre o modelo dos dados 
armazenados, já que em algumas implementações, as consultas necessitam dos metadados para estabelecer a correção sintática de uma consulta (por exemplo, determinar a existência de um atributo);

- Melhorar a qualidade dos dados - nos sistemas de informação, os dados devem ser consistentes, atualizados, corretos e completos. Os metadados mantêm informações sobre a origem destes dados, quais transformações foram aplicadas sobre eles (mantendo, inclusive, informações sobre sua linhagem), quais são seus significados e quem é responsável por sua qualidade;

- Apoiar os processos de integração - a integração de dados provenientes de bases heterogêneas e sistemas de informação ou a interoperabilidade de várias fontes de dados requerem metadados sobre a estrutura e o significado de cada fonte de dados. Além disso, os componentes de software necessários para a integração dependem da disponibilidade das descrições de interfaces e de metadados relativos aos outros componentes do sistema;

- Apoiar a manutenção do sistema, a análise e projeto de novas aplicações e processos de negócio - os metadados fornecem o controle e confiabilidade ao processo de desenvolvimento de uma aplicação, disponibilizando informações sobre a estrutura, o significado e a origem dos dados e sobre as aplicações e componentes de software existentes no sistema e que precisem de extensões;

- Automatizar várias tarefas administrativas - os metadados permitem especificar mecanismos de controle que serão utilizados em tempo de execução de várias tarefas administrativas.

Conforme (INTEL TECHNOLOGY JOURNAL, 2004), os principais tipos de aplicação dos metadados são:

- Análise de impacto - possibilita o entendimento sobre as dependências dos dados e seus relacionamentos e a percepção exata sobre quais os efeitos que alterações em qualquer elemento de dado podem causar;

- Reutilização - consiste na capacidade de se reutilizar objetos com a mínima ou se possível, nenhuma interrupção no processo de negócios. 
A reutilização permite economizar tempo e recursos (pessoas, sistemas e dados);

- Relatórios - possibilitam uma visão resumida ou detalhada dos dados, por exemplo, o entendimento de todos os elementos de dados em uma tabela específica.

Diferentes áreas requerem o gerenciamento de metadados, como, por exemplo, bancos de dados, sistemas de recuperação de informações, engenharia de software, bibliotecas digitais, sistemas de telecomunicação, entre outros (STAUDT; VADUVA; VETTERLI, 1999). Este trabalho tem como foco o uso de metadados em sistemas de recuperação de informações e sistemas de bancos de dados integrados, ambos como parte de sistemas de Data Warehouse. Assim, a seguir é detalhado o uso dos metadados em sistemas de Data Warehouse.

\subsection{METADADOS EM SISTEMAS DE DATA WAREHOUSE}

Todas as vezes que dados são movidos ou transformados, metadados devem ser envolvidos para controlar este movimento, especificando informações como: localização dos dados, ordem de execução dos processos e mapeamentos da fonte e origem dos dados. Conforme Bernstein e Bergstraesser (1999), o Data Warehouse é o tipo de aplicação que mais requer controle sobre a movimentação e transformação de dados, sendo, cada vez mais, componente importante da arquitetura de informação das empresas. A diversidade de informações a serem armazenadas como metadados de um sistema de Data Warehouse é grande, uma vez que os Data Warehouses são criados a partir de diferentes tipos e fontes de informação e requerem uma série de processos de transformação e carga para as bases de destino. Além disso, diferentes tipos de aplicações de consultas e análises fazem parte do uso do Data Warehouse, bem como os perfis distintos de acessos de seus usuários.

A Figura 8 apresenta a arquitetura de um sistema de Data Warehouse, destacando seus principais componentes. Os metadados devem, então, conter informações relevantes sobre a arquitetura, a criação e manutenção, o gerenciamento e o uso do Data Warehouse. Todos os componentes de um sistema de Data Warehouse, 
conforme representados na figura, devem estar descritos e seu uso deve ser gerenciado pelos metadados. Em relação aos dados, devem existir metadados sobre os esquemas das fontes de dados (sistemas transacionais), do Data Warehouse e dos data marts, significados dos indicadores de negócio armazenados, segurança de acesso, bem como outras informações pertinentes aos dados. Quanto aos processos, os metadados devem refletir as regras de extração, transformação e carga dos dados, freqüência dos processos de manutenção, políticas de eliminação de inconsistências das bases, linhagem dos dados migrados e transformados, entre outros aspectos.

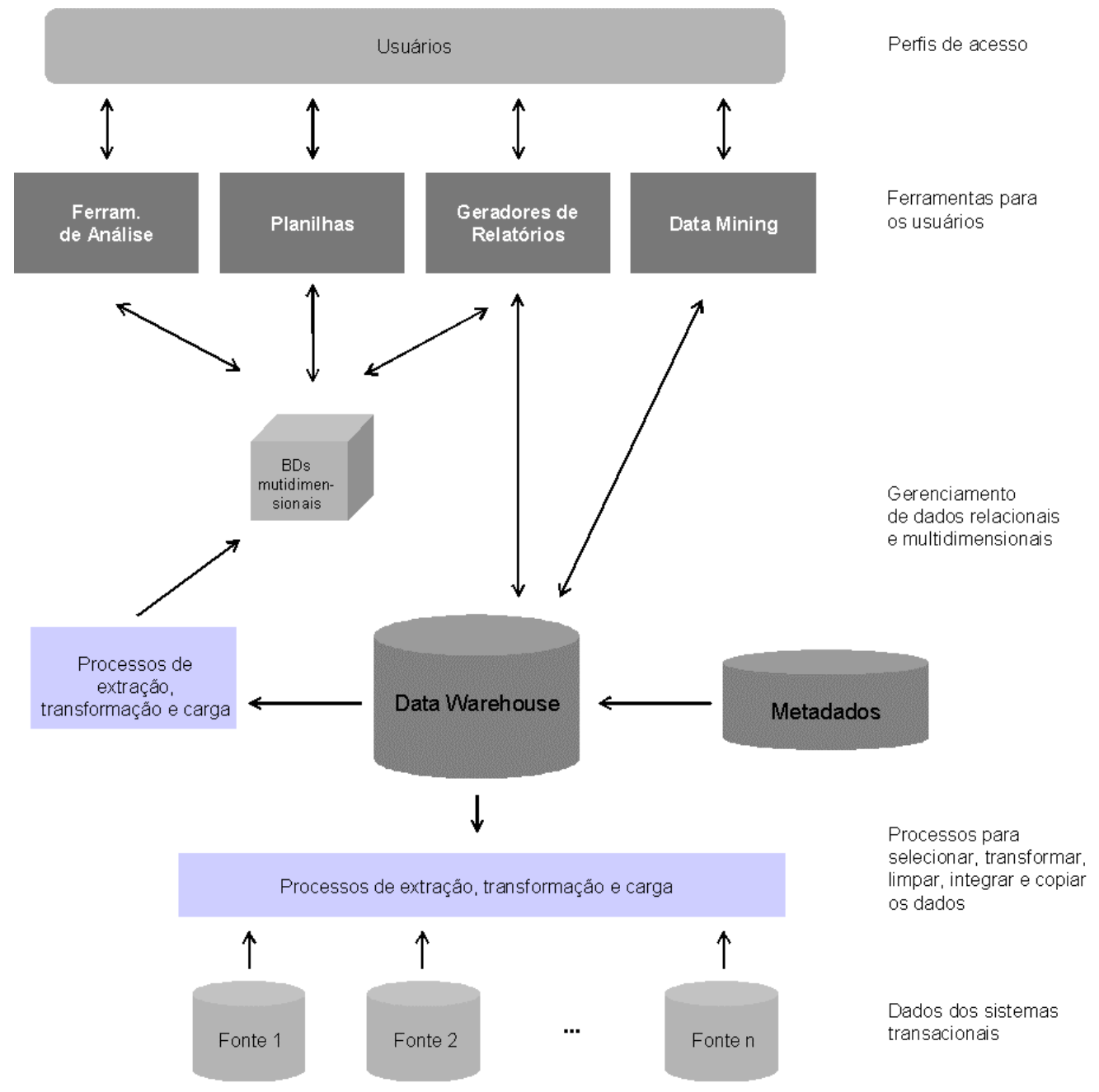

Figura 8 - Os principais componentes de um sistema de Data Warehouse

Além de seus componentes que, por sua diversidade, conferem aos metadados alta complexidade, o Data Warehouse é também caracterizado por um ciclo de vida 
bastante elaborado. Conforme Vassiliadis et al. (2001), em uma permanente fase de projeto, o responsável pelo Data Warehouse (que, neste trabalho, será referenciado por ADW - Administrador do Data Warehouse) deve produzir e manter um modelo conceitual e um modelo lógico, normalmente de grandes proporções, além do projeto físico detalhado, elaborado para acesso eficiente, devido ao grande volume de dados a serem armazenados e consultados. O ADW também deve lidar com processos de administração do Data Warehouse que têm estrutura complexa, numerosos e difíceis de codificar, além de cuidar de processos de contingência, para o caso de erros. Finalmente, a fase de evolução envolve uma combinação de projeto e tarefas de administração, pois, conforme o tempo passa, as regras de negócio das organizações mudam, novos dados e aplicações são solicitados pelos usuários, novas fontes de informação passam a estar disponíveis bem como novas versões dos componentes de software utilizados. Desta forma, a arquitetura do Data Warehouse deve evoluir para suportar, de forma eficiente, os processos de tomada de decisão de seus usuários. Estas evoluções podem levar a alterações no esquema dos dados armazenados no Data Warehouse e nas janelas de tempo dos processamentos de extração, transformação e carga dos dados, gerando mais complexidade à manutenção do sistema (QUIX, 1999).

\subsubsection{Tipos de metadados}

Em relação ao conteúdo dos metadados, os administradores do Data Warehouse, bem como outros usuários de nível técnico, estão interessados, principalmente, nos metadados relacionados à implementação técnica, chamados de metadados técnicos. Já os usuários finais ou de negócios, estão interessados em entender a semântica dos negócios modelados no Data Warehouse e, por esta razão, necessitam de metadados semânticos para formar uma visão orientada aos negócios, conforme Stöhr; Muller e Rahm (1999). Assim, o conjunto de metadados pode ser dividido em duas classes, descritas abaixo:

- Metadados técnicos - também chamados de metadados administrativos ou estruturais, que descrevem informações sobre: 
- A arquitetura e os esquemas dos sistemas operacionais, o Data Warehouse e os data marts, incluindo informações sobre tabelas, estruturas de registro, restrições de atributos, gatilhos ou visões definidas em diferentes bases de dados ou arquivos;

- As dependências e mapeamentos entre as fontes operacionais, o Data Warehouse e seus data marts, incluindo movimentações dos dados, filtros, transformações e agregações, além de mapeamentos da camada física (armazenamento físico) do Data Warehouse com a camada lógica, ou seja, a visão orientada a negócios que determina o contexto do Data Warehouse (significa o mapeamento entre os metadados técnicos e os semânticos).

- Metadados semânticos - também chamados de metadados de negócios, têm por objetivo fornecer descrições orientadas ao conteúdo do Data Warehouse. Estas descrições devem ser inteligíveis para os usuários que não estão familiarizados com as descrições técnicas ou linguagens de consulta como SQL. Os metadados semânticos devem contemplar os seguintes tipos de metadados orientados a negócios:

- Representação do modelo de dados da organização, seus conceitos de negócios e seus relacionamentos. Com base neste modelo, o usuário de negócios, que não está familiarizado com os aspectos técnicos pode entender quais são os dados disponíveis no Data Warehouse;

- Modelos de dados multidimensionais que são parte importante do modelo conceitual da organização e apresentam ao usuário informações sobre as dimensões, hierarquias das dimensões, cubos de dados (denota uma organização multidimensional dos fatos, ou métricas, dentro do domínio de negócios) e níveis de agregação dos dados;

Com a representação dos metadados semânticos, os usuários de negócio podem realizar navegações nas visões de dados orientadas a negócios, além de consultas ad-hoc no nível dos conceitos de negócios 
sem necessidade de ter conhecimentos de detalhes técnicos como, por exemplo, linguagens de consulta como SQL.

Como qualquer outro tipo de dados, os metadados requerem armazenamento persistente, isto é um repositório para mantê-los (MARCO, 2004) e, com isso, requerem também um modelo de informação (ou esquema) que descreva os metadados armazenados (BERNSTEIN; BERGSTRAESSER, 1999). Assim, devido à grande importância dos metadados, neste trabalho, todos os componentes, processos e dados do Data Warehouse devem, portanto, ser acompanhados e administrados por meio de um repositório de metadados, tendo como principal objetivo efetuar o gerenciamento de todos componentes da arquitetura proposta, bem como os processos e seus parâmetros de execução.

\subsubsection{Arquiteturas de metadados}

Em relação à arquitetura dos metadados, Marco (2004) propõe um ambiente de gerenciamento de metadados, chamado de MME (Managed Meta data Environment), que representa os componentes da arquitetura, as pessoas e os processos necessários para, sistematicamente, obter, armazenar e disseminar os metadados na organização. Este ambiente é aqui apresentado, de forma a representar uma arquitetura base para implementação de metadados em sistemas de Data Warehouse, por ser independente de ferramentas, por possuir todos os componentes necessários, conceitualmente, para sua representação e por fornecer uma visão ampla sobre o gerenciamento de metadados.

O ambiente de gerenciamento de metadados, proposto por Marco (2004), pode ser implementado em arquitetura centralizada, descentralizada ou em arquitetura distribuída, sendo:

- Arquitetura centralizada - oferece um metamodelo único, uniforme e consistente que define e organiza os metadados em um repositório de metadados global. Permite uma abordagem consolidada para administrar e compartilhar metadados na organização;

- Arquitetura descentralizada - oferece um metamodelo uniforme e consistente que define e organiza um subconjunto do repositório global 
dos metadados, que ficam armazenados no repositório global e define também elementos de metadados compartilhados, armazenados nos repositórios locais de metadados. Todos os metadados compartilhados e reutilizados entre os vários repositórios locais devem, primeiramente, estar no repositório global, porém o acesso e compartilhamento dos repositórios locais dos metadados são independentes do repositório global;

- Arquitetura distribuída - contempla vários repositórios disjuntos e autônomos de metadados, que possuem seu próprio metamodelo, representando o conteúdo e organização interna destes metadados. Cada repositório é responsável pelo compartilhamento e administração de seus metadados. O repositório global dos metadados não armazena metadados que aparecem nestes repositórios locais, mantendo, porém, ponteiros para os metadados nos repositórios locais e informações sobre como acessá-los.

A Figura 9 apresenta os principais componentes presentes no ambiente de gerenciamento de metadados MME. É importante lembrar que estes componentes formam o subconjunto mínimo necessário para a implementação completa do gerenciamento de metadados com qualidade, principalmente em ambientes complexos como Data Warehouses.

Os componentes representados na Figura 9, são apresentados de forma a estabelecer componentes genéricos para a implementação e uso de metadados:

- Camada de fonte dos metadados - o propósito desta camada é extrair metadados das fontes e enviá-los à camada de integração dos metadados ou diretamente ao repositório de metadados. Em uma arquitetura distribuída, alguns metadados são acessados por meio do uso de ponteiros e apresentados aos usuários no momento em que são solicitados. Estes ponteiros são gerenciados pela camada de fonte dos metadados e armazenados no repositório de metadados. $O$ número e a diversidade das fontes de metadados variam conforme os requisitos de negócios, sendo que as fontes mais comuns são: ferramentas de software, usuários finais, documentos e planilhas, 
mensagens e transações, aplicações, sites da web e comércio eletrônico, além de aplicações de terceiros;

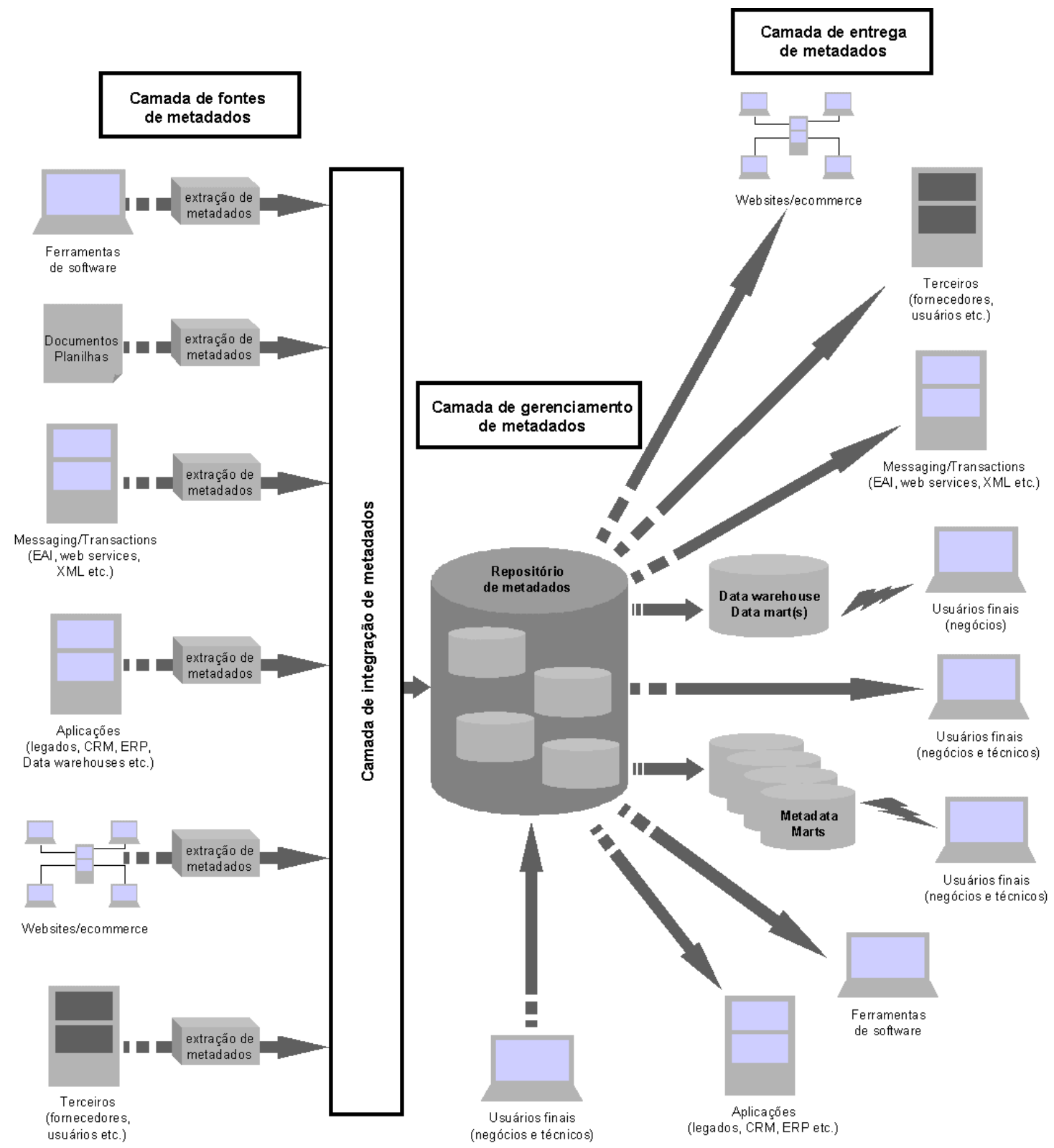

Figura 9 - MME - ambiente de gerenciamento de metadados proposto por Marco (2004)

- Camada de integração dos metadados - esta camada combina as várias fontes de metadados, integrando-as e carregando-as no repositório de metadados. Os passos específicos deste processo dependem da forma de implementação, ou seja, pode ser realizado por meio da construção personalizada ou da utilização de ferramentas de integração de metadados que auxiliam o processo; 
- Repositório de metadados - é uma base de dados projetada para obter, armazenar e disseminar os metadados. Este repositório é responsável pela catalogação e armazenamento físico persistente dos metadados. O repositório deve ser genérico, integrado, corrente e histórico. Por repositório genérico entende-se a implementação um metamodelo físico que armazena metadados por área, ao contrário de uma visão voltada para a aplicação (por exemplo, já indicando o tipo e o fornecedor do banco de dados utilizado, ou indicando uma aplicação específica), não recomendada por dificultar a manutenção dos metadados. O repositório deve fornecer uma visão integrada dos principais assuntos dos metadados, permitindo ao usuário visualizar todas as entidades da organização e não apenas entidades armazenadas em determinado gerenciador de banco de dados ou em determinadas aplicações. O repositório deve também conter metadados atuais, sendo que os metadados devem ser, periodicamente, atualizados para refletir os ambientes de negócios e técnico atuais, com o objetivo de garantir sua utilidade, refletindo a realidade. Além destes aspectos, é importante que o repositório mantenha visões históricas dos metadados, pois isto permite à organização entender como o modelo de negócios muda ao longo do tempo;

- Camada de gerenciamento dos metadados - esta camada fornece gerenciamento sistemático do repositório dos metadados e dos outros componentes do MME. Também apresenta variações dependendo se sua implementação é feita de forma personalizada ou por meio de ferramentas de integração disponíveis no mercado. As funções executadas nesta camada são, principalmente: backup, recuperação da base de dados, modificações na base de dados, ajustes na base de dados, gerenciamento do ambiente, programação de tarefas, eliminação de dados desnecessários, estatísticas de carga e de consultas, geração de relatórios, processos de segurança, mapeamento e movimentação de fontes de dados, gerenciamento da interface com o usuário e versionamento; 
- Subconjuntos do repositório dos metadados (meta data marts) - um meta data mart é uma estrutura de base de dados, normalmente originada do repositório de metadados, projetada para atender às necessidades de um determinado grupo de usuários dos metadados. Uma das razões propostas por Marco (2004), que justifica a criação de meta data marts, é devido a necessidades específicas de um determinado grupo de usuários do data mart que pode requerer que os metadados estejam organizados de forma diferente do repositório de metadados.

- Camada de entrega dos metadados - esta camada permite entregar aos usuários, aplicações ou ferramentas, informações armazenadas no repositório de metadados. Os principais elementos que podem necessitar receber informações de metadados são: aplicações, Data Warehouses e data marts, usuários finais (de negócios e técnicos), meta data marts, ferramentas de software, aplicações de terceiros, web sites, entre outros.

Com a arquitetura proposta por Marco (2004), pode-se perceber que a construção e manutenção de metadados são muito mais que simplesmente manter uma base de dados com os metadados, mas sim manter um ambiente complexo e seus diversos componentes, atendendo às necessidades de usuários específicos ou de aplicações que requerem os metadados, sejam eles técnicos ou semânticos.

\subsection{TRABALHOS RELACIONADOS}

Devido à importância do tema, vários trabalhos de pesquisa têm sido desenvolvidos e divulgados. Nesta seção são apresentados os principais trabalhos de pesquisa em metadados, alguns específicos para Data Warehouses.

O ConceptBase (JARKE et al., 1995) é um sistema dedutivo, desenvolvido como um sistema de base de dados para informações conceituais, ou seja, metadados. A linguagem de representação de conhecimento para codificar requisitos dos modelos de sistemas de informação é o Telos (MYLOPOULOS et al., 1990), sendo que sua base é sobre uma estrutura de dados que representa uniformemente objetos, 
classes, meta classes, atributos e instâncias de classes, assim como relacionamento subclasse-superclasse. O ConceptBase serviu de base para dois importantes trabalhos sobre qualidade de Data Warehouse (CALVANESE et al., 1998; JEUSFELD; QUIX; JARKE, 1998), que apresentam um amplo modelo de metadados em um contexto relacionado à medida de qualidade dos componentes do Data Warehouse. Os trabalhos englobam, de forma bastante ampla, metadados técnicos e semânticos.

O Meta-FIS, projeto do Information Systems Institute of the University of Münster (BECKER; HOLTEN, 1998; HOLTEN, 1999) descreve um modelo de metadados semântico para modelos de dados conceituais sem englobar metadados técnicos nem a interdependência entre os metadados técnicos e os semânticos.

No contexto de qualidade do Data Warehouse (DWQ - Data Warehouse Quality) os trabalhos (VASSILIADIS et al., 2001; CALVANESE et al., 1998; JEUSFELD; QUIX; JARKE, 1998; JARKE et al., 1998) propõem um modelo de metadados abrangente voltado para medir a qualidade dos componentes do Data Warehouse, envolvendo aspectos de metadados técnicos e semânticos. Nos trabalhos (VASSILIADIS et al., 2001; JEUSFELD; QUIX; JARKE, 1998; JARKE et al., 1998), os autores estendem a arquitetura tradicional de metadados em Data Warehouses. Propõem uma arquitetura de metadados em três perspectivas: conceitual, lógica e física, com o objetivo de melhor avaliar a qualidade dos componentes de um Data Warehouse.

Um modelo uniforme e integrador para metadados de Data Warehouse é proposto por Stöhr; Muller e Rahm (1999), que possibilita a representação das interdependências entre os metadados técnicos e semânticos, uma vez que estas interdependências formam um importante pré-requisito para a transformação das consultas formuladas no nível do modelo de negócios em consultas executáveis nos repositórios físicos de dados.

Ainda que integração de informações seja um tema antigo e bastante discutido, tem novamente se tornado importante devido ao grande aumento na utilização da Internet e de tecnologias web nos últimos anos. Projetos como TSIMMIS (CHAWATE et al., 1994), Squirrel (HULL, 1996) e WHIPS (HAMMER et al., 1995) têm seu foco na integração de dados heterogêneos por meio de componentes integradores e mediadores, utilizando diferentes formalismos lógicos e técnicas de implementação. O projeto Information Manifold de pesquisa da AT\&T (LEVY; 
SRIVASTAVE; KIRK, 1995) oferece um modelo conceitual como base para integração.

Com a análise dos trabalhos mencionados, pode-se perceber a importância do uso de metadados como base de integração de informações e para o gerenciamento eficaz dos componentes que envolvem arquiteturas de Data Warehouse, uma vez que permitem descrever os componentes em diferentes níveis de abstração e formalização incluindo diferentes tipos de usuários.

É fato também que, quanto mais complexa for a arquitetura do ambiente a ser controlado, mais importante e necessário se faz o uso de metadados.

Por esta razão, o uso dos metadados ultrapassa os limites do meio acadêmico, em suas várias pesquisas, em direção ao meio comercial, com sua implementação em diversas ferramentas comerciais e esforços de padronização. A padronização de metadados se torna um fator importante, uma vez que permite integrar, em uma mesma arquitetura, diversas e distintas ferramentas e componentes em um mesmo ambiente de Data Warehouse. O uso dos metadados pelos vários componentes do Data Warehouse, quando tratado de forma padronizada, possibilita o gerenciamento uniforme e eficiente de metadados técnicos e semânticos. Um importante objetivo desta padronização é possibilitar a implementação de metadados nos projetos de Data Warehouse de forma independente dos componentes de tecnologia utilizados. Isto significa que, mesmo que diferentes fornecedores de software estejam envolvidos, a troca de metadados entre os diversos componentes é possível e segue o padrão estabelecido.

Assim, na próxima seção são abordados os principais esforços de padronização de metadados em ambientes de Data Warehouse.

\subsection{ESFORÇOS DE PADRONIZAÇÃO DE METADADOS PARA DATA WAREHOUSE}

A maioria das aplicações e dos sistemas de bancos de dados que compõem a arquitetura do Data Warehouse define e utiliza metadados de forma diferente. Cada uma utiliza estruturas de programação, sintaxe e semântica diferentes para modelar 
seu conjunto de metadados e, normalmente, a semântica fica embutida nos sistemas que utilizam os dados. Estas incompatibilidades fazem com que a tentativa de uma aplicação descobrir e interagir com os dados mantidos por outra aplicação seja um desafio, agravado pelo grande número e complexidade de aplicações, fontes de dados, protocolos de troca de informações e de plataformas nas quais as aplicações e os dados estão disponíveis.

Não apenas as aplicações de Data Warehouse têm que integrar diferentes bancos de dados, como os próprios bancos de dados capturam diferentes aspectos do modelo de negócios. Isto significa que, além de esquemas estruturalmente diferentes, eles se referem a diferentes aspectos e informações de negócios, pois, normalmente, estão em sistemas diversos, espalhados pela empresa. É importante lembrar que, dentre as múltiplas fontes estruturadas que contribuem para a composição dos Data Warehouses, outros tipos de informação são agregados, como por exemplo, arquivos gerados pela captura de dados de click-stream em sistemas de Internet (MOSHER, 2002). Todos os diferentes tipos de dados envolvidos têm que ser extraídos, transformados e carregados na base de dados do Data Warehouse, utilizando aplicações de ETL (Extraction, Transformation and Load), desenvolvidas pela empresa usuária do Data Warehouse ou por terceiros ou, ainda, adquirida de um fornecedor deste tipo de ferramenta.

Uma das soluções usadas para se integrar todos os componentes do Data Warehouse e compartilhar informações de metadados é desenvolver interfaces entre as aplicações, de forma que elas possam compartilhar dados de diferentes maneiras. Estes esforços decorrem da ausência de um modelo comum para a criação dos metadados, chamado de metamodelo. Sem este modelo, torna-se difícil o compartilhamento dos dados mais simples, que muitas vezes compõem a integração de aplicações, componentes e sistemas complexos.

Conforme Vassiliadis; Bouzeghoub e Quix (2000), todos os componentes de um Data Warehouse devem ser administrados a partir de um repositório de metadados, auxiliando o administrador e o projetista do Data Warehouse. Desta forma, a unificação dos metadados relacionados aos diferentes componentes e processos de um sistema de Data Warehouse torna-se essencial para garantir a qualidade do sistema resultante. Para se alcançar este objetivo é necessário utilizar um padrão comum para representar os metadados, ou seja, um modelo de metadados, 
chamado de metamodelo. Um modelo bem definido manterá informações precisas sobre as características e atributos de uma instância em particular, com definições exatas e sem ambigüidades das características de um modelo para os diferentes formatos de troca de informações e de linguagens e em diferentes níveis de abstração.

Existem, atualmente, algumas iniciativas de padronização de metadados para sistemas de Data Warehouse. Esta seção tem por objetivo descrever os principais padrões.

\subsubsection{MDAPI}

A API multidimensional (MDAPI) (THE OLAP COUNCIL, 1998) definida pelo OLAP Council é uma especificação não-proprietária de uma API orientada a objetos que apresenta uma série de funções OLAP. O OLAP Council foi estabelecido em janeiro de 1995, tendo como principais membros empresas como IBM, Oracle, Sun, Platinum, Hyperion Solutions, NCR, Cognos, Business Objects entre outras.

A MDAPI é a especificação de um conjunto de funções OLAP que as implementações dos fornecedores de soluções deveriam suportar. Algumas delas são:

- Conexão com o servidor e login;

- Funções de consultas aos metadados;

- Funções de consultas aos dados multidimensionais;

- Capacidades de filtragens e ordenações;

- Gerenciamento de erros.

As unidades de informação básicas da API são os membros, que podem ser entendidos como abstrações de células mais características adicionais descritas como propriedades. Um subtipo especial de membro são as métricas com atributos predefinidos como escala, precisão etc. Em tempo de execução estes membros recebem atribuições de valores que correspondem aos seus tipos específicos de dados. Os membros são organizados em dimensões compostas por uma ou mais hierarquias com diferentes níveis de detalhes e agregação. Tipos de dimensões 
especiais estão disponíveis para as dimensões que tratam o tempo e as métricas (fatos). A MDAPI oferece dois tipos básicos de consultas, chamadas de Cube para acesso aos dados e MemberQuery para recuperação dos metadados.

É importante ressaltar que a MDAPI não é um metamodelo, mas um modelo de implementação e que está relacionada apenas aos aspectos de dados e metadados dos componentes OLAP do Data Warehouse.

\subsubsection{OIM}

O Open Information Model (OIM) (METADATA COALITION, 1999) definido pela Meta Data Coalition (MDC) é uma especificação extensível, não-proprietária e independente de tecnologia, de metadados que representa os ambientes e arquiteturas corporativos. O OIM foi, inicialmente, desenvolvido pela Microsoft Corporation e Platinum Technology, tendo sido, posteriormente, transferido para o Meta Data Coalition, que é um grupo de fornecedores e usuários interessados na definição, implementação e evolução de um formato de intercâmbio de metadados e seus respectivos mecanismos de apoio. O OIM é um metamodelo que apóia a engenharia de software.

A visão do OIM inclui aspectos como análise, projeto, objetos, componentes, bases de dados, Data Warehouse e gestão de conhecimento, tendo um escopo bastante abrangente e que extrapola o ambiente das aplicações de Data Warehouse.

Em relação aos aspectos específicos do gerenciamento de metadados para Data Warehouse, o OIM possui modelos como:

- Modelo de transformação de informações de bases de dados, que define metadados que descrevem os processos que mapeiam e transformam os conteúdos de várias fontes e destinos de armazenamento de dados. Dentre os variados tipos de transformações, pode-se citar, como exemplo, a transformação de dados operacionais em estruturas com representações normalizadas, relacionais ou orientadas a análises, garantindo, inclusive, a capacidade de acompanhamento da linhagem dos dados por meio das diversas operações de transformação. 
- Modelo de informação OLAP, que descreve as informações sobre bases de dados multidimensionais. Exemplos de elementos suportados são:

- Cube - componente básico na análise multidimensional, descrevendo uma tabela fato e uma ou mais tabelas dimensão que, juntas, formam um star ou snowflake schema;

- Cubo virtual - cubo não materializado;

- Partição - descreve parte de um cubo (particionado por questões de desempenho ou de armazenamento);

- Agregação - define agrupamentos pré-calculados dos dados armazenados em um cubo;

- Hierarquia da dimensão - define como uma dimensão se decompõe em subdimensões.

- Modelo de informação semântica, que também é uma extensão do Modelo de informação de bases de dados e define os mapeamentos do tipo schema-to-semantic. Este modelo mantém as descrições dos modelos de semântica e seus relacionamentos com os esquemas da base de dados.

- Modelo de informação orientado a registro, que é um metamodelo que descreve fontes de dados orientadas a registros, que possibilita capturar informação sobre definições de registros (COBOL, PL/I etc.).

Em setembro de 2000, o grupo MDC se juntou ao Object Management Group (OMG) para trabalhar em um conjunto único de especificações de metadados. Esta especificação recebeu o nome de Common Warehouse Metamodel Specification (CWM), sendo que sua primeira versão foi publicada pelo OMG em fevereiro de 2001 (OMG - OBJECT MANAGEMENT GROUP, 2001).

\subsubsection{CWM}

Conforme definido em (OMG, 2001), o propósito principal do CWM é permitir a troca de metadados de Data Warehouse entre as ferramentas, plataformas e repositórios 
de metadados, que compõem o ambiente do Data Warehouse, distribuídos em ambientes heterogêneos. O CWM é baseado em três importantes padrões, a saber:

- UML - Unified Modeling Language, um padrão para modelagem, do OMG;

- MOF - Meta Object Facility, um padrão do OMG, para metamodelagem e repositório de metadados;

- XMI - XML Metadata Interchange, um padrão para troca de metadados, também do OMG.

O padrão UML define uma linguagem rica de modelagem orientada a objetos, suportada por várias ferramentas gráficas. O padrão MOF define uma estrutura para definição de modelos de metadados, fornecendo ferramentas com interfaces programáveis para armazenar e acessar os metadados em um repositório. O padrão XMI possibilita a troca de metadados, como arquivos em formato baseado no padrão XML. Os principais aspectos da arquitetura proposta pelo CWM incluem:

- Arquitetura de metamodelagem em quatro camadas, para manipulação de metadados em repositórios de objetos distribuídos;

- Uso da notação UML para representar os metamodelos e modelos;

- Uso dos modelos de informação padrão (UML) para descrever a semântica de modelos de análise e projeto de objetos;

- Uso do MOF para definir e manipular metamodelos de forma programável, utilizando as interfaces definidas pelo CORBA;

- Uso do XMI para troca de metadados.

A especificação (OMG, 2001) consiste, principalmente, de definições de metamodelos ${ }^{5}$ nos seguintes domínios:

- Object model (um subconjunto da UML);

- Base (foundation) do CWM;

- Recursos de dados relacionais;

- Recursos de dados em registros;

- Recursos de dados multidimensionais;

\footnotetext{
${ }^{5}$ Um metamodelo é um modelo de metadados.
} 
- Recursos de dados em XML;

- Transformações de dados;

- OLAP (On-line Analytical Processing);

- Data mining;

- Visualização de informações;

- Nomenclatura de negócios;

- Processos do warehouse;

- Operação do warehouse.

A adoção do CWM por vários fornecedores de componentes de sistemas de Data Warehouse, a partir de 2000, demonstra sua aplicabilidade em soluções de Data Warehouse e apóia a solução de um de seus problemas mais críticos atualmente - 0 gerenciamento e troca de metadados.

Por meio desta arquitetura, o CWM implementa a troca de metadados com uma abordagem orientada a modelos, na qual os modelos de objetos, que representam os metadados em uma ferramenta específica, são construídos de acordo com as especificações sintáticas e semânticas de um metamodelo comum (PAIGE, 1984). Dessa forma, o CWM é capaz de resolver um número significativo de problemas relacionados à integração dos metadados e ferramentas, na comunidade de Data Warehouse (CHANG, 2000).

\subsection{O PADRÃO DE METADADOS ESCOLHIDO PARA A ARQUITETURA PROPOSTA NESTE TRABALHO}

Por ser o metamodelo mais completo para sistemas de Data Warehouse, o CWM é o padrão de metadados utilizado para compor a arquitetura deste trabalho.

Empresas como a IBM, a Oracle, a NCR, a Unisys, a Hyperion, entre outras, que fornecem importantes componentes para os sistemas de Data Warehouse como, por exemplo, bases de dados relacionais e multidimensionais, ferramentas de análise, relatórios, repositórios de metadados, para citar apenas alguns, já suportam o CWM para troca de metadados (CHANG, 2000). Este é um importante fator, que demonstra a viabilidade de implementação prática do metamodelo CWM. 
Assim, nesta seção, o CWM é detalhado, com o objetivo de destacar todos os componentes que podem ser utilizados para a implementação da arquitetura proposta neste trabalho.

\subsubsection{O metamodelo do CWM}

É grande a quantidade de dados que as empresas têm que processar em ambientes de Data Warehouse, transformando estes dados em conhecimento útil para apoiar os processos de tomada de decisão, com o objetivo de obter mais inteligência nos modelos e processos de negócios.

Neste cenário, um dos componentes mais importantes é o gerenciamento e controle dos metadados, utilizados para criar, manter, gerenciar e utilizar o Data Warehouse. Porém, a proliferação de ferramentas de gerenciamento e análise de dados tem resultado em muitas representações e formas de tratamento diferentes dos metadados.

O CWM, como resposta para estes problemas, fornece uma estrutura capaz de representar os metadados de forma única, partindo de um metamodelo que representa os metadados nas grandes áreas de interesse das tecnologias de Data Warehouse. Este metamodelo está representado na Figura 10.

O metamodelo do CWM é projetado para maximizar a reutilização do Object Model (um subconjunto da UML) e compartilhar construções comuns de modelagem, sempre que possível.

\subsubsection{A organização do CWM}

Conforme representado na Figura 10, o metamodelo do CWM utiliza pacotes de metamodelos e uma estrutura hierárquica dos mesmos, para controlar a complexidade, favorecer o entendimento e proporcionar reutilização. Os elementos do modelo estão agrupados nos seguintes metamodelos: Object Model, Foundation, Resource, Analisys e Management. 


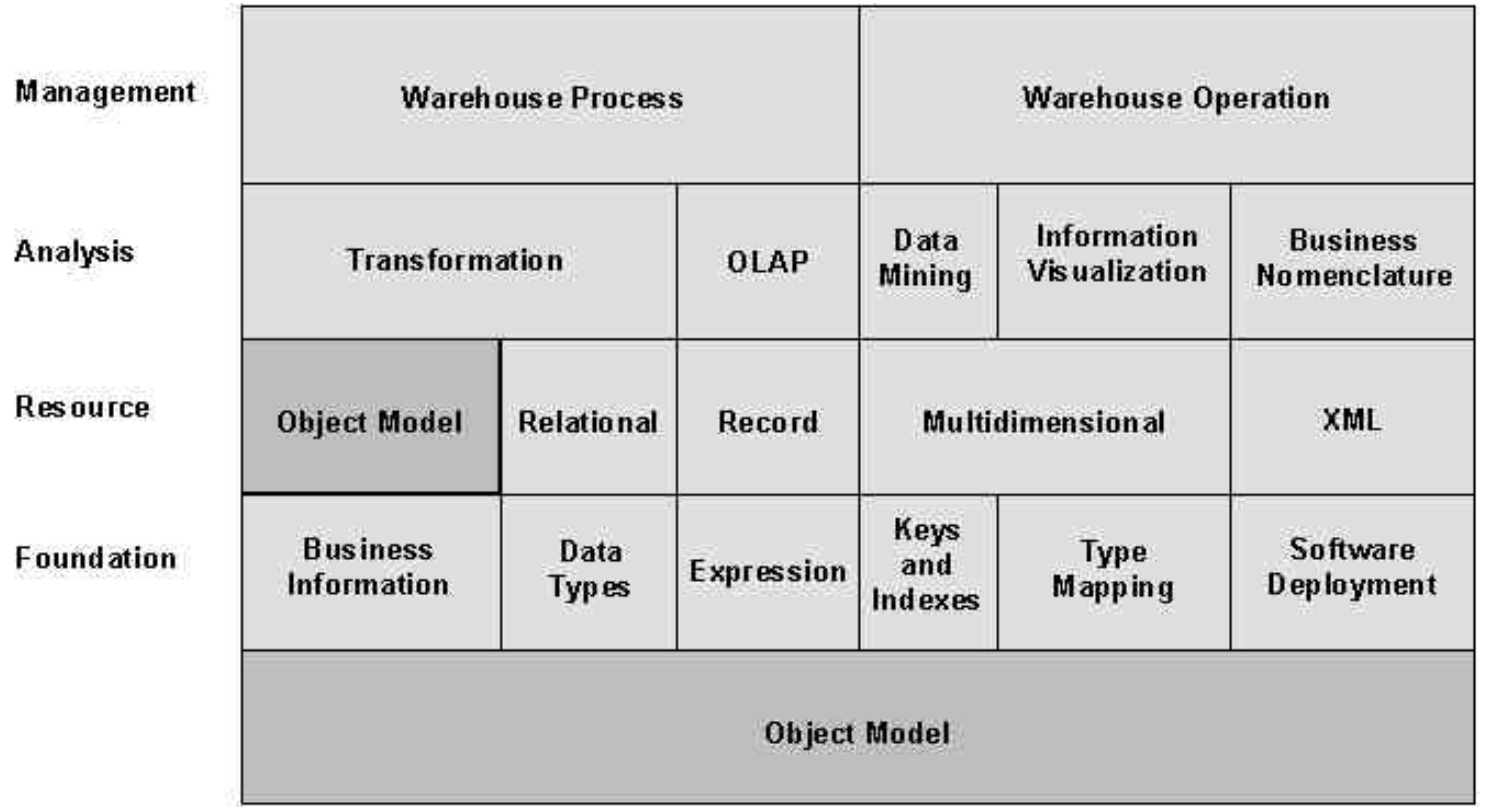

Figura 10 - 0 metamodelo do CWM.

\section{a. Metamodelo ObjectModel}

O ObjectModel é um subconjunto da UML que inclui apenas as características necessárias para criar e descrever o CWM. É apresentado como uma coleção de metamodelos, agrupados devido a possuírem um mesmo objetivo: fornecer construções de metamodelo básicas para todos os outros metamodelos do CWM.

O ObjectModel é composto por quatro metamodelos, a saber:

- Core: contém as classes e associações dos metamodelos básicos utilizadas por todos os outros metamodelos do CWM;

- Behavioral: agrupa classes e associações que descrevem o comportamento dos tipos do CWM;

- Relationships: agrupa classes e associações que descrevem os relacionamentos entre os objetos das informações armazenadas no CWM;

- Instance: permite a inclusão de instâncias de dados dentro dos metadados.

\section{b. Metamodelo Foundation}

O Foundation é uma coleção de metamodelos que contém elementos de modelos que representam conceitos e estruturas compartilhadas por outros metamodelos do 
CWM. Por esta razão, os elementos do modelo Foundation, freqüentemente, têm natureza mais genérica que os elementos encontrados nos níveis mais altos da arquitetura do CWM.

Os metamodelos que compõem o Foundation são:

- Business Information: fornece serviços genéricos para todos os outros metamodelos do CWM que apóiam as necessidades dos sistemas de Data Warehouse e de business intelligence em informações orientadas aos negócios, como a representação dos responsáveis e de como contactá-los, além de outras informações descritivas;

- DataType: suporta a definição de construções que podem ser utilizadas para criar tipos de dados específicos;

- Expression: fornece apoio para a definição de árvores de expressão no CWM, sendo que, cada função ou operador matemático que aparece na expressão é representado no metamodelo;

- KeysIndexes: permite representar chaves e índices, utilizados para especificar instâncias e identificar ordenações de instâncias;

- SoftwareDeployment. contém classes para armazenar como o software é utilizado no Data Warehouse, incluindo características como sua versão, tipo de software, fornecedor, entre outras;

- TypeMapping: suporta o mapeamento dos tipos de dados entre diferentes sistemas indicando os tipos de dados compatíveis entre os diferentes sistemas.

\section{c. Metamodelo Resource}

Este metamodelo descreve as estruturas de dados presentes nos sistemas de Data Warehouse. Os metamodelos que compõem o Resource são:

- Relational: descreve os dados que podem ser acessados por meio de uma interface relacional, como a interface nativa de um gerenciador de banco de dados relacional, ODBC ou JDBC;

- Record: compreende os conceitos básicos de um registro e sua estrutura, de forma bastante abrangente, incluindo tanto a noção tradicional de registro (armazenados em arquivos ou bases de dados), 
assim como os tipos de dados estruturados das linguagens de programação;

- Multidimensional: representação genérica de bancos de dados multidimensionais, também chamados de bancos de dados OLAP, possibilitando representar suas estruturas de dados internas;

- XML: contém classes e associações que representam metadados que descrevem os recursos de dados XML.

\section{d. Metamodelo Analysis}

Neste metamodelo, são descritos os aspectos de tratamento e análise sobre os dados armazenados no sistema de Data Warehouse. Os metamodelos que compõem o Analysis são:

- Transformation: classes e associações que representam metadados de transformação entre todos os tipos de dados utilizados no Data Warehouse e presentes, principalmente, nos processos de extração, transformação e carga. Ele é especialmente projetado para relacionar uma transformação com suas fontes e destinos de dados, permitir agrupamento e seqüência de transformações em unidades lógicas, representando execuções seqüenciais ou paralelas (ou uma combinação das duas);

- OLAP: define um metamodelo para os conceitos comuns à maioria dos sistemas OLAP, aplicações típicas de acesso e análise do Data Warehouse;

- Data mining: armazena informações relativas às aplicações de data mining, que fornecem informação descritiva sobre padrões e relacionamentos entre os dados, modelos preditivos, entre outros;

- Information Visualization: define metadados para os aspectos relacionados à "publicação de informações" ou, de forma mais genérica, "visualização de informações";

- BusinessNomenclature: contém classes e associações que podem ser utilizados para representar os metadados de negócios e oferece a construção Taxonomia, representando informação semântica e 
relacionamentos, e Glossário, representando o vocabulário de um domínio de negócios ou de um usuário.

\section{e. Metamodelo Management}

O metamodelo Management permite representar os aspectos relacionados à operação e execução dos processos do ambiente de Data Warehouse. Os metamodelos que compõem o Management são:

- Warehouse Process: documenta o fluxo dos processos utilizados para executar as transformações. Um objeto do metamodelo WarehouseProcess associa uma transformação a um conjunto de eventos que poderão ser utilizados para disparar a execução destas transformações;

- Warehouse operation: contém classes que armazenam a operação no dia-a-dia dos processos do warehouse, representando aspectos sobre execuções das transformações (identificação, resultados), medidas (métricas do sistema) e solicitações de alterações (para registrar alterações propostas sobre os elementos armazenados).

\subsubsection{Estudo de viabilidade de utilização do CWM}

Para avaliar a utilização do CWM nos sistemas de Data Warehouse, o OMG destaca os quatro principais cenários de uso. O primeiro cenário envolve o contexto dos processos de extração, transformação e carga dos dados (ETL). Este cenário, com seu conjunto de processos é tão importante na implementação do warehouse, que chega a consumir mais de $50 \%$ dos recursos utilizados para o projeto todo. O segundo cenário está associado às ferramentas mais importantes e mais utilizadas pelos usuários finais, as ferramentas OLAP. O terceiro cenário contempla as outras ferramentas, também utilizadas pelos usuários finais, e complementa o segundo cenário de utilização do warehouse. O quarto e último cenário avaliado neste trabalho está relacionado aos processos de administração do Data Warehouse, que envolvem atividades de controle e monitoramento do estado do sistema e dos dados nele contidos. 
A aplicação dos conceitos do CWM nestes quatro cenários demonstra sua viabilidade para representar os metadados de todos os processos e estruturas existentes em sistemas de Data Warehouse. A análise detalhada destes cenários pode ser encontrada na especificação do CWM (OMG, 2001). 


\section{SEGURANÇA DE ACESSO EM DATA WAREHOUSES}

Por conter informações referentes a diversos modelos de negócios e diversas áreas na empresa, o Data Warehouse armazena, em um mesmo repositório, um acervo de alto valor para a corporação com, muitas vezes, conjuntos de dados confidenciais.

A importância e criticidade que as informações armazenadas no Data Warehouse têm para as organizações, faz com que seus administradores tenham que gerenciar diversos aspectos de segurança, garantindo que apenas usuários autorizados façam uso dos dados armazenados, referentes às suas respectivas áreas de negócio.

Conforme Warigon (1997), as necessidades de segurança de um ambiente de Data Warehouse são similares às de outros sistemas de computação distribuída. Assim, Katic et al. (1998) indica que é de extrema importância um controle que possa garantir a confidencialidade, integridade e disponibilidade dos dados do Data Warehouse.

O aspecto confidencialidade está relacionado com a proteção da informação contra exposição não autorizada, seja por acesso direto, seja por inferência lógica indireta. A integridade requer que os dados sejam protegidos contra modificações intencionais de caráter nocivo ou acidental, incluindo inserção de dados falsos ou incorretos, contaminação ou destruição dos dados. A disponibilidade é uma característica que garante que os dados estejam disponíveis para os usuários, no momento em que forem necessários.

Os aspectos de integridade e disponibilidade são normalmente tratados pelas organizações em um âmbito mais amplo do que o abordado neste trabalho.

Alguns tópicos relacionados à integridade dos dados, no caso de Data Warehouse, ficam a cargo de controles implementados pelos gerenciadores de bancos de dados e da acuracidade do processo de carga que extrai os dados dos sistemas transacionais e, após transformações, os carrega no Data Warehouse central. O tratamento da integridade dos dados está fora do escopo deste trabalho, sendo que, parte-se do pressuposto que os dados armazenados encontram-se íntegros.

O aspecto de disponibilidade dos dados é normalmente tratado pelas organizações utilizando mecanismos e procedimentos realizados para o conjunto total de dados e 
aplicações corporativos e, por esta razão, também não será detalhado dentro do escopo deste trabalho, que pressupõe que os dados estão disponíveis sempre que forem requisitados.

Assim, dentre os aspectos de segurança apresentados por Katic et al. (1998), o único que será tratado na arquitetura proposta por este trabalho é a confidencialidade dos dados armazenados.

\subsection{OS REQUISITOS DE SEGURANÇA}

De acordo com Katic et al. (1998), os requisitos de segurança descrevem todas as condições de segurança que devem ser consideradas no ambiente do Data Warehouse. Apesar de existirem diversos requisitos de segurança, para o escopo deste trabalho serão tratados apenas dois: requerimentos de acesso e requerimentos de rede.

O objetivo principal do controle de segurança é prevenir acessos não autorizados aos dados armazenados no Data Warehouse, ou seja, permitir que um usuário tenha acesso apenas ao conjunto de dados a que está autorizado. É preciso então, garantir, por meio de mecanismos de controle de acesso, que o usuário receberá no data mart de sua estação de trabalho, apenas o conjunto de dados pertinente às suas atividades e área de negócios. Assim, é necessário definir que tipos e quais objetos o usuário tem permissão de acessar.

Partindo-se do pressuposto que o modelo de dados do Data Warehouse segue os conceitos da modelagem multidimensional, será necessário definir quais objetos, dentro dos fatos, dimensões e níveis de agregação estão disponíveis para cada um dos usuários.

Como os dados armazenados no Data Warehouse central serão transmitidos para as estações cliente através de uma rede, no momento da sincronização, é importante também estabelecer mecanismos que impeçam a exposição das informações transferidas e que sejam capazes de gerenciar situações de erros ou interrupções das transferências dos dados. É importante, então, que sejam utilizados mecanismos de codificação dos dados para o processo de sincronização entre o 
Data Warehouse central e as estações cliente além de estabelecer controles que garantam que o conjunto de dados foi transferido completa e corretamente.

Para a implementação dos requisitos apresentados nesta seção, são definidas, então, camadas de tratamento de segurança que devem compor a arquitetura proposta neste trabalho. A Tabela 4 apresenta um resumo dos aspectos de segurança que devem ser definidos para garantir que apenas usuários autorizados possam ter acesso ao conteúdo das informações.

Tabela 4 - Componentes do controle de segurança de acesso.

\begin{tabular}{cl}
\hline \multicolumn{1}{c}{ Camada } & \multicolumn{1}{c}{ Objetos } \\
\hline Camada de dados & \\
\hline Esquema & Tabelas autorizadas \\
\hline Tabelas fato & Métricas (atributos) autorizados \\
\hline Tabelas dimensão & Níveis de agregação (atributos) autorizados \\
\hline Usuários/grupos de usuários & Valores da dimensão (conteúdo) autorizados \\
\hline Camada da rede & Perfil de acesso do usuário/grupo \\
\hline Dados & \\
\hline
\end{tabular}

\subsection{A NECESSIDADE DE METADADOS DE SEGURANÇA}

Conforme descrito no capítulo 4, os metadados são parte essencial de um Data Warehouse, principalmente se sua implementação compreende não apenas o Data Warehouse central, mas também recursos de informação distribuídos. Katic et al. (1998) destacam que além de mapear as fontes de dados em suas respectivas bases de destino, descrever e apoiar a geração de código para transformar os dados e controlar sua movimentação, os metadados também descrevem os mecanismos de segurança em um ambiente de Data Warehouse.

Quando um usuário acessa os dados de um Data Warehouse, um componente de gerenciamento da segurança deve verificar se o usuário tem permissão para efetuar esta consulta. Para garantir isso, é necessário verificar as autorizações correspondentes analisando os metadados de segurança, previamente cadastrados para aquele perfil de usuário. 
O trabalho de Katic et al. (1998) propõe uma forma de permitir que diferentes usuários tenham acesso a diferentes partes do Data Warehouse, sendo que para cada usuário (ou grupo de usuários com o mesmo perfil) é definida uma visão limitada do Data Warehouse.

O método proposto consiste em duas grandes fases: o estágio off-line, no qual os usuários e seus perfis de acesso são cadastrados e o estágio on-line, no qual as restrições são verificadas e a consulta é reescrita.

Ao executar funções de análises multidimensionais como drill-down, roll-up ou outras, o usuário recebe sua visão "reduzida" do Data Warehouse. Katic et al. (1998) implementam este conceito utilizando camadas de software, cada uma delas responsável por uma etapa do controle de segurança. A camada proposta por Katic et al. (1998), no estágio on-line, é responsável pelo gerenciamento de segurança nas consultas (SQML - Secure Query Management Layer) que, ao receber uma consulta ao Data Warehouse proveniente de uma estação, realiza a análise sintática da referida consulta e, com base na identificação do usuário e perfil de acesso, a SQML verifica o escopo da consulta e a modifica, substituindo partes da consulta de tal forma que apenas sejam acessados níveis de informação permitidos para este usuário. Este é um aspecto complexo e importante de segurança, já que estruturas específicas do modelo multidimensional como, por exemplo, determinados níveis de agregação dentro das dimensões, podem não estar autorizados para acesso de um usuário específico.

Todos os controles de segurança propostos no trabalho de Katic et al. (1998) são armazenados como metadados, assim, para o escopo do presente trabalho, serão acrescentadas estruturas de segurança de acesso aos metadados já previstos, conforme descrito na seção 4.5 .

\subsection{OS COMPONENTES DE SEGURANÇA ESCOLHIDOS PARA A ARQUITETURA PROPOSTA NESTE TRABALHO}

O objetivo de se definir um controle de segurança para o escopo do presente trabalho é garantir que as solicitações e execuções de sincronização dos data marts 
localizados na plataforma móveis sejam realizadas apenas sobre o conjunto de informações em que o usuário esteja autorizado e que estas informações sejam transferidas garantindo sua confidencialidade.

Tendo como base alguns dos aspectos apresentados por Katic et al. (1998), são descritos, a seguir, os componentes de segurança para a arquitetura proposta no presente trabalho.

A integração destes componentes com os outros elementos da arquitetura proposta neste trabalho é descrita no capítulo 6.

\subsubsection{O cadastramento do perfil dos usuários}

A primeira parte do processo de controle de segurança é criar mecanismos que permitam a definição dos usuários das plataformas móveis e seus perfis de acesso, para que, no momento da sincronização, apenas dados autorizados sejam transmitidos.

Ao conjunto de metadados previstos para este trabalho, serão acrescentadas informações que permitam controlar o acesso aos dados específicos armazenados no Data Warehouse central. As tarefas que compreendem esta etapa são descritas abaixo:

- Definir usuários e grupos (usuários com o mesmo perfil), com seus respectivos atributos de identificação;

- Para cada tabela fato autorizada, definir:

- Atributos (métricas) autorizados;

- Valores autorizados dentro de cada métrica;

- Para cada tabela dimensão autorizada, definir:

- Níveis de agregação autorizados;

- Valores autorizados dentro de cada nível de agregação. 


\subsubsection{Segurança na validação e preparação para a sincronização}

Ao se conectar ao servidor do Data Warehouse central para solicitação de sincronização, o usuário deve se identificar. Com base no seu perfil de acesso, são efetuadas a identificação e a preparação dos conjuntos de informações a serem transmitidos. Esta segunda parte do processo de controle de segurança é realizada durante a solicitação de sincronização e o componente de segurança identifica as estruturas de dados às quais o usuário tem acesso, garantindo que apenas conjuntos de informações autorizadas serão sincronizadas.

\subsubsection{Segurança durante a sincronização}

Uma vez que o conjunto de informações está pronto para sincronização, este componente de segurança inicia a terceira parte do processo de controle de segurança. Nesta etapa, são geradas informações de controles que irão possibilitar, posteriormente, a verificação de completude no processo de sincronização. Outra importante tarefa desta etapa é codificar o conjunto de informações antes de iniciar o processo de transmissão para as plataformas móveis.

Assim, a Figura 11 representa graficamente as etapas do controle de segurança apresentado acima. 


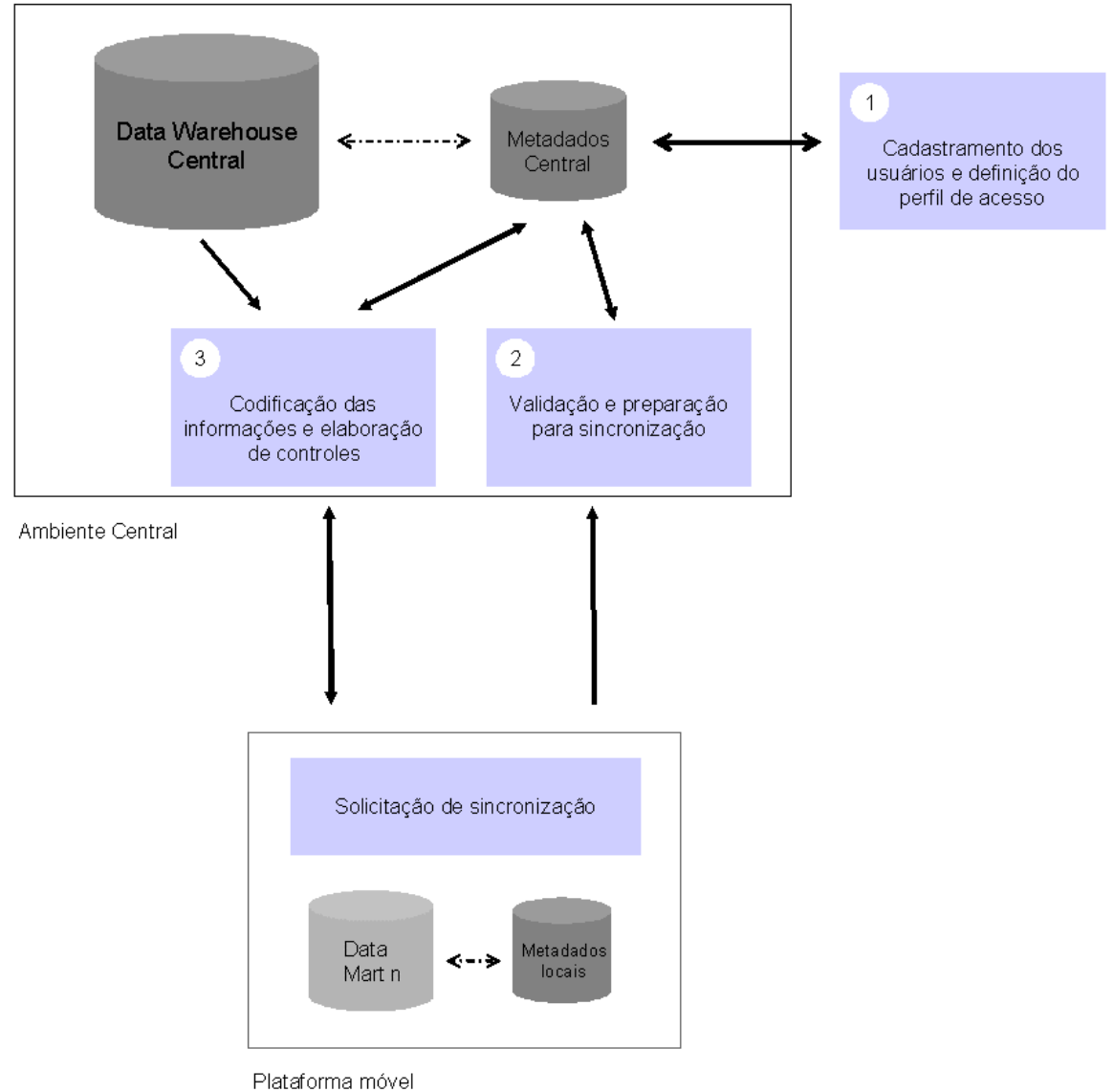

Figura 11 - Etapas do controle de segurança dos dados 


\section{PROPOSTA DE ARQUITETURA PARA SINCRONISMO DE DATA WAREHOUSES EM PLATAFORMAS MÓVEIS}

\subsection{MOTIVAÇÃO}

A principal motivação para propor uma arquitetura de Data Warehouse em plataformas móveis, baseia-se no fato de que boa parte dos usuários do Data Warehouse está em diferentes localidades ou sempre em movimento. Como exemplo típico deste tipo de usuário pode-se citar os profissionais da área comercial, sempre em visita a clientes, bem como escritórios que não estão permanentemente conectados ao Data Warehouse central, mas necessitam acessá-lo. Conforme Schlesinger et al. (2001) destaca, para atender estes novos requisitos do ambiente de negócios, seria útil manter partes do Data Warehouse nas estações cliente, possibilitando processamento local. Como a capacidade de armazenamento dos sistemas cliente é limitada e os usuários, normalmente, precisam de apenas uma pequena fração dos dados, uma parte do Data Warehouse pode ser replicada nas estações cliente. Como exemplo, Schlesinger et al. (2001) sugere que um profissional de vendas, responsável por uma certa região, está interessado apenas em obter dados sobre seus clientes e subsidiárias. Esta informação é, então, copiada para seu computador portátil ou atualizada, caso já exista uma versão anterior, no momento de sua conexão com o ambiente do Data Warehouse central.

Os trabalhos publicados sobre este tema tratam apenas de partes do processo. Foram mencionados, nas seções correspondentes do presente texto, trabalhos que propõem modelos e algoritmos de sincronismo de Data Warehouse, tanto no que se refere aos dados, quanto à evolução do esquema, modelos e algoritmos de sincronismo para Data Warehouses em bases móveis, importância e arquitetura de metadados para Data Warehouse, bem como trabalhos sobre segurança na utilização dos Data Warehouses. Os trabalhos pesquisados tratam dos temas de forma específica, sendo que nenhum deles, no entanto, apresentou uma arquitetura que relacionasse todos estes componentes, necessários para a implementação de data marts em plataformas móveis sincronizadas ao Data Warehouse central. 
O presente trabalho apresenta, portanto, uma proposta para esta arquitetura, descrevendo todos estes componentes, necessários para a implementação do tipo de sincronismo baseado em um Data Warehouse central e data marts localizados em plataformas móveis.

\subsection{VISÃO GERAL DA ARQUITETURA PROPOSTA}

A arquitetura do Data Warehouse central e das plataformas móveis é equivalente a uma arquitetura cliente servidor com algumas especificidades em relação ao uso no ambiente do Data Warehouse. O cliente é um computador separado, que vai sincronizar seus dados com as alterações ocorridas no servidor (SCHLESINGER et al., 2001). O conteúdo dos dados a serem sincronizados depende do perfil do cliente, uma vez que cada um dos clientes pode requerer conjuntos de informações específicas, dependendo do modelo de negócios e das autorizações de acesso.

Para se implementar um modelo de sincronismo entre o Data Warehouse central e as bases nas estações cliente, é necessário se definir uma arquitetura que descreva o processo de sincronismo entre o Data Warehouse central e os subconjuntos de dados do Data Warehouse armazenados nas estações cliente.

Com base nos trabalhos publicados, mencionados nas seções anteriores, este trabalho apresenta uma proposta de arquitetura (dados e processos) para sincronização entre o Data Warehouse central, armazenado no servidor, e os subconjuntos de dados do Data Warehouse central, localizados nas estações clientes (plataformas móveis). Esta arquitetura está baseada nos componentes representados na Figura 12.

$\mathrm{Na}$ arquitetura apresentada na Figura 12 os principais processos são aqueles representados como primeira e segunda etapas do processo de sincronismo, discutidos nas seções 2.1 e 2.2, respectivamente.

Durante a primeira etapa do processo de sincronismo, o Data Warehouse central é carregado e atualizado, freqüentemente, com base nas informações provenientes dos diversos sistemas transacionais. Esta etapa é composta por um conjunto de 
processos de manutenção de dados responsável por manter o Data Warehouse central atualizado em períodos de carga pré-definidos.

A segunda etapa do processo de sincronismo, representada na Figura 12 está dividida em dois grandes conjuntos de processos:

- Conjunto de processos de manutenção de esquema - que agrupa os processos responsáveis por garantir que qualquer evolução no esquema do Data Warehouse central seja refletida nas bases de dados das plataformas móveis, quando aplicável e;

- Conjunto de processos de manutenção de dados - que agrupa os processos responsáveis por garantir que novos dados armazenados no Data Warehouse central sejam replicados nas bases de dados das plataformas móveis, de acordo com o perfil do usuário da plataforma. Estes processos são similares aos processos executados na primeira etapa de sincronismo.

Os processos que envolvem sincronismo dos dados tanto entre os sistemas transacionais e o Data Warehouse central (primeira etapa do processo de sincronismo), quanto entre o Data Warehouse central e os data marts nas plataformas móveis (segunda etapa do processo de sincronismo) são processos que já foram amplamente discutidos em inúmeros trabalhos publicados anteriormente e detalhados no capítulo 2, não sendo detalhados novamente neste capítulo.

O mesmo não ocorre com os processos que garantem que as mudanças no esquema realizadas no Data Warehouse central sejam refletidas nos data marts nas plataformas móveis, também presentes na segunda etapa do processo de sincronismo. É importante, portanto, no presente trabalho, apresentar e descrever um conjunto de processos relativos à manutenção do esquema que permita classificar e avaliar a complexidade das alterações de esquema que ocorrem no Data Warehouse central e que devem ser replicadas nas bases de dados das plataformas móveis.

Nas próximas seções são descritas as estruturas de dados que compõem esta arquitetura e os processos que compõem a segunda etapa do processo de sincronismo. 


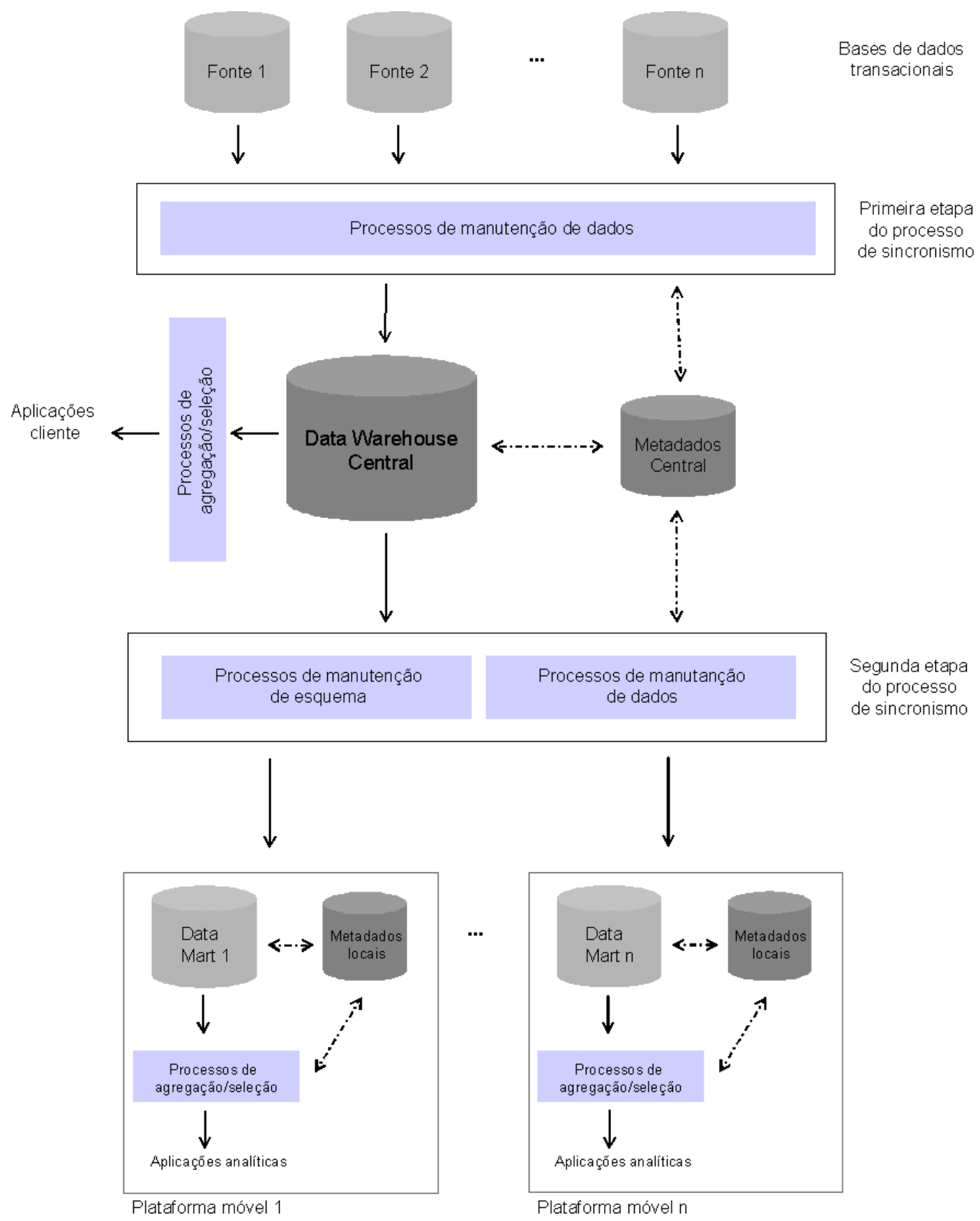

Figura 12 - Arquitetura de utilização de Data Warehouse em plataformas móveis - visão geral das estruturas e processos

\subsubsection{As estruturas de dados que compõem a arquitetura proposta}

A arquitetura apresentada na Figura 12 está composta por várias bases de dados, responsáveis por armazenar os diversos tipos de informações relacionados a um ambiente de Data Warehouse. 


\section{As bases de dados transacionais}

O ponto de partida de toda a estrutura são as bases de dados transacionais, fontes de dados para as aplicações analíticas. Nestas bases estão os dados gerenciados e manipulados pelas aplicações transacionais da organização, que são relevantes para o ambiente analítico. Normalmente, apenas um conjunto de sistemas transacionais é escolhido como base para as aplicações analíticas, dependendo do modelo de negócios que está sendo tratado. Com o passar do tempo, novos conjuntos de dados transacionais vão sendo incorporados como fontes de informação para o Data Warehouse e, conseqüentemente, para as aplicações analíticas, conforme as necessidades do negócio, fazendo com que o sistema representado na Figura 12 esteja em constante evolução.

O detalhamento destas bases transacionais não é necessário, uma vez que estas bases são específicas e exclusivas das aplicações transacionais da organização. Sua presença na arquitetura é suficiente para o escopo deste trabalho.

\section{O Data Warehouse central}

A base de dados que compõe o Data Warehouse central é uma estrutura de dados que armazena a informação analítica selecionada das bases de dados transacionais. Após passar por um processo de extração, transformação e carga, representado na Figura 12 como a primeira etapa do processo de sincronismo, os dados das bases transacionais estão prontos para serem utilizados pelas aplicações analíticas.

O Data Warehouse central, dentro do escopo deste trabalho, é modelado seguindo as regras de modelagem multidimensional de Kimball (2002), com as informações representadas em fatos e dimensões. É, também dentro do escopo deste trabalho, implementado em bases de dados relacionais. Estas bases armazenam todo 0 conjunto de informações analíticas a serem utilizadas pelos usuários que acessam diretamente o Data Warehouse central, além de ser a fonte para os data marts localizados nas plataformas móveis que, periodicamente, solicitam transferência dos dados, para manterem suas bases locais atualizadas e sincronizadas com o Data Warehouse central.

Por ser um tema já tratado em diversos trabalhos anteriores, a modelagem multidimensional não é descrita neste trabalho. Uma apresentação detalhada das 
características da modelagem multidimensional podem ser encontradas em Kimbal (2002).

\section{O conjunto central de metadados}

Uma estrutura bastante importante para a arquitetura apresentada na Figura 12 é a base que armazena os metadados na plataforma central. Estes metadados contêm informações sobre todas as estruturas de dados e sobre todos os processos que compõem a arquitetura apresentada. A importância dos metadados, bem como a descrição de suas principais características encontram-se no capítulo 4.

Conforme mencionado na seção 4.5, o padrão de metadados escolhido para a arquitetura proposta neste trabalho é o CWM - Common Warehouse Metamodel (OMG, 2001). Este padrão é considerado um dos mais completos para um sistema de Data Warehouse, por possibilitar o armazenamento de todos os seus principais componentes.

Desta forma, com base no metamodelo CWM, os metadados armazenam todas as informações necessárias para possibilitar a automatização dos processos que mantêm os data marts, nas plataformas móveis, sincronizados com o Data Warehouse central.

Este conjunto de metadados, além de manter informações sobre o conteúdo das tabelas do Data Warehouse central e dos data marts localizados nas plataformas móveis, mantém informações sobre seus esquemas. Assim, todas as alterações de esquema das estruturas de dados ficam registradas nos metadados e são utilizadas como base para a análise de complexidade e de impacto, apresentadas na seção 6.3, e para controlar o período de transição apresentado na seção 3.3.

As informações de segurança de acesso também estão armazenadas no conjunto central de metadados, garantindo que o usuário da plataforma móvel receba apenas os conjuntos de dados para os quais está autorizado.

\section{Os data marts das plataformas móveis}

Os data marts locais são a fonte de dados para as aplicações analíticas executadas nas plataformas móveis. Da mesma forma que o Data Warehouse central, sua 
modelagem é baseada nos conceitos de modelagem multidimensional de Kimball (2002). A diferença entre os data marts locais e o Data Warehouse central é o conjunto de informações armazenado. Enquanto que o Data Warehouse central funciona como base para todos os usuários do sistema, cada data mart armazena apenas o conjunto de informações autorizado para o usuário da plataforma móvel.

O processo de sincronização dos data marts locais com o Data Warehouse central garante que cada usuário tenha sua base de dados local atualizada, refletindo todas as alterações de conteúdo ocorridas, dentro do escopo estabelecido para cada usuário.

Caso o Data Warehouse central passe a contar com novas estruturas de dados, como por exemplo, tabelas ou colunas, o data mart local também deve ser atualizado, caso estas novas estruturas façam parte do escopo estabelecido para o usuário.

Assim, cada data mart contém um subconjunto das informações armazenadas no Data Warehouse central, garantindo a possibilidade do usuário executar suas próprias aplicações analíticas quando estiver desconectado da base central.

\section{Os metadados locais}

Da mesma forma que os data marts são subconjuntos de informações do Data Warehouse central, os metadados locais são subconjuntos da base de metadados central, armazenando informações de metadados pertinentes apenas às estruturas autorizadas para o usuário da plataforma móvel.

Este conjunto de metadados locais contém informações sobre os dados armazenados no data mart e sobre as aplicações analíticas locais. Além disso, os metadados locais armazenam importantes informações sobre os processos de sincronismo realizados com a base central, apoiando os processos de carga, provendo informações de controle de sua completude e freqüência.

Da mesma forma que o conjunto central de metadados, os metadados locais também são baseados no metamodelo CWM. 


\subsubsection{Os processos que compõem o sincronismo entre o Data Warehouse central e as bases de dados das plataformas móveis}

Por ser, dentro do escopo do presente trabalho, o conjunto de processos mais importante, a segunda etapa do processo de sincronismo, representada na Figura 12 é descrita detalhadamente nesta seção.

Esta etapa de sincronismo é composta por uma série de fases, representados na Figura 13.

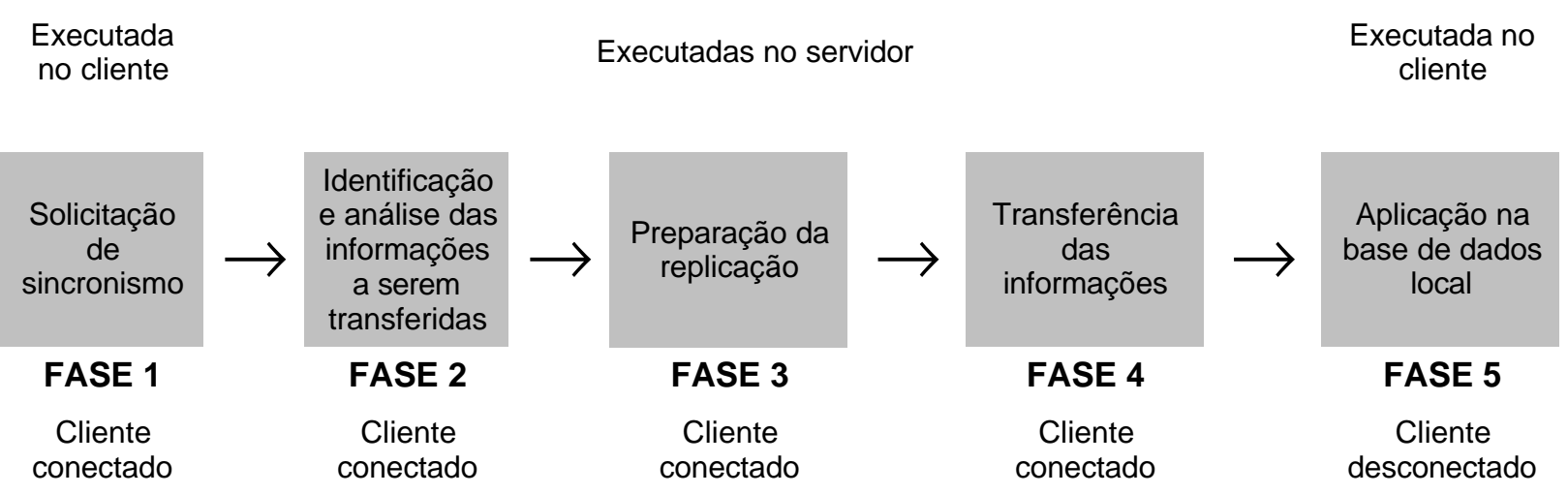

Figura 13 - Principais fases para sincronismo do Data Warehouse central com as bases nas estações clientes

Um resumo das características destas fases é descrito abaixo:

1. Fase de solicitação de sincronismo - nesta fase, a estação cliente solicita que o processo de sincronismo seja iniciado.

2. Fase de identificação das informações a serem transferidas - nesta fase as informações a serem transferidas são identificadas, com base nas características da estação cliente que está sendo sincronizada e avaliadas, conforme sua complexidade.

3. Fase de preparação da replicação - durante esta fase, são preparadas as estruturas que contêm as informações que serão transferidas.

4. Fase de transferência dos dados - nesta fase é executada a transferência das estruturas preparadas previamente para a estação cliente. 
5. Fase de aplicação na base de dados local - as estruturas de dados que foram transferidas são aplicadas na base de dados, que contém o data mart local, nas estações cliente.

Conforme mencionado na seção 6.2.1, dentre as informações armazenadas no metadados, na plataforma central, estão as informações referentes ao esquema do Data Warehouse. Desta forma, é importante destacar que o processo de sincronização das alterações nos dados armazenados na plataforma central engloba tanto os dados analíticos armazenados no Data Warehouse, quanto as informações armazenadas no metadados.

A fase 1 é iniciada quando o cliente móvel solicita ao servidor (Data Warehouse central) o sincronismo de seu data mart local. Conforme mencionado na seção 2.2 é utilizada, no presente trabalho, a abordagem pull-based, em que a estação cliente solicita ao servidor a sincronização de sua base de dados, no momento em que deseja realizar a sincronização de seu data mart local. Neste momento, a estação cliente deve estar conectada ao servidor do Data Warehouse central, uma vez que o processo de sincronização é iniciado apenas a partir da solicitação do cliente. Segue, abaixo, uma visão geral das etapas desta fase 1:

- Cliente seleciona informações de controle sobre a última sincronização bem sucedida - esta etapa utiliza metadados local;

- Cliente se conecta ao servidor, identifica-se e solicita sincronização, enviando informações de controle - processo de identificação do usuário e controle de segurança (implementado conforme descrito nas seções 5.3.1 e 5.3.2) e utiliza metadados local;

- Servidor valida identificação do cliente - com base nesta identificação, será estabelecido o limite de acesso do usuário ao conjunto de dados na plataforma central, durante a fase 2. Esta etapa utiliza metadados central;

- Servidor armazena controles para sincronização - esta etapa utiliza metadados central;

Todos os metadados envolvidos nesta fase devem ser implementados por meio do padrão CWM, uma vez que, além dos objetos presentes no modelo, é possível estendê-lo com dados específicos de acordo com a necessidade da organização e dos projetos. 
Uma vez solicitado, o processo de sincronismo se inicia e, na fase 2 do processo. Cabe ao Data Warehouse central identificar o conjunto de informações a ser transferido, de forma a garantir que o data mart da plataforma móvel seja capaz de refletir as informações atualizadas, conforme armazenadas no Data Warehouse central. Esta fase envolve uma série de tarefas, como: identificação do usuário e controle de acesso - para levantamento das informações pertinentes ao limite de acesso do usuário (dados e metadados), identificação de informações de metadados que devem ser transferidas (alterações de metadados de segurança de acesso, alterações de metadados de esquemas e alterações de metadados de dados), identificação de alterações nos esquemas de dados do data mart, classificação e avaliação da complexidade das alterações nos esquemas e identificação das instâncias de dados que devem ser transferidos (alterações feitas nas instâncias de dados das tabelas fatos e dimensões).

Esta fase prevê que a estação cliente esteja conectada ao servidor do Data Warehouse central uma vez que o processo de avaliação da complexidade das alterações nos esquemas possa interagir com o usuário da plataforma móvel. A idéia é que uma vez avaliada a complexidade, pode-se dar ao usuário a opção de sincronizar apenas os dados (no esquema antigo do Data Warehouse central), postergando a sincronização do esquema. Para que esta alternativa seja válida, os conceitos de período de transição, apresentados por Ambler e Sadalage (2006), apresentados na seção 3.3, devem estar implementados. Segue, abaixo, uma visão geral das etapas desta fase 2:

Com base na identificação do usuário:

- Servidor seleciona informações sobre a última sincronização bem sucedida - esta etapa utiliza metadados central;

- Servidor identifica limite de informações autorizadas para o usuário- esta etapa utiliza metadados central;

Com base no último ponto de sincronização bem sucedida e dentro do limite de informações autorizadas para o usuário:

- Servidor identifica conjunto de informações de metadados a serem transferidas - processo do tipo sincronização de dados, ainda que sejam 
dados armazenados como metadados (descrito na seção 2.2), e que utiliza metadados central;

- Servidor identifica conjunto de informações sobre alterações de esquema a serem transferidas - processo do tipo sincronização de dados, ainda que sejam dados armazenados como metadados (descrito na seção 2.2) e que utiliza metadados central;

- Servidor avalia a complexidade das alterações nos esquemas a serem repassados para o cliente - processo que avalia a complexidade e impacto na manutenção do esquema (descrito na seção 6.3.2) e utiliza metadados central;

- Servidor identifica o conjunto de instâncias de dados do Data Warehouse a serem transferidos - esta etapa é um processo tipo sincronização de dados (descrito na seção 2.2) e utiliza o Data Warehouse central (com estrutura descrita na seção 6.2.1).

Uma vez levantadas as informações necessárias para o processo de sincronismo, na fase 3 serão preparados os conjuntos de dados a serem transferidos e aplicados na base local. Teoricamente, esta fase não requer que a plataforma móvel esteja conectada ao servidor do Data Warehouse central, porém, como a fase precedente e a fase sucessora a esta requerem conexão, não faz sentido desconectar o cliente apenas para a execução desta etapa. Uma visão geral das etapas desta fase 3 é apresentada abaixo:

- Servidor prepara instruções para a implementação das alterações de esquema - este processo gera o conjunto de scripts SQL para a implementação das alterações, utilizando metadados central;

- Servidor prepara as estruturas na forma e ordem em que devem ser aplicadas no cliente - esta etapa utiliza metadados central;

- Servidor prepara controle de segurança da transferência das informações para o cliente - este processo tem como base os controles de segurança na transferência das informações (descrito na seção 5.3.3) e utiliza metadados central;

A fase 4 do processo de sincronismo, responsável pelos mecanismos de transferência das informações do servidor para as estações cliente, não faz parte do 
escopo deste trabalho e não será discutida na arquitetura aqui apresentada. Neste caso, assume-se que algum mecanismo para codificação dos dados no servidor (para transferência segura das informações), transferência e de decodificação dos dados na estação cliente esteja disponível e operando corretamente.

Por fim, na fase 5, o conjunto de informações transferido deve ser aplicado nas bases de dados locais. Assim como a fase 2, esta fase também requer que uma série de tarefas sejam executadas, como: a aplicação das atualizações na base de metadados (alterações de metadados de segurança de acesso, alterações de metadados de esquemas e alterações de metadados de dados), a aplicação das atualizações dos esquemas de dados do data mart e a aplicação dos dados atualizados (alterações nas tabelas fatos e dimensões). Uma visão geral das etapas desta fase 5 é apresentada abaixo:

- Cliente recebe conjunto de dados e notifica o servidor, envia informações de controle para o servidor e armazena informações de controle local processo que tem como base os controles de segurança na transferência das informações (descrito na seção 5.3.3) e utiliza metadados central e local;

- Cliente aplica alterações de metadados (inclui informações sobre alterações de esquema) - processo do tipo sincronização de dados, ainda que sejam dados armazenadas como metadados (descrito na seção 2.2) e que utiliza metadados local;

- Cliente aplica as alterações de esquema nos data marts locais - executa o conjunto de scripts SQL para a implementação das alterações, utilizando o data mart local (estrutura descrita na seção 06.2.1);

- Cliente aplica as alterações nas instâncias de dados - processo do tipo sincronização de dados, ainda que sejam dados armazenadas como metadados (descrito na seção 2.2, utilizando o data mart local (estrutura descrita na seção 6.2.1);

- Cliente notifica servidor sobre o sucesso ou insucesso da aplicação das alterações - este processo tem como base os controles de segurança na transferência das informações (descrito na seção 5.3.3) e utiliza metadados central e local; 
- Servidor atualiza controle de período de transição - este processo tem como base o controle do período de transição (descrito na seção6.3.1) e utiliza metadados central;

- Cliente armazena informações de controle local - este processo tem como base os controles de segurança na transferência das informações (descrito na seção 05.3.3), utilizando metadados local.

Como pode ser visto no detalhamento apresentado acima, todas as fases requerem algoritmos e estruturas de dados para serem executadas. Estes algoritmos e estruturas ao serem inter-relacionados e organizados em uma arquitetura, devem ser capazes de oferecer serviços de sincronismo entre o data mart na plataforma móvel e o Data Warehouse central, serviços de metadados, necessários para descrever os dados e processos envolvidos, bem como serviços de controle de segurança na utilização e seleção das informações no Data Warehouse central.

A arquitetura descrita nas seções acima serve de cenário para realizar uma análise de complexidade e de impacto das alterações no esquema do Data Warehouse central e, conseqüentemente, dos data marts nas plataformas móveis. Assim, uma vez descrito este cenário para estabelecer o escopo desta avaliação, as próximas seções apresentam os aspectos envolvidos na avaliação da complexidade e do impactos das alterações de esquema.

\subsection{A AVALIAÇÃO DA COMPLEXIDADE E DO IMPACTO DAS}

\section{ALTERAÇÕES NO ESQUEMA}

É bastante comum observar, em qualquer sistema que utilize um banco de dados, que seu esquema está em constante evolução. Novas aplicações ou funcionalidades vão sendo acrescentadas ao sistema que, freqüentemente, requer inclusões, alterações ou eliminações de estruturas que compõem a base de dados. O mesmo ocorre em ambientes de Data Warehouse, nos quais novas necessidades de análises surgem, decorrentes de mudanças no modelo de negócios, acarretando alterações na estrutura da base de dados. 
Quando se trata de uma arquitetura de Data Warehouse em plataformas móveis, como a apresentada neste trabalho, é importante identificar e avaliar a complexidade das alterações realizadas no Data Warehouse central que devem ser repassadas para o data mart na plataforma móvel. As alterações de esquema devem ser planejadas e sua implementação realizada na melhor alternativa possível, preferencialmente utilizando processos automatizados. Os processos de manutenção destas bases devem ser simplificados e de rápida execução, pois o usuário da plataforma móvel está ligado ao ambiente central através de conexões de baixa velocidade, na maioria dos casos. Assim, é importante identificar a complexidade dos processos de manutenção, com o objetivo de se escolher a alternativa mais simples e rápida. Em determinados casos, a manutenção incremental pode ser a melhor alternativa, porém, em outros, a recriação do ambiente como um todo, ou de partes dele, deve ser avaliada.

Levando-se em conta todas as estruturas e processos que compõem esta arquitetura, descritos na seção 6.2, a evolução do esquema pode aumentar em complexidade o processo de atualização das bases de dados nas plataformas móveis. Vários trabalhos, mencionados na seção 2.2, tratam dos processos de sincronização de dados, apresentando algoritmos comprovadamente eficientes, inclusive em ambientes de Data Warehouse distribuído, porém pouco se tem discutido sobre os aspectos relacionados à manutenção e evolução de esquema neste ambiente.

Os trabalhos já publicados e mencionados na seção 3.2, que se referem à manutenção do esquema, apresentam algumas limitações, se forem utilizados na arquitetura apresentada neste trabalho. A maioria dos trabalhos citados mostra alternativas para representar a evolução de esquema, bem como garantir a consistência da base de dados, porém não avaliam a complexidade dos processos de replicação das alterações no esquema das bases localizadas nas plataformas móveis.

Assim, nas próximas seções, o presente trabalho apresenta diretrizes para se avaliar a complexidade e o impacto das modificações efetuadas no Data Warehouse central e que devem ser repassadas para as bases nas plataformas móveis, tendo como base uma classificação das possíveis alterações e de sua complexidade. 
Dependendo do nível de complexidade exigido para se sincronizar as alterações ocorridas no esquema do Data Warehouse central, o usuário pode optar por adiar o sincronismo de esquema. O usuário pode, naquele momento, sincronizar apenas os dados, no esquema antigo, sem receber as novas alterações e os dados relativos à mudança do esquema.

Para estabelecer as diretrizes de análise da complexidade e impacto das alterações de esquema, destaca-se a importância do trabalho desenvolvido em Ambler e Sadalage (2006). Apesar dos conceitos e processos apresentados por Ambler e Sadalage (2006) sobre database refactoring não se aplicarem diretamente para melhorias e extensões do modelo de dados, são utilizados, no presente trabalho, como base para classificar as possíveis alterações e para os processos de avaliação e aplicação das mudanças de esquema tanto no Data Warehouse central quanto nas bases existentes nas plataformas móveis.

O ambiente de Data Warehouse favorece a implementação dos conceitos e processos de Ambler e Sadalage (2006) por ser um ambiente de baixo nível de acoplamento, sendo composto, em sua plataforma central, por uma base de dados, um conjunto de programas de extração e aplicações analíticas que apenas consultam os dados armazenados. Da mesma forma, nas plataformas móveis, o sistema apresenta nível de acoplamento ainda mais baixo, pois os processos de extração estão consolidados em uma única aplicação. A Figura 14 representa 0 ambiente de Data Warehouse em plataformas móveis, sob o ponto de vista do nível de acoplamento, considerando os conceitos de acoplamento citados por Ambler e Sadalage (2006). 




Figura 14 - Representação do nível de acoplamento das bases de dados do Data Warehouse central e das plataformas móveis

Conforme descrito na seção 3.3.2, Ambler e Sadalage (2006) também apresentam uma classificação das alterações possíveis sobre uma base de dados. O presente trabalho parte desta classificação, adaptando-a ao ambiente de Data Warehouse em plataformas móveis. Com base nesta classificação e na identificação das operações e dos objetos afetados, torna-se possível avaliar o grau de complexidade e o impacto que pode resultar da sincronização do esquema.

\subsubsection{O cenário de manutenção de esquema}

$\mathrm{Na}$ arquitetura proposta neste trabalho, as plataformas móveis solicitam ao ambiente central que sejam executados os processos de sincronismo. Assim, a periodicidade e freqüência das sincronizações são decididas pelos usuários da plataforma cliente. Os administradores do ambiente do Data Warehouse não podem precisar quando um usuário irá solicitar a execução dos processos de sincronização.

Assim, é comum observar, nestes ambientes, que algumas das plataformas móveis efetuam sincronismo com maior freqüência, enquanto que outras demoram mais, esperando por um momento mais oportuno para executar este processo, que pode depender da disponibilidade de recursos como tempo, boa qualidade de conexão e 
necessidade dos negócios, para citar as principais causas. Nestas circunstâncias, algumas das plataformas móveis estarão sincronizadas com a base de dados enquanto que outras, ainda não.

Em relação ao sincronismo dos dados, uma vez que os novos dados estão armazenados no Data Warehouse central, é indiferente, sob o ponto de vista técnico, para o administrador do ambiente, se todos os usuários já realizaram a sincronização ou se alguns deles ainda não têm em suas bases locais os dados mais atuais.

Diferentemente do sincronismo dos dados, o sincronismo de esquema requer um controle adicional durante o período em que apenas parte das plataformas móveis está sincronizada. Isto porque é possível que o usuário de uma das plataformas móveis necessite dos dados atualizados, porém não dispõe de recursos para realizar um processo, por vezes mais complexo, que é a sincronização do esquema, que pode envolver criação de novas estruturas ou alteração em estruturas já existentes na base de dados, acarretando a execução de processos adicionais.

Desta forma, existe a necessidade de se manter estruturas que possibilitem ao usuário optar por não realizar a sincronização de esquema em um determinado momento, trabalhando com o esquema antigo, enquanto que usuários de outras plataformas móveis já sincronizaram o esquema e utilizam, portanto, as novas estruturas. Para atender esta necessidade, Ambler e Sadalage (2006) sugerem um período de transição, com prazo de validade estabelecido pelos administradores do sistema, garantindo que, obrigatoriamente, em algum momento, todos os usuários tenham que sincronizar as alterações de esquema. Durante este período de transição, os usuários podem ter acesso ao esquema antigo ou ao esquema novo, dependendo de suas necessidades. É importante lembrar que durante o período de transição um usuário ou aplicação pode ter acesso apenas a um dos esquemas.

Com essa alternativa proposta por Ambler e Sadalage (2006), alguns dos data marts poderão estar atualizados, trabalhando com o novo esquema enquanto que outros poderão manter-se, por algum tempo ainda, sincronizando apenas os conjuntos de dados, com o esquema antigo. Assim que todas as plataformas móveis estiverem atualizadas o esquema de transição pode ser removido. 
Outro importante aspecto que compõe este cenário é que, com o objetivo de apoiar a replicação de uma modificação de esquema realizada no Data Warehouse central, torna-se necessário o armazenamento de informações de metadados que descrevam as características da modificação realizada e possibilitem seu gerenciamento e controle. Assim, acrescenta-se às estruturas de dados já descritas na seção 6.2.1, um conjunto de informações nos metadados sobre a alteração de esquema, que possibilite a análise de sua complexidade, no momento de sua replicação para as bases de dados das plataformas móveis.

Este conjunto de informações deve ser armazenado para cada alteração no esquema e deve identificar, pelo menos o número seqüencial da alteração (para permitir a replicação serial de um conjunto de alterações de esquema), a data da alteração, a descrição da alteração (para justificar sua necessidade) e o indicador do período de transição (para indicar se esta alteração ainda mantém período de transição ativo, quando nem todas as plataformas já sincronizaram, ou se o período de transição já está inativo ou concluído, quando todas as plataformas já sincronizaram com sucesso).

\subsubsection{O processo de análise da complexidade e do impacto das alterações no Data Warehouse central}

A análise de complexidade e de impacto das alterações deve ser realizada, inicialmente, no Data Warehouse central, no momento em que a alteração é implementada. Os resultados desta análise devem ser armazenados nos metadados, para possibilitar análises específicas para uma determinada plataforma móvel. Isto é necessário, uma vez que a plataforma móvel difere da plataforma central por manter apenas parte dos objetos existentes no Data Warehouse central, tanto em relação aos dados, quanto em relação aos processos. Além disso, a estratégia para o período de transição e os mecanismos para migração dos dados, que são avaliados na seção 6.3.1, apenas fazem sentido no ambiente central do Data Warehouse.

Portanto, a análise da complexidade deve ser feita em dois momentos. Primeiramente, a análise é realizada para o Data Warehouse central e, no momento 
da sincronização de esquema, é necessária uma reavaliação sobre a análise já realizada e armazenada, levando-se em conta apenas os objetos que se encontram dentro do escopo de acesso do usuário que está solicitando a sincronização.

O processo de análise da complexidade e impacto das alterações de esquema inicia-se com a identificação da alteração solicitada. A implementação de uma alteração pode requerer que várias operações sobre a base de dados e aplicações sejam realizadas, assim, a partir deste ponto, a alteração é decomposta nas diversas operações necessárias para sua execução, indicando também os objetos relacionados.

Estas operações são mapeadas com diferentes complexidades e que podem ser avaliadas, possibilitando, assim, sua quantificação.

Nas próximas seções este processo é detalhado.

\subsubsection{A classificação das alterações de esquema}

Existe uma grande quantidade de alterações de esquema normalmente utilizadas em bancos de dados. Ambler e Sadalage (2006) citam, pelo menos, 60 delas. Por esta razão, é importante identificar as principais alterações que ocorrem em ambientes de Data Warehouse, dentro da arquitetura proposta neste trabalho. As próximas seções têm por objetivo identificar as principais alterações de esquema neste contexto e classificá-las para facilitar sua análise.

Cada tipo de alteração de esquema impacta diferentes objetos em diferentes níveis. Desta forma, cada uma das possíveis alterações de esquema em ambiente de Data Warehouse deve ser analisada, sob o ponto de vista de sua complexidade e impacto causados em outros objetos do sistema.

Partindo da classificação de database refactorings proposta por Ambler e Sadalage (2006), o presente trabalho identifica uma lista com as principais alterações de esquema em ambientes de Data Warehouse. Esta lista não tem a pretensão de ser uma lista completa de todas as possíveis alterações de esquema, porém, representa apenas as mais importantes, dentro do escopo do presente trabalho. 
Conforme mencionado na seção 3.3.2, Ambler e Sadalage (2006) apresentam um agrupamento das manutenções de esquema em categorias. As categorias são: estrutural, qualidade de dados, integridade referencial, arquitetural, método e transformação não-refactoring. Este trabalho utiliza as categorias propostas por Ambler e Sadalage (2006) como base, para facilitar a enumeração e análise das alterações de esquema mais importantes. Deve-se ter em mente que o agrupamento proposto por Ambler e Sadalage (2006) inclui também uma categoria de alterações que não são consideradas como database refactoring. O presente trabalho analisa diferentes tipos de alteração de esquema, sem se preocupar se a alteração está enquadrada ou não como um database refactoring.

Assim, a partir deste ponto do presente trabalho, a classificação proposta por Ambler e Sadalage (2006) é adaptada para qualquer tipo de alteração, seja um database refactoring ou não, da mesma forma que as categorias de agrupamento de Ambler e Sadalage (2006) são adaptadas para melhor atender o ambiente de Data Warehouse.

A lista das alterações compreende:

- Alterações de esquema estruturais:

- Adicionar COLUNA;

- Remover COLUNA;

- Adicionar TABELA;

- Remover TABELA;

- Adicionar VISÃO;

- Remover VISÃO;

- Adicionar SURROGATE KEY;

- Mover COlUNA;

- Renomear COLUNA;

- Renomear TABELA;

- Renomear VISÃO.

- Alterações de esquema sobre qualidade de dados:

- Criar TABELA de LOOKUP;

- Remover RESTRIÇÃO de COLUNA;

- Remover VALOR DEFAULT;

- Remover RESTRIÇÃO de NÃO-NULO; 
- Adicionar RESTRIÇÃO de COLUNA;

- Adicionar VALOR DEFAULT;

- Adicionar RESTRIÇÃO de NÃO-NULO.

- Alterações de esquema de integridade referencial:

- Adicionar RESTRIÇÃO de CHAVE ESTRANGEIRA;

- Remover RESTRIÇÃO de CHAVE ESTRANGEIRA.

- Alterações de esquema na arquitetura:

- Adicionar CÓDIGO;

- Remover CÓDIGO;

- Adicionar ÍNDICE;

- Remover ÍNDICE.

Cada uma destas alterações está detalhada no APÊNDICE A, com as seguintes informações:

- Nome da alteração e seu principal objetivo;

- Características específicas, que apresenta os aspectos relevantes específicos para a alteração em questão;

- Objetos possivelmente impactados, que lista os objetos impactados que podem necessitar de manutenção, em decorrência da alteração de esquema em questão;

- Mecanismo de migração de dados, caso seja necessário a implementação de um mecanismo de migração e/ou transformação dos dados para completar a alteração de esquema.

- Estratégia para período de transição mostra qual a estratégia a ser utilizada para garantir o acesso ao esquema antigo e ao novo, durante o período de transição.

\subsubsection{As operações para avaliar a complexidade}

Como já mencionado, cada alteração que ocorre no esquema do Data Warehouse central, e que deve ser replicada nos data marts locais, é composta de um conjunto de operações. 
Para ilustrar este conceito, toma-se uma alteração de esquema que requeira a inclusão de uma nova coluna calculada. A inclusão desta nova coluna pode resultar em várias operações como, por exemplo: incluir a coluna propriamente dita, alterar uma ou mais visões existentes, alterar um ou mais triggers existentes ou criar um novo trigger que possibilite manter o cálculo da coluna. Além desta operação, os programas de aplicação também sofrerão alterações, uma vez que pode ser necessário exibir esta nova coluna como um novo indicador nos painéis analíticos. Assim, em relação aos programas de aplicação analítica, pode ser necessária uma operação para alterar um programa existente ou incluir um novo programa. 0 mesmo vale para os outros objetos, possivelmente impactados pela criação de uma nova coluna calculada. Este exemplo mostra que uma alteração de esquema pode acarretar um conjunto de operações que devem ser realizadas sobre diferentes objetos, aumentando, assim, a complexidade e o impacto causado por uma alteração de esquema.

Cada vez que uma alteração no esquema do Data Warehouse central é realizada, é necessário avaliar as operações que a compõem. Para isso, é importante realizar uma análise dos objetos impactados e das operações realizadas sobre eles, em decorrência da alteração do esquema, sendo que estes objetos podem ser de diferentes naturezas, desde atributos dentro de uma tabela até programas ou painéis analíticos (OLAP) que manipulam a informação na plataforma móvel. Os objetos que podem ser impactados por uma alteração de esquema são:

- Controles de integridade - em alguns casos de alteração de esquema pode ser necessário alterar, incluir ou excluir controles de integridade relacionados ao objeto alterado. Como exemplo, o caso de substituir uma chave do tipo surrogate por uma chave natural, possivelmente com outro nome, pode acarretar necessidade de se alterar controles de integridade referencial, na mesma tabela ou em outras;

- Triggers/Stored procedures - Triggers são objetos que estão acoplados à definição de tabelas, sendo que, algumas alterações no esquema podem invalidar um trigger. Por esta razão, pode ser necessário, no momento da alteração do esquema, alterar ou eliminar um trigger. Em algumas situações, a criação e execução de novos triggers também pode ser necessária. Procedimentos armazenados no 
banco de dados (stored procedures) também podem necessitar de alterações, pois acessam tabelas, visões e colunas que podem ser parte das alterações. Da mesma forma que os triggers, novas stored procedures podem ser criadas e executadas em decorrência de uma alteração de esquema. Como exemplo, pode-se citar a introdução de uma nova coluna calculada em uma tabela, que vai requerer, como uma das alternativas possíveis, a criação de um trigger para manter o valor da coluna sempre calculado de acordo com as regras do negócio.

- Visões - caso existam visões que envolvam tabelas e colunas alteradas na manutenção do esquema, as visões também deverão sofre atualizações para refletir as mudanças. Um exemplo é a alteração de esquema que inclui uma nova coluna em uma tabela e que deve ser refletida nas visões relacionadas.

- Tabelas e colunas - algumas alterações de esquema podem requerer modificações em uma ou mais tabelas e suas colunas.

- Programas de carga/sincronização - em decorrência de uma alteração de esquema, os processos de carga dos dados também podem necessitar de alteração. Uma nova tabela ou coluna pode acarretar a alteração dos programas de carga para possibilitar que os conteúdos da nova tabela ou da nova coluna possam ser armazenados nas plataformas móveis. Desta forma, um novo processo de carga e sincronização ou alterações no processo existente devem ser repassadas à plataforma móvel, antes que os novos dados sejam sincronizados.

- Programas ou aplicações analíticas - a alteração de esquema, dependendo do caso, deve também se refletir nas aplicações analíticas. Painéis, planilhas, gráficos, indicadores e outros objetos que compõem as aplicações analíticas podem requerer alterações. Assim, estes objetos também podem ser impactados por uma alteração de esquema. Um exemplo pode ser a introdução de uma nova métrica na tabela fato, com o objetivo de atender a uma nova necessidade de negócio. A apresentação desta nova métrica pode requerer alterações nas aplicações analíticas. 
- Migração de dados - uma alteração no esquema pode requerer a preservação dos dados existentes. Uma das razões para esta necessidade é a de possibilitar sua recuperação em algum momento no futuro. Outra razão pode ser a necessidade de se transformar ou realizar algum tratamento específico ao conteúdo dos dados armazenados, envolvidos na alteração de esquema. Para atender estas situações, deverão ser criados e executados procedimentos específicos para migração e/ou tratamento dos dados em uma tabela temporária, por exemplo. Estes programas têm uma função específica e podem ser executados uma única vez, dependendo do caso. Em grande parte das vezes, estes programas são necessários para garantir o período de transição e não fazem parte dos programas de carga e sincronização.

Com base na análise destes objetos, é possível analisar o impacto causado por uma alteração de esquema, resultando em uma avaliação de sua complexidade. Cada uma das possíveis alterações de esquema deve ser avaliada conforme as operações apresentadas na Tabela 5.

Vale lembrar que estas operações são aquelas consideradas relevantes para o escopo deste trabalho e, certamente, não constituem uma lista completa.

Em relação às operações apresentadas na Tabela 5, algumas observações são necessárias:

- Pressupõe-se que as tarefas necessárias para a criação ou alteração dos objetos, como por exemplo, elaboração de um script para a criação de uma nova tabela, elaboração de um script para alteração de um trigger, desenvolvimento de um programa de carga ou de aplicação analítica, são realizadas pela equipe de desenvolvimento. Estas atividades não são consideradas para a avaliação da complexidade e impacto discutida neste trabalho. $\mathrm{Na}$ análise aqui apresentada, são avaliados apenas os recursos necessários para a implantação e execução do script ou programa;

- Quando possível, as operações são realizadas por meio de scripts de SQL. 
Tabela 5 - Operações para avaliação de complexidade e impactos das alterações de esquema (continua)

\begin{tabular}{|c|c|c|c|}
\hline $\begin{array}{l}\text { Tipo de objeto } \\
\text { impactado }\end{array}$ & Descrição da operação & $\begin{array}{l}\text { Complexidade } \\
\text { estimada para a } \\
\text { execução da } \\
\text { operação }\end{array}$ & $\begin{array}{l}\text { Identificação dos } \\
\text { objetos que serão } \\
\text { impactados }\end{array}$ \\
\hline \multirow{2}{*}{$\begin{array}{l}\text { Controle de } \\
\text { integridade }\end{array}$} & $\begin{array}{l}\text { Alteração do controle na } \\
\text { mesma tabela (pode ser } \\
\text { inclusão de novo controle, } \\
\text { alteração de controle } \\
\text { existente ou eliminação de } \\
\text { controle existente) }\end{array}$ & $\begin{array}{l}\text { Baixa, Média } \\
\text { ou Alta }\end{array}$ & \\
\hline & $\begin{array}{l}\text { Alteração do controle em } \\
\text { tabela diferente (pode ser } \\
\text { inclusão de novo controle, } \\
\text { alteração de controle } \\
\text { existente ou eliminação de } \\
\text { controle existente) }\end{array}$ & $\begin{array}{l}\text { Baixa, Média } \\
\text { ou Alta }\end{array}$ & \\
\hline \multirow{3}{*}{ Trigger } & Alteração de trigger existente & $\begin{array}{l}\text { Baixa, Média } \\
\text { ou Alta }\end{array}$ & \\
\hline & $\begin{array}{l}\text { Eliminação de trigger } \\
\text { existente }\end{array}$ & $\begin{array}{l}\text { Baixa, Média } \\
\text { ou Alta }\end{array}$ & \\
\hline & Inclusão de novo trigger & $\begin{array}{l}\text { Baixa, Média } \\
\text { ou Alta }\end{array}$ & \\
\hline \multirow{3}{*}{$\begin{array}{l}\text { Stored } \\
\text { procedure }\end{array}$} & $\begin{array}{l}\text { Alteração de stored } \\
\text { procedure existente }\end{array}$ & $\begin{array}{l}\text { Baixa, Média } \\
\text { ou Alta }\end{array}$ & \\
\hline & $\begin{array}{l}\text { Eliminação de stored } \\
\text { procedure existente }\end{array}$ & $\begin{array}{l}\text { Baixa, Média } \\
\text { ou Alta }\end{array}$ & \\
\hline & $\begin{array}{l}\text { Inclusão de novo stored } \\
\text { procedure }\end{array}$ & $\begin{array}{l}\text { Baixa, Média } \\
\text { ou Alta }\end{array}$ & \\
\hline \multirow{3}{*}{ Visões } & Alteração de visão existente & $\begin{array}{l}\text { Baixa, Média } \\
\text { ou Alta }\end{array}$ & \\
\hline & Eliminação de visão existente & $\begin{array}{l}\text { Baixa, Média } \\
\text { ou Alta }\end{array}$ & \\
\hline & Inclusão de nova visão & $\begin{array}{l}\text { Baixa, Média } \\
\text { ou Alta }\end{array}$ & \\
\hline \multirow{3}{*}{ Tabela } & Alteração de tabela existente & $\begin{array}{l}\text { Baixa, Média } \\
\text { ou Alta }\end{array}$ & \\
\hline & $\begin{array}{l}\text { Eliminação de tabela } \\
\text { existente }\end{array}$ & $\begin{array}{l}\text { Baixa, Média } \\
\text { ou Alta }\end{array}$ & \\
\hline & Inclusão de nova tabela & $\begin{array}{l}\text { Baixa, Média } \\
\text { ou Alta }\end{array}$ & \\
\hline \multirow{3}{*}{ Coluna } & Alteração de coluna existente & $\begin{array}{l}\text { Baixa, Média } \\
\text { ou Alta }\end{array}$ & \\
\hline & $\begin{array}{l}\text { Eliminação de coluna } \\
\text { existente }\end{array}$ & $\begin{array}{l}\text { Baixa, Média } \\
\text { ou Alta }\end{array}$ & \\
\hline & Inclusão de nova coluna & $\begin{array}{l}\text { Baixa, Média } \\
\text { ou Alta }\end{array}$ & \\
\hline
\end{tabular}


Tabela 5 - Operações para avaliação de complexidade e impactos das alterações de esquema (conclusão)

\begin{tabular}{|c|c|c|c|}
\hline $\begin{array}{l}\text { Tipo de objeto } \\
\text { impactado }\end{array}$ & Descrição da operação & $\begin{array}{l}\text { Complexidade } \\
\text { estimada para a } \\
\text { execução da } \\
\text { operação }\end{array}$ & $\begin{array}{l}\text { Identificação dos } \\
\text { objetos que serão } \\
\text { impactados }\end{array}$ \\
\hline \multirow{4}{*}{$\begin{array}{l}\text { Programa de carga } \\
\text { /sincronização }\end{array}$} & $\begin{array}{l}\text { Alteração de programa } \\
\text { existente }\end{array}$ & $\begin{array}{l}\text { Baixa, Média } \\
\text { ou Alta }\end{array}$ & \\
\hline & $\begin{array}{l}\text { Eliminação de programa } \\
\text { existente }\end{array}$ & $\begin{array}{c}\text { Baixa, Média } \\
\text { ou Alta }\end{array}$ & \\
\hline & Inclusão de novo programa & $\begin{array}{l}\text { Baixa, Média } \\
\text { ou Alta }\end{array}$ & \\
\hline & Execução de novo programa & $\begin{array}{l}\text { Baixa, Média } \\
\text { ou Alta }\end{array}$ & \\
\hline \multirow{3}{*}{$\begin{array}{l}\text { Programa de } \\
\text { aplicação analítica }\end{array}$} & $\begin{array}{l}\text { Alteração de programa } \\
\text { existente }\end{array}$ & $\begin{array}{l}\text { Baixa, Média } \\
\text { ou Alta }\end{array}$ & \\
\hline & $\begin{array}{l}\text { Eliminação de programa } \\
\text { existente }\end{array}$ & $\begin{array}{l}\text { Baixa, Média } \\
\text { ou Alta }\end{array}$ & \\
\hline & Inclusão de novo programa & $\begin{array}{l}\text { Baixa, Média } \\
\text { ou Alta }\end{array}$ & \\
\hline \multirow{2}{*}{$\begin{array}{l}\text { Programa de } \\
\text { migração de dados }\end{array}$} & Inclusão de novo programa & $\begin{array}{c}\text { Baixa, Média } \\
\text { ou Alta }\end{array}$ & \\
\hline & Execução de programa & $\begin{array}{l}\text { Baixa, Média } \\
\text { ou Alta }\end{array}$ & \\
\hline
\end{tabular}

A implementação de uma alteração pode requerer mais de uma operação do mesmo tipo, sobre objetos diferentes. Por esta razão, para se avaliar o impacto e a complexidade de uma alteração é preciso identificar a quantidade das operações sobre os objetos impactados e quais são estes objetos. Desta forma, utilizando a quantidade de operações necessárias e o fator da complexidade, pode-se obter uma referência do impacto e complexidade da alteração no esquema.

A atribuição da complexidade estimada (Alta, Média ou Baixa) para as operações deve ser escolhida em função das características do ambiente operacional onde está implantado o ambiente do Data Warehouse central e das plataformas móveis. Estas complexidades são estabelecidas em função da dificuldade de se executar a operação. Por exemplo, a eliminação de uma visão existente pode ser considerada, normalmente, de complexidade baixa, já que é muito simples a criação e execução de um comando SQL "DROP VIEW". Um exemplo de complexidade média pode ser aquela atribuída a uma operação que irá incluir um controle de integridade em uma tabela. Esta operação não pode ser considerada de baixa complexidade, uma vez 
que durante sua excução diversas verificações nas bases de dados serão executadas pelo gerenciador de banco de dados. Da mesma forma, a operação de execução de um programa de carga/sincronização pode ser algo considerado de alta complexidade, em muitos casos.

Pode ser interessante, para o administrador do Data Warehouse, quantificar cada uma das complexidades estimadas em função do tempo gasto para sua execução. Assim, pode-se estabelecer, por meio de medições que, em média, uma operação de alta complexidade leva $x$ segundos para ser executada, enquanto que uma operação de média complexidade leva $y$ segundos e a de baixa complexidade leva $z$ segundos. Desta forma, pode-se quantificar qual o recurso de tempo necessário que a sincronização de uma alteração de esquema agregaria ao processo de atualização dos data marts na plataforma móvel.

Dependendo do resultado, pode-se apresentar ao usuário alternativas de sincronização que, apesar de não serem detalhadas neste trabalho, são citadas a seguir.

A primeira alternativa é implementar a alteração do esquema, acrescentando-se ao processo de sincronização os recursos de tempo necessários. Esta é uma boa opção quando a alteração do esquema é considerada simples, tem baixa complexidade e impacta um pequeno número de objetos.

Outra opção, nos casos em que a alteração do esquema requer uma grande quantidade de recursos é a eliminação e recriação da estrutura completa do ambiente analítico na plataforma móvel (data marts e aplicações).

Uma terceira alternativa é o adiamento da sincronização de esquema, mantendo, inicialmente, apenas a sincronização das instâncias dos dados sem refletir as alterações de esquema.

A escolha e oferta de uma, dentre as alternativas citadas, requer uma estimativa prévia dos recursos necessários para as diferentes opções de implantação das alterações.

Esta estimativa pode ser realizada por meio de medições prévias, armazenadas nos metadados como valores de referência (estabelecendo "quanto custa" cada uma das alternativas). Uma vez que a complexidade da sincronização do esquema for avaliada, é possível, por meio de comparações com os valores de referência, 
oferecer ao usuário da plataforma móvel a melhor alternativa de sincronização para aquele momento.

Sugere-se que, para estabelecer estes valores de referência, as seguintes estimativas de consumo de recursos devem ser realizadas:

- Execução da sincronização de esquema - realizada por meio de medições para estimar o tempo necessário para realizar a alteração de esquema na plataforma móvel, tendo como base a complexidade estimada (por meio da análise apresentada neste trabalho), capacidade de processamento da plataforma móvel e a qualidade da conexão com a plataforma central;

- Reconstrução completa do ambiente analítico na plataforma móvel (eliminação e recriação completa de data marts, programas de carga e aplicações analíticas) - estimativa prévia, realizada por meio de medições, com base na capacidade de processamento da plataforma móvel e a qualidade da conexão com a plataforma central;

- Execução apenas da sincronização de dados, postergando-se a sincronização do esquema - estimativa em função do tempo necessário para sua execução, tendo como base a capacidade de processamento da plataforma móvel e a qualidade da conexão com a plataforma central.

As estimativas dos recursos necessários para a implantação das diferentes opções de sincronização não fazem parte do escopo deste trabalho e são apresentadas apenas como referência.

\subsubsection{Resumo do modelo de avaliação de complexidade e impacto da manutenção de esquema}

Uma vez apresentadas as principais alterações de esquema em um ambiente de Data Warehouse e os parâmetros para quantificar estas alterações, esta seção apresenta um resumo do processo de avaliação da complexidade e do impacto em uma manutenção de esquema. 
Quando surge a necessidade de uma alteração no esquema, é realizada a identificação de todos os objetos envolvidos e são estabelecidas as características do período de transição, seguindo a metodologia sugerida por Ambler e Sadalage (2006) e apresentada na seção 3.3.3 do presente trabalho. Desta forma, é possível entender quantos e quais são os objetos afetados pela alteração de esquema.

Quando uma alteração de esquema ocorre, esta alteração deve ser traduzida para um conjunto de operações a serem implementadas na base de dados, conforme apresentado na Tabela 5. Assim, uma vez estabelecido o conjunto de operações que devem ser realizadas para se implementar a alteração de esquema, pode-se avaliar o impacto resultante nos objetos da base de dados.

A análise é efetuada ao se preencher os dados na Tabela 5, que, com base nas quantidades de operações sobre os objetos impactados, permite avaliar o impacto causado pela alteração de esquema.

Estas informações devem ficar armazenadas nos metadados do Data Warehouse central, para permitir a oferta de alternativas para o usuário das plataformas móveis no momento em que solicita a sincronização de esquema para seu data mart local.

Esta análise permite planejar a manutenção do esquema nas plataformas móveis, garantindo que o processo possa ser automatizado. Podem surgir situações em que, em função da alta complexidade do processo, seja necessária uma reengenharia, realizada pelos administradores do sistema.

Com a realização desta análise, também é possível oferecer alternativas no momento da sincronização de esquema, uma vez que existem situações em que a quantidade e complexidade das alterações podem justificar uma total reconstrução do ambiente analítico da plataforma móvel, com a remoção dos componentes seguida de uma carga completa do ambiente.

Outra alternativa possível é permitir ao usuário adiar a execução do processo de sincronização de esquema, sincronizando apenas os dados naquele momento. 


\subsection{ESTUDO DE CASO}

Com o objetivo de ilustrar a análise de complexidade e de impacto das alterações de esquema, nesta seção é apresentado um estudo de caso.

O estudo de caso está baseado no modelo de negócios de uma área comercial, sendo os usuários das plataformas móveis (notebooks) profissionais que, além de executarem tarefas operacionais de vendas em suas estações cliente, necessitam também de bases analíticas com informações gerenciais e de acompanhamento de vendas de sua carteira de clientes.

As informações gerenciais e analíticas da organização estão armazenadas em um Data Warehouse, localizado na plataforma central, que contém informações pertinentes a todos os clientes, sendo que a cada profissional usuário da plataforma móvel é autorizado o acesso às informações relativas ao seu conjunto de clientes.

Uma vez que novas transações comerciais com os clientes da organização são realizadas, estas são armazenadas nos sistemas transacionais e, utilizando-se processos de extração, transformação e carga, informações pertinentes são transferidas para o Data Warehouse central. Conforme solicitação dos usuários das plataformas móveis, conjuntos específicos de informações são transferidos para as estações cliente, possibilitando análise de informações por meio de ferramentas OLAP.

\subsubsection{Representação na arquitetura proposta}

O cenário de negócios apresentado acima é um cenário típico em várias organizações de mercado e é adequado para implementação na arquitetura proposta neste trabalho. A Figura 15 representa esta implementação, mostrando os componentes de dados e de processos necessários para atender o modelo de negócios do estudo de caso.

Segue abaixo a descrição das estruturas de dados, componentes da arquitetura representada na Figura 15. O conjunto de informações neste estudo de caso representa apenas as informações relevantes para este contexto, como um exemplo. 


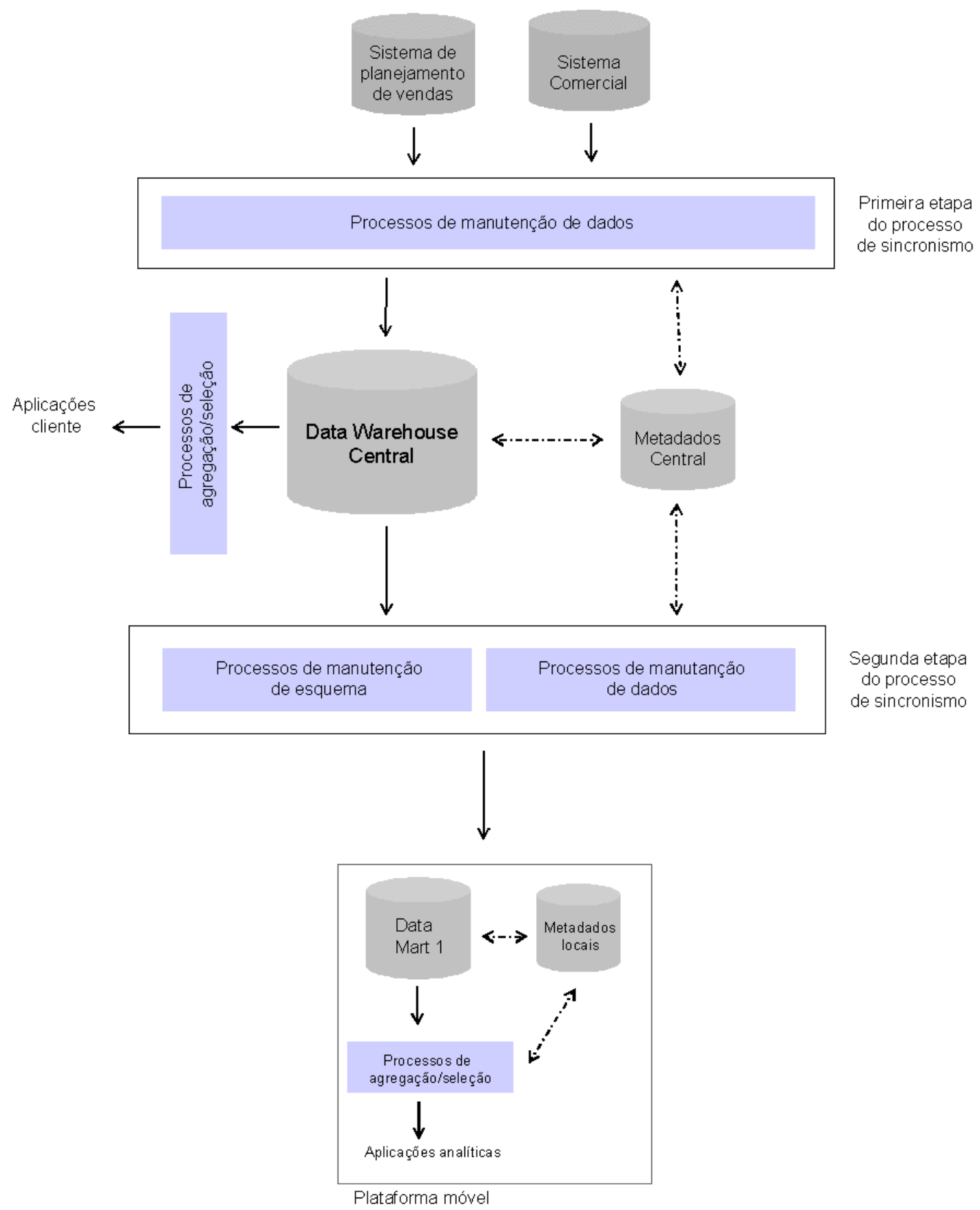

Figura 15 - Implementação do modelo do estudo de caso na arquitetura proposta

Entende-se que, dependendo da organização, estas informações podem estar armazenadas em diferentes sistemas transacionais.

Sistemas transacionais, que servem de fonte de informações para o Data Warehouse central, sendo:

- Sistema comercial, contendo as informações: cadastro de clientes, cadastro de produtos, vendas realizadas (quantidade de itens vendidos e valor das vendas), preço e custo dos produtos. 
- Sistema de planejamento de vendas, contendo as informações: vendas previstas (quantidade de itens previstos e valor previsto das vendas).

Data Warehouse central, com informações analíticas sobre o planejamento e resultados da área comercial. O modelo está implementado em star schema, conforme a modelagem multidimensional proposta por Kimbal (2002). A Figura 16 , representa a tabela fato deste modelo, bem como as dimensões de negócios Produto, Geografia e Tempo.

Com base neste modelo, as tabelas armazenadas no Data Warehouse central, para implementar o estudo de caso, são:

- Fato_vendas (cod prod, cod tempo, cod cliente, val_venda_real, qtd_item_venda_real, val_venda_prev, qtd_item_venda_prev, val_preco_medio,val_custo_medio)

- Dim_prod (cod prod, dsc_item, dsc_linha, dsc_categ)

- Dim_cliente (cod cliente, dsc_cliente, dsc_cid, dsc_uf, dsc_reg)

- Dim_tempo ( $\left.\underline{\text { cod tempo }}, d s c \_d a t a, d s c \_m e s, d s c \_s e m, d s c \_a n o\right)$

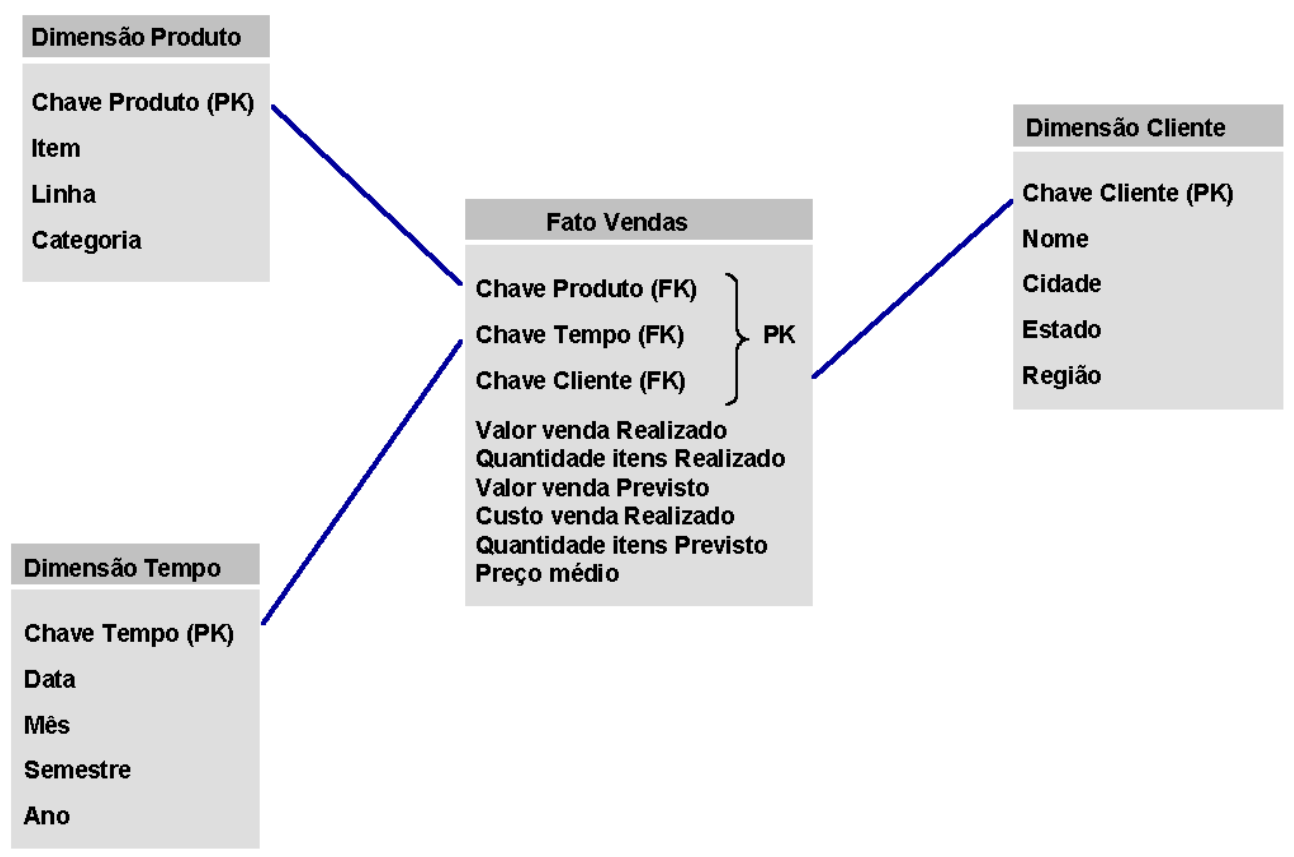

Figura 16 - Modelo multidimensional de Vendas utilizado no estudo de caso

Metadados central, com metadados técnicos e semânticos sobre o ambiente do Data Warehouse e aplicações analíticas. As tabelas que armazenam os 
metadados são implementadas no modelo proposto pelo padrão CWM (OMG, 2001), armazenando metadados sobre:

- Modelo de negócio: descrições do modelo de negócios, seus responsáveis (com informações descritivas);

- Tabelas relacionais: descreve a tabela fato vendas e as dimensões Produto, Tempo e Cliente (Fato_vendas, Dim_prod, Dim_tempo e Dim_cliente);

- Base multidimensional e vendas: descreve o cubo de vendas criado pela ferramenta OLAP implementada para oferecer recursos analíticos para os usuários;

- Painéis analíticos criados para os usuários;

- Informação semântica, de relacionamento e de origem das métricas da tabela Fato_vendas, descrevendo seu significado, composição e relacionamento com outras métricas, orientação do indicador (mais alto, melhor ou mais baixo, melhor);

- Fluxo dos processos de extração, transformação e carga representados na primeira e na segunda etapa do sincronismo;

- Resultados e medidas de desempenho dos processos de sincronismo;

- Definição do usuário (representante comercial) com atributos de identificação;

- Perfil de acesso do usuário, indicando as métricas (atributos da tabela Fato_vendas) autorizadas e os valores autorizados dentro de cada métrica, níveis de agregação das dimensões autorizados e valores autorizados dentro de cada nível de agregação.

Data mart localizado na plataforma móvel, com informações analíticas sobre o planejamento e resultados da área comercial, autorizadas para o usuário. Assim como no Data Warehouse central, o modelo está implementado em star schema, conforme a modelagem multidimensional proposta por Kimbal (2002), com estrutura idêntica àquela implementada no Data Warehouse central. A principal diferença da implementação das tabelas no Data Warehouse central e no data 
mart está relacionada ao seu conteúdo. Enquanto que no Data Warehouse central estão armazenadas informações pertinentes a todas as vendas da organização, no data mart do usuário, na plataforma móvel, estão apenas as vendas relativas aos clientes de negócio atendidos pelo usuário. Assim, no data mart local, são armazenadas tabelas com a mesma estrutura do Data Warehouse central, a saber:

- Fato_vendas (cod prod, cod tempo, cod cliente, val_venda_real, qtd_item_venda_real, val_venda_prev, qtd_item_venda_prev, val_preco_medio,val_custo_medio)

- Dim_prod (od prod, dsc_item, dsc_linha, dsc_categ)

- Dim_cliente (cod cliente, dsc_cliente, dsc_cid, dsc_uf, dsc_reg)

- Dim_tempo (cod tempo, dsc_data,dsc_mes, dsc_sem, dsc_ano)

No metadados local, da mesma forma que o metadados central, estão armazenados metadados técnicos e semânticos sobre o ambiente da plataforma móvel. As tabelas que armazenam os metadados locais são também implementadas no modelo proposto pelo padrão CWM (OMG, 2001), porém seu conteúdo é restrito ao ambiente da plataforma móvel e seu usuário, armazenando metadados sobre:

- Tabelas relacionais: descreve a tabela fato vendas e as dimensões Produto, Tempo e Cliente (Fato_vendas, Dim_prod, Dim_tempo e Dim_cliente);

- Base multidimensional e vendas: descreve o cubo de vendas criado pela ferramenta OLAP implementada para oferecer recursos analíticos para o usuário da plataforma móvel;

- Painéis analíticos criados e disponíveis para o usuário da plataforma móvel;

- Informação semântica, de relacionamento e de origem das métricas da tabela Fato_vendas, autorizadas para o usuário da plataforma móvel, descrevendo seu significado, composição e relacionamento com outras métricas, orientação do indicador (mais alto, melhor ou mais baixo, melhor); 
- Resultados e medidas de desempenho dos processos de sincronismo daquela plataforma móvel com a plataforma central;

- Definição do usuário (representante comercial) com atributos de identificação;

- Perfil de acesso do usuário, indicando as métricas (atributos da tabela Fato_vendas) autorizadas e os valores autorizados dentro de cada métrica, níveis de agregação das dimensões autorizados e valores autorizados dentro de cada nível de agregação.

\subsubsection{A segunda etapa do processo de sincronismo}

Nesta etapa, é necessário seguir todas as fases descritas na seção 6.2.2. Assim, quando o usuário da plataforma móvel conectar seu computador ao servidor central, inicia-se a fase 1, ou seja, esta estação solicita que o processo de sincronismo seja iniciado. O computador móvel envia ao servidor informações de controle sobre a última sincronização bem sucedida e o servidor valida a identificação do usuário para iniciar a próxima fase.

$\mathrm{Na}$ fase 2, o servidor identifica as informações que devem ser enviadas para a plataforma móvel, de forma que seja possível atualizar o ambiente da estação cliente. Neste caso particular, será solicitado o sincronismo do modelo multidimensional Vendas.

Nesta fase, são identificadas primeiramente as informações armazenadas no metadados, que serão replicadas na plataforma móvel. Em segundo lugar as informações sobre alterações de esquema e, por fim, são identificados os conjuntos de instâncias de dados do data warehouse a serem transferidos.

Neste estudo de caso, além das novas instâncias da tabela Fato_vendas que devem ser enviadas para a plataforma móvel, está prevista a sincronização de esquema referente à inclusão de uma nova coluna calculada, que irá conter o valor da margem de lucro das vendas. A partir desta alteração de esquema, todas as informações de vendas armazenadas na tabela fato deverão ter esta nova coluna calculada. 
De modo a simplificar o estudo de caso, a margem de lucro será calculada utilizando-se a diferença entre o valor da venda (realizado) e o custo da venda (realizado). Assim, nesta fase são identificadas:

1. As informações de metadados, referentes à nova coluna margem de lucro, que deverão ser transferidas para a plataforma móvel (descrições técnicas e semânticas);

2. As informações sobre alteração de esquema, também referentes a esta nova coluna, que deverão estar refletidas na base de dados da plataforma móvel. Esta etapa, especificamente, é tratada com mais detalhes na seção 6.4.3.

3. As instâncias de dados armazenadas no Data Warehouse central que deverão ser replicadas no data mart local da plataforma móvel. Estas instâncias são linhas específicas selecionadas da tabela Fato_Vendas e, possivelmente, das tabelas dimensão.

Após a identificação dos conjuntos de dados que serão transferidos e sincronizados com a plataforma móvel, inicia-se a fase 3 , quando o servidor prepara estes conjuntos de dados para serem transferidos, no formato e ordem em que serão aplicadas na base de dados da estação cliente.

Durante a próxima fase, representada na seção 6.2.2 como fase 4, os dados são fisicamente transferidos para a plataforma móvel e, após a conclusão da transferência, com sucesso, a plataforma móvel pode encerrar a conexão com o servidor e iniciar a última fase, denominada fase 5.

Nesta fase, a plataforma móvel aplica as alterações recebidas, iniciando a atualização de sua base local com as alterações de metadados, seguida das alterações de esquema e pelas alterações nas instâncias dos dados no data mart local. A plataforma móvel conclui a sincronização armazenando informações de controle sobre o sucesso ou fracasso do processo. 


\subsubsection{O processo de manutenção de esquema}

Com o objetivo de tornar o estudo de caso mais completo, nesta seção será apresentada, detalhadamente, a análise de complexidade e de impacto de uma alteração de esquema, dentro do modelo de negócios proposto.

Como já mencionado, a alteração de esquema escolhida é a inclusão de uma coluna, na tabela fato, para calcular a margem de lucro de cada venda realizada (como a diferença entre o valor da venda realizado e o custo da venda realizado).

Para delimitar o escopo do estudo de caso, algumas premissas são estabelecidas:

- A nova coluna, que será identificada pelo nome Val_margem, precisa ter seu conteúdo calculado cada vez que uma nova linha for inserida na tabela fato. A nova coluna terá seu conteúdo calculado por meio de um trigger na base de dados, ou seja, a cada linha incluída na tabela fato, é realizado o cálculo, de forma automática pelo gerenciador de banco de dados, para preencher corretamente o valor da nova coluna. Este trigger será identificado pelo nome de Tr_calc_val_margem;

- A tabela fato já contém linhas carregadas, de forma que será necessário efetuar uma carga inicial para popular os valores da nova coluna. $O$ programa a ser criado para realizar esta carga inicial será identificado pelo nome de Sp_pop_val_margem;

- A nova coluna deve ser visualizada na aplicação analítica, de modo que será necessário alterar a aplicação;

- Existem três programas da aplicação analítica (painéis) e duas visões que devem ser alterados, de modo a permitir que a nova métrica possa ser visualizada pelo usuário. Os programas são identificados por nomes fictícios, a saber: Painel_aplic_01, Painel_aplic_02 e Painel_aplic_03. O mesmo acontece com as visões, identificadas com o nomes: View_1 e View_2.

Portanto, a inclusão de uma nova coluna calculada, dentro do contexto apresentado, prevê a execução das seguintes alterações de esquema na base de dados:

- ADICIONAR COLUNA - para adicionar a nova coluna que conterá a margem de lucro; 
- REMOVER VISÃO - com base nas premissas estabelecidas, será necessário remover as visões existentes para que novas visões sejam incluídas e apresentem a nova coluna;

- ADICIONAR VISÃO - conforme comentário no item anterior;

- ADICIONAR CÓDIGO - será necessário criar um trigger para manter a nova coluna calculada.

Cada uma destas alterações tem suas próprias características e se desdobram em um conjunto de operações. Assim, as operações necessárias para se implementar as alterações podem ter sua complexidade quantificada com o preenchimento da tabela, conforme o modelo apresentado na Tabela 5.

A alteração de esquema ADICIONAR COLUNA será desdobrada em uma operação Inclusão de nova coluna, sendo que a nova coluna a ser incluída terá nome Val_margem.

A alteração de esquema REMOVER VISÃO será desdobrada em duas operações Eliminação de visão existente, removendo as visões View_1 e View_2.

A alteração de esquema ADICIONAR VISÃO será desdobrada também em duas operações Inclusão de nova visão, incluindo as visões View_1 e View_2 já contemplando a nova coluna Val_margem.

A alteração de esquema ADICIONAR CÓDIGO será desdobrada em uma operação de Inclusão de novo trigger, para incluir o trigger Tr_calc_val_margem, que manterá a coluna Val_margem sempre calculada.

Além das operações descritas acima, serão necessárias três operações Alteração de programa existente para alterar os programas de aplicação analítica Painel_aplic_01, Painel_aplic_02 e Painel_aplic_03.

Será necessária também uma operação para criar o programa de migração de dados, Criação de novo programa, para popular inicialmente a coluna Val_margem e uma operação de Execução de programa, para executar o novo programa Sp_pop_val_margem criado.

O resultado da identificação e quantificação das operações deste estudo de caso é mostrado na Tabela 6, onde os valores preenchidos estão em itálico. 
Tabela 6 - Representação das operações resultantes do estudo de caso (continua)

\begin{tabular}{|c|c|c|c|}
\hline $\begin{array}{l}\text { Tipo de objeto } \\
\text { impactado }\end{array}$ & Descrição da operação & $\begin{array}{l}\text { Complexidade } \\
\text { estimada para a } \\
\text { execução da } \\
\text { operação }\end{array}$ & $\begin{array}{l}\text { Identificação dos } \\
\text { objetos que serão } \\
\text { impactados }\end{array}$ \\
\hline \multirow{2}{*}{$\begin{array}{l}\text { Controle de } \\
\text { integridade }\end{array}$} & $\begin{array}{l}\text { Alteração do controle na } \\
\text { mesma tabela (pode ser } \\
\text { inclusão de novo controle, } \\
\text { alteração de controle } \\
\text { existente ou eliminação de } \\
\text { controle existente) }\end{array}$ & Média & \\
\hline & $\begin{array}{l}\text { Alteração do controle em } \\
\text { tabela diferente (pode ser } \\
\text { inclusão de novo controle, } \\
\text { alteração de controle } \\
\text { existente ou eliminação de } \\
\text { controle existente) }\end{array}$ & Média & \\
\hline \multirow{3}{*}{ Trigger } & Alteração de trigger existente & Média & \\
\hline & $\begin{array}{l}\text { Eliminação de trigger } \\
\text { existente }\end{array}$ & Baixa & \\
\hline & Inclusão de novo trigger & Média & Tr_calc_val_margem \\
\hline \multirow{3}{*}{$\begin{array}{l}\text { Stored } \\
\text { procedure }\end{array}$} & $\begin{array}{l}\text { Alteração de stored } \\
\text { procedure existente }\end{array}$ & Média & \\
\hline & $\begin{array}{l}\text { Eliminação de stored } \\
\text { procedure existente }\end{array}$ & Baixa & \\
\hline & $\begin{array}{l}\text { Inclusão de novo stored } \\
\text { procedure }\end{array}$ & Média & \\
\hline \multirow{3}{*}{ Visões } & Alteração de visão existente & Média & \\
\hline & Eliminação de visão existente & Baixa & $\begin{array}{l}\text { View_1 } \\
\text { View_2 }\end{array}$ \\
\hline & Inclusão de nova visão & Média & $\begin{array}{l}\text { View_1 } \\
\text { View_2 }\end{array}$ \\
\hline \multirow{3}{*}{ Tabela } & Alteração de tabela existente & Média & \\
\hline & $\begin{array}{l}\text { Eliminação de tabela } \\
\text { existente }\end{array}$ & Média & \\
\hline & Inclusão de nova tabela & Média & \\
\hline \multirow{3}{*}{ Coluna } & Alteração de coluna existente & Média & \\
\hline & $\begin{array}{l}\text { Eliminação de coluna } \\
\text { existente }\end{array}$ & Média & \\
\hline & Inclusão de nova coluna & Média & Val_margem \\
\hline
\end{tabular}


Tabela 6 - Representação das operações resultantes do estudo de caso (conclusão)

\begin{tabular}{|c|c|c|c|}
\hline $\begin{array}{l}\text { Tipo de objeto } \\
\text { impactado }\end{array}$ & Descrição da operação & $\begin{array}{l}\text { Complexidade } \\
\text { estimada para a } \\
\text { execução da } \\
\text { operação }\end{array}$ & $\begin{array}{l}\text { Identificação dos } \\
\text { objetos que serão } \\
\text { impactados }\end{array}$ \\
\hline \multirow{4}{*}{$\begin{array}{l}\text { Programa de carga } \\
\text { /sincronização }\end{array}$} & $\begin{array}{l}\text { Alteração de programa } \\
\text { existente }\end{array}$ & Média & \\
\hline & $\begin{array}{l}\text { Eliminação de programa } \\
\text { existente }\end{array}$ & Baixa & \\
\hline & Inclusão de novo programa & Média & \\
\hline & Execução de novo programa & Alta & \\
\hline \multirow{3}{*}{$\begin{array}{l}\text { Programa de } \\
\text { aplicação analítica }\end{array}$} & $\begin{array}{l}\text { Alteração de programa } \\
\text { existente }\end{array}$ & Média & $\begin{array}{l}\text { Painel_aplic_01 } \\
\text { Painel_aplic_02 } \\
\text { Painel_aplic_03 }\end{array}$ \\
\hline & $\begin{array}{l}\text { Eliminação de programa } \\
\text { existente }\end{array}$ & Baixa & \\
\hline & Inclusão de novo programa & Média & \\
\hline \multirow{2}{*}{$\begin{array}{l}\text { Programa de } \\
\text { migração de dados }\end{array}$} & Inclusão de novo programa & Média & Sp_pop_val_margem \\
\hline & Execução de programa & Alta & Sp_pop_val_margem \\
\hline
\end{tabular}

Os nomes utilizados para os objetos impactados neste estudo de caso e apresentados na Tabela 6, na coluna "Identificação dos objetos que serão impactados", são nomes fictícios, já descritos e utilizados apenas para ilustrar melhor o estudo.

Supondo que o administrador do data warehouse já tenha estabelecido o tempo médio de execução de operações de alta, média e baixa complexidade em, por exemplo, 60 segundos, 30 segundos e 10 segundos, respectivamente, é possível calcular o acréscimo de tempo, no processo de sincronização, necessário para se implementar a atualização do esquema.

Neste estudo de caso, serão necessárias uma operação de alta complexidade, oito operações de média complexidade e duas operações de baixa complexidade. Com base nos valores de tempo citados acima, a implementação da alteração do esquema consumiria aproximadamente 5 minutos e 20 segundos.

Conforme a aplicação das diretrizes propostas no presente trabalho, com base no exemplo citado neste estudo de caso pode-se avaliar a complexidade que a inclusão de uma nova coluna calculada requer, bem como o impacto causado por esta inclusão em outros objetos da base de dados. 
Este resultado pode auxiliar os administradores do ambiente a planejar as alterações de esquema, propondo, por exemplo, um agrupamento de alterações que possam ser realizadas com sucesso pelas plataformas móveis ou, em casos de grande complexidade ou de um grande número de alterações a serem realizadas, propor a reconstrução total do ambiente analítico nestas plataformas. 


\section{CONCLUSÃO}

\subsection{RELEVÂNCIA DO PROBLEMA}

Por se constituir em uma das principais aplicações dos bancos de dados, atualmente utilizadas, envolvendo desde os níveis operacionais até os mais estratégicos, os Data Warehouses estão se tornando soluções imprescindíveis para um grande número de empresas. Sua expansão, para atender às necessidades de negócio em ambientes distribuídos em plataformas móveis, requer um conjunto complexo de dados e processos visando garantir que as informações que chegam aos usuários finais, principalmente aqueles responsáveis pela tomada de decisão, estejam corretas e atualizadas, além de serem entregues no momento preciso.

Este trabalho apresentou uma arquitetura, descrevendo as estruturas de dados e processos para a implementação do uso de Data Warehouses em ambientes distribuídos em plataformas móveis e transformando estes componentes em soluções já conhecidas, justificando sua viabilidade.

Além disso, este trabalho discutiu os aspectos relativos à manutenção de esquema entre o Data Warehouse central e as plataformas móveis, ainda pouco discutido em trabalhos já publicados e apresentou diretrizes para avaliação da complexidade e do impacto causados por uma mudança no esquema nestas bases.

Cada alteração de esquema ocorrida no Data Warehouse central, e que deve ser repassada aos data marts da plataforma móvel, acarreta a execução de um conjunto de operações sobre determinados objetos dos bancos de dados. Neste trabalho, as operações são apresentadas em uma tabela e sua complexidade é quantificada, de modo a possibilitar a avaliação da complexidade da manutenção do esquema. Além disso, cada um dos objetos impactados é identificado assim como as operações a serem executadas sobre eles. Para facilitar a identificação das operações necessárias em uma manutenção de esquema, este trabalho apresenta uma classificação das alterações de esquema, permitindo identificar quantas e quais operações devem ser executadas. 
Como os processos de manutenção dos data marts, localizados nas plataformas móveis, devem ser simplificados e de rápida execução, é importante identificar a complexidade e o impacto dos processos de manutenção, com o objetivo de se escolher a alternativa mais simples e rápida. Em determinados casos, a manutenção incremental pode ser a melhor alternativa, porém, em outros, a recriação do ambiente como um todo, ou de partes dele, deve ser avaliada.

\subsection{CONTRIBUIÇÕES DO TRABALHO}

A arquitetura apresentada neste trabalho permite aos administradores do Data Warehouse implementar um ambiente distribuído, com sincronismo de informações entre o Data Warehouse central e as plataformas móveis, utilizando as já comprovadas alternativas de implementação dos componentes de dados e de processos descritas no presente trabalho.

Através da implementação desta arquitetura, os administradores do data warehouse podem manter um ambiente distribuído de informações, otimizando o uso de recursos e controlando as atualizações das bases de dados das plataformas móveis.

Para os usuários, a implementação desta arquitetura oferece uma forma de trabalho que permite maximizar o uso das informações gerenciais contidas no Data Warehouse central, favorecendo os processos de negócios.

Outro resultado deste trabalho é um conjunto de diretrizes para a análise da complexidade e do impacto das alterações de esquema, que permite aos administradores do ambiente planejar a manutenção do esquema nas plataformas móveis, com o objetivo de garantir que todo o processo possa ser automatizado, identificando as situações que podem necessitar de intervenção humana. Como já mencionado, os resultados do presente trabalho complementam os estudos já realizados e publicados sobre evolução e manutenção de esquemas em bancos de dados, oferecendo orientações para o projeto otimizado dos processos de sincronismo entre o Data Warehouse central e os data marts nas plataformas móveis. 
Uma vez que manter o sincronismo de esquema entre o Data Warehouse central e os data marts nas plataformas móveis pode envolver a criação de novas estruturas ou alteração em estruturas já existentes na base de dados, que acarretam a execução de processos adicionais, este trabalho também auxilia os administradores do ambiente a planejar as alterações de esquema, propondo alternativas como, por exemplo, um agrupamento de alterações que possam ser realizadas com sucesso pelas plataformas móveis ou, em casos de grande complexidade ou de um grande número de alterações a serem realizadas, propor a reconstrução total do ambiente analítico nestas plataformas.

Além disso, este trabalho mostra que, dependendo do nível de complexidade exigido para se sincronizar as alterações ocorridas no esquema do Data Warehouse central, o usuário pode optar por adiar o sincronismo de esquema, sincronizando apenas os dados, no esquema antigo, sem receber as novas alterações e os dados relativos à mudança do esquema, favorecendo as atividades relativas aos processos de negócios.

\subsection{FUTURAS PESQUISAS}

Os próximos passos deste trabalho podem ser divididos em três frentes:

1. Elaboração de metodologia para utilização da análise de complexidade e de impacto de manutenção e esquema.

Neste trabalho foram apresentadas as diretrizes para a análise de complexidade e de impacto na manutenção de esquema. Entretanto, para tornar tal proposta mais fundamentada é possível criar uma metodologia para tal análise, com utilização de técnicas de especificação formal de engenharia de software.

2. Implementar a análise de complexidade e de impacto, de forma automatizada.

A quantificação das operações e de suas complexidades foram calculadas, neste trabalho, de forma manual e por meio de interação humana. Para auxiliar os administradores do ambiente a analisar de forma 
mais rápida e correta o impacto causado por uma manutenção de esquema, a automatização desta quantificação é necessária, utilizando como base os metadados armazenados.

3. Implementar, de forma automatizada, a avaliação das alternativas de implementação das diferentes opções de sincronização de esquema.

Foram citadas, neste trabalho, alternativas para a implementação de manutenções de esquema, face à sua complexidade. Algumas das possíveis opções foram apresentadas, além da implementação das alterações de esquema, como a eliminação e recriação da estrutura completa do ambiente analítico na plataforma móvel (data marts e aplicações) ou o adiamento da sincronização de esquema, mantendo, inicialmente, apenas a sincronização das instâncias os dados sem refletir as alterações de esquema. É importante que a oferta e escolha de uma, dentre as alternativas citadas acima, possa se implementada de forma automatizada tomando por base as estimativas prévias dos recursos necessários para estas diferentes opções de implantação das alterações. 


\section{REFERÊNCIAS BIBLIOGRÁFICAS}

ADAMSON, C.; VENERABLE, M. Data Warehouse Design Solutions, New York: John Wiley \& Sons, 1998. 523p.

AGRAWAL, D. et al. Efficient View Maintenance at Data Warehouses. In: INTERNATIONAL CONFERENCE ON MANAGEMENT OF DATA, New York, 1997. Anais. New York: ACM Press, 1997. p.417-427.

AMBLER, S. W. Agile database techniques: effective strategies for agile software developer. 1. ed. New York: John Wiley \& Sons, 2003. 484 p.

AMBLER, S. W.; SADALAGE, P. J. Refactoring databases. 1.ed. Boston: AddisonWesley, 2006. 350 p;

BANERJEE, J., et al. Semantics and implementation of schema evolution in objectoriented databases. In: ACM SIGMOD INTENATIONAL CONFERENCE ON MANAGEMENT OF DATA, San Francisco, 1987. Anais. San Francisco: ACM Press, 1987. p.311-322.

BARALIS, E.; PARABOSCHI, S.; TENIENTE, E. Materialized view selection in a Multidimensional Database. In: INTERNATIONAL CONFERENCE ON VERY LARGE DATABASES, 23., 1997, Athens. Anais. San Francisco: Morgan Kaufmann, 1997. p. 156-165.

BECKER, J., HOLTEN, R. Fachlonzeptuelle Spezifikation von Führungsinformationssystemen (Conceptual specification of Management of Information Systems). Wirtschaftsinformatik, v.40, n. 6, p. 483-492, 1998.

BERNSTEIN, P. A., BERGSTRAESSER, T. Meta-data support for data transformations using Microsoft repository. IEEE Data Engineering Bulletin, v.22, n.11, p.9-14, 1999.

BLAKELEY, J.A.; COBURUNM, N.; LARSON, P. Updating derived relations: detecting irrelevant and autonomously computable updates. ACM Transactions on Database Systems, v. 14, n. 3, p. 369-400, 1989. 
BLAKELEY, J.A.; LARSON P.; TOMPA, F. Efficiently updating materialized views. In: ACM SIGMOD INTERNATIONAL CONFERENCE ON MANAGEMENT OF DATA, Washington, D.C., 1986. Anais. New York: ACM Press, 1986. p.61-71.

CALVANESE, D. et al. Source Integration in Data Warehouses. DWQ Technical Report, 1998. 6 p.

CASTRO, C., GRANDI, F., SCALAS, M. Schema versioning for multitemporal relational databases. Information Systems, v. 22, n. 5, p. 249-290, 1997.

CERI, S.; WIDOM, J. Deriving incremental production rules for incremental view maintenance. In: VERY LARGE DATABASES, 17., local, 1991. Anais. San Francisco: Morgan Kaufmann, 1991. p. 577-589.

CHAN, M.; VA LEONG, H. SI, A. Incremental update to aggregated information for Data Warehouses over Internet. In: ACM INTERNATIONAL WORKSHOP ON DATA WAREHOUSING AND OLAP (DOLAP), 3., McLean, 2000. Anais. New York: ACM Press, 2000. p.57-64.

CHANG, D., Common warehouse metamodel (CWM), UML and XML, palestra proferida por ocasião do Metadata Conference/DAMA Symposium, Washington, D.C., 2000. Disponível em: <http://www.cwmforum.org/cwm.pdf>. Acesso em: 9 set. 2006.

CHAWATE, S. et al.. The TSIMMIS project: Integration of heterogeneous information sources. In: MEETING OF THE INFORMATION PROCESSING SOCIETY OF JAPAN (IPSJ), 10., Tyo, 1994. Anais. [S.I.; s.n.], 1994. p.7-18.

ELKAN, C. Independence of logic database queries and updates. In: ACM SIGACTSIGMOD-SIGART SYMPOSIUM ON PRINCIPLES OF DATABASE SYSTEMS (PODS), 9, Nashville, 1990. Anais. New York: ACM Press, 1990. p.154-160.

FAN, H., POULOVASSILIS, A. Using AutoMed metadata in data warehousing environments. In: ACM INTERNATIONAL WORKSHOP ON DATA WAREHOUSING AND OLAP (DOLAP), 6, New Orleans, 2003. Anais. New York: ACM Press, 2003. p.86-93. 
FERRANDINA, F. et al. A semantic approach for schema evolution and versioning in the O2 Object Database System. In: INTERNATIONAL CONFERENCE ON VERY LARGE DATABASES, 1995, Zurich. Anais San Francisco: Morgan Kaufmann, 1995. p. $170-181$.

FOWLER, M. Refactoring: improving the design of existing code. Menlo Park: Addison-Wesley Longman, 1999. $431 \mathrm{p}$.

FRANCONI, E., GRANDI F., MANDREOLI, F. Schema evolution and versioning: a logical and computational characterisation. In: INTERNATIONAL WORKSHOP ON FOUNDATIONS OF MODELS AND LANGUAGES FOR DATA AND OBJECTS, 9, Schloss Dagstuhl, 2000. Anais. Berlin: Springer, 2001, p. 85-99.

GONÇALVES, B. M. M. T. Alternativas para propagação das atualizações de um banco de dados operacional para um Data Warehouse. 2002. Dissertação (Mestrado) - Instituto de Matemática e Estatística, Universidade de São Paulo, São Paulo, 2002.

GUPTA, A. Partial information based integrity constraint checking. 1994. 135p. Tese (Doutorado) - Department of Computer Science, Stanford University, Stanford, 1994.

GUPTA, A.; BLAKELEY, J. A. Maintaining views using materialized views. Documento não publicado, 1994.

GUPTA, A.; JAGADISH, V.; MUMICK, I. S. Data integration using self-maintainable views. In: INTERNATIONAL CONFERENCE ON EXTENDING DATABASE TECHNOLOGY, 5, Avignon, 1996. Berlin: Springer, 1996. p. 140-144.

GUPTA, A.; MUMICK I.S. Maintenance of materialized views: problems, techniques, and applications. IEEE Data Engineering Bulletin, v. 18, n.2, p. 3-18, 1995.

GUPTA, A.; MUMICK, I. S.; SUBRAHMANIAN, V. S. Maintaining views incrementally. In: INTERNATIONAL CONFERENCE ON MANAGEMENT OF DATA, 1993, Washington, D. C. Anais New York: ACM Press, 1993. p. 157-166. 
HAMMER, J. et al. The Stanford Data Warehousing Project. IEEE Data Engineering Bulletin, v. 18, n. 2, p. 41-48, 1995.

HARRISON, J.; DIETRICH, S. Maintenance of materialized views in a deductive database: an update propagation approach. In. WORKSHOP ON DEDUCTIVE DATABASES, 1992, Washington, D.C. Anais [S.I.; s.n.], 1992. p. 56-65.

HOLTEN, R. A Framework for Information Warehouse Development Processes. Working Reports of Institut für Wirtschaftsinformatik, n. 67, 1999.

HULL, R., ZHOU, G. A Framework for supporting data integration using the materialized and virtual approaches. INTERNATIONAL CONFERENCE MANAGEMENT OF DATA, 1996, Montreal. Anais New York: ACM Press, 1996. p. 481-492.

IEEE DATA ENGINEERING BULLETIN, Special Issue on Materialized Views and Data Warehousing, New York: Institute of Electrical and Electronics Engineers, v. 18, n. 2, jun. 1995.

INMON, W. H.; HACKATHORN, R. D. Como usar o Data Warehouse. Rio de Janeiro: Infobo, 1997. 278 p.

INTEL TECHNOLOGY JOURNAL - Metadata Management: the Foundation for Enterprise Information Integration. v. 8, n. 4, nov. 2004.

ITALIANO, I. C. Classificação dos domínios transacionais e analíticos para avaliação de alternativas de sincronismo em projetos de Data Warehouse. 2002, 159 p. Dissertação (Mestrado) - Instituto de Matemática e Estatística, Universidade de São Paulo, São Paulo, 2002.

JAGADISH, H. V.; MUMICK, I. S.; SILBERSCHATZ, A. View maintenance issues in the chronicle data model. In: SYMPOSIUM ON PRINCIPLES OF DATABASE SYSTEMS, 14, 1995, San Jose. Anais New York: ACM Press, 1995. p. 113-124.

JARKE, M. et al. Concept base: a deductive object base for meta data management. Journal of Intelligent Information Systems, v. 4, n. 2, p. 167-192, 1995. 
JARKE, M. et al. Architecture and Quality in Data Warehouses. In: INTERNATIONAL CONFERENCE ON ADVANCED INFORMATION SYSTEMS ENGINEERING, 10, 1998, Pisa. Anais Berlin: Springer, 1998. p. 93-113.

JEUSFELD, M.A., QUIX, C., JARKE, M. Design and Analysis of Quality Information for Data Warehouses. In: INTERNATIONAL CONFERENCE ON CONCEPTUAL MODELING, 17, Singapore, 1998. Anais Berlin: Springer, 1998. p. 349-362

KATIC, N. et al. A Prototype Model for Data Warehouse Security Based on Metadata. In: CONFERENCE ON DATABASE AND EXPERT SYSTEMS APPLICATIONS, 9, 1998, Vienna. Anais [S.I.]: IEEE Computer Society, 1998, v.8, p. 300-308.

KELLY, S. Data Warehousing The Route to Mass Customization, New York:John Wiley \& Sons, 1994. 226p.

KIMBALL, R. Data Warehouse Toolkit: The Complete Guide to Dimensional Modeling. New York: John Wiley \& Sons, 2 ed., 2002. 464 p.

KUECHENHOFF, $V$. On the efficient computation of the difference between consecutive database states. In: INTERNATIONAL CONFERENCE ON DEDUCTIVE AND OBJECT-ORIENTED DATABASES, 1991, Munich. Anais Berlin: Springer, 1991. p.478-502.

LEE, K.C.K, SI, A., VA LEONG, H. Incremental view update for a mobile databases. Knowledge Information Systems, v. 2, n. 4, p. 413-437, 2000.

LEVY, A.Y., SRIVASTAVE, D., KIRK, T. Data model and query evaluation in global information systems. Journal of Intelligent Information Systems, v. 5, n. 2, p. 121143, 1995.

LEVY, A.Y.; SAGIV, Y. Queries independent of updates. In: INTERNATIONAL CONFERENCE ON VERY LARGE DATABASES, 1993, Dublin. Anais San Francisco: Morgan Kaufamann, 1993. p. 171-181. 
MARCO, D. Universal Meta Data Models. New York: John Wiley \& Sons, 2004. $478 \mathrm{p}$.

METADATA COALITION, Open Information Model, versão 1.0, 1999. Disponível em:<http://www.mdcinfo.com/OIM/OIM10.html $>$.

MONK, S.; SOMMERVILE, I. A model for versioning of classes in object-oriented databases. In: BRITISH NATIONAL CONFERENCE ON DATABASES, 10, 1992, Aberdeen. Anais Berlin: Springer, 1992. p. 42-58.

MOSHER, C. A new specification for managing metadata. Sun Microsystems, Inc., 2002. Disponível em:

$<$ http://developer.java.sun.com/developer/technicalArticles/J2EE/JMI>. Acesso em: out. 2006.

NOY, N., KLEIN, M. Ontology evolution: Note the same as schema evolution. Knowledge and Information Systems, v. 6, n. 4, p. 428-440, 2004.

MYLOPOULOS, J. et al. Telos: representing knowledge about information systems. ACM Transactions on Information Systems, v. 8, n. 4, p. 325-362, out. 1990.

OMG - OBJECT MANAGEMENT GROUP. Common Warehouse Metamodel Specification, 2001. Disponível em: <http://www.omg.org>. Acesso em: jan.2007.

PAIGE, R. Applications of finite differencing to database integrity control and query/transaction optimization. Advances in Database Theory. New York: Plenum Press, 1984, p. 171-209.

PENNEY, D. J.; STEIN, J. Class modification in the GemStone object-oriented DBMS. In: INTERNATIONAL CONFERENCE ON OBJECT-ORIENTED PROGRAMMING SYSTEMS, LANGUAGES, AND APPLICATIONS, 1987, Orlando. Anais New York: ACM Press, SIGPLAN Notices, 1987, v. 22, n. 12. p. 111-117. 
PETERS, R. J.; ÖZSU, M. T. An Axiomatic Model of Dynamic Schema Evolution in Objectbase Systems. ACM Transaction on Database Systems, v. 22, n. 1, p. 75$114,1997$.

QIAN, X.; WIEDERHOLD, G. Incremental recomputation of active relational expression. IEEE Transactions on Knowledge and Data Engineering, v. 3, n. 3, 1991.

QUASS, D. et al. Making views self-maintainable for data warehousing. In: INTERNATIONAL CONFERENCE ON PARALLEL AND DISTRIBUTED INFORMATION SYSTEMS, 4, 1996, Miami Beach. Anais [S.I.]: IEEE Computer Society, 1996. p. 158-169.

QUASS, D. Materialized views in Data Warehouses. Tese (Doutorado) Department of Computer Science, Stanford University, 1997.

QUASS, D.; WIDOM, J. On-line Warehouse View Maintenace. In: INTERNATIONAL CONFERENCE ON MANAGEMENT OF DATA, 1997, Tucson. Anais New York: ACM Press, 1997. p. 393-404.

QUIX, C. Repository support for Data Warehouse evolution. In: INTERNATIONAL WORKSHOP ON DESIGN AND MANAGEMENT OF DATA WAREHOUSES, 1999, Heidelberg. Anais [S.I.]: CEUR-WS, 1999. v.19. p. 4.

RODDICK, J. F.; SNODGRASS, R. T. Schema Versioning. THE TSQL2 TEMPORAL QUERY LANGUAGE, 1995. [S.I.]: Kluwer, 1995. p. 425-446.

SALEM, K. et al. How to Roll a Join: Asynchronous Incremental Views Maintenance. In: ACM SIGMOD INTERNACIONAL CONFERENCE ON MANAGEMENT OF DATA, Dallas, 2000. Anais New York: ACM Press, 2000. p.129-140.

SAMPAIO, M. C.; DIAS, P. M.; BAPTISTA, C. S. Incremental updates on mobile datawarehousing using optimized hierarchical views and new aggregation operators. In: INTERNATIONAL CONFERENCE ON ADVANCED INFORMATION NETWORKING AND APPLICATIONS, 17, 2003, China. Anais [S.I.]: IEEE Computer Society, 2003. p. 78-83. 
SCHLESINGER, L. et al. Efficiently Synchronizing Multidimensional Schema Data. In: INTERNATIONAL WORKSHOP ON DATA WAREHOUSING AND OLAP, 4, 2001, Atlanta. Anais New York: ACM Press, 2001. p. 69-76.

SHARAF. M. A. et al. Efficient dissemination of aggregate data over the wireless web. In: INTERNATIONAL WORKSHOP ON THE WEB AND DATABASES, 6, 2003, San Diego. Anais New York: ACM Press, 2003. p. 93-98.

SHMUELI, O.; ITAI, A. Maintenance of views. Sigmod Record, v. 14, n. 2, p. 240255, 1984.

STANOI, I. et al. Data Warehousing Alternatives for Mobile Environments. In: INTERNATIONAL WORKSHOP ON DATA ENGINEERING FOR WIRELESS AND MOBILE ACCESS, 1999, Seattle. Anais New York: ACM Press, 1999. p. 110-115.

STAUDT, M., VADUVA, A., VETTERLI, T. Metadata management and data warehousing. Zurich: University of Zurich, 1999. (Technical Report 21, ifi-99.04).

STÖHR, T., MULLER, R., RAHM, E. An integrative and uniform model for metadata management in data warehousing environments. In: INTERNATIONAL WORKSHOP ON DESIGN AND MANAGEMENT OF DATA WAREHOUSES, 1999, Heidelberg. Anais [S.I.]: CEUR-WS, 1999. v. 19. p. 12.

THE OLAP COUNCIL. The MDAPI specification, 1998. Disponível em: $<$ http://www.olapcouncil.org/research/apily.htm>. Acesso em: jan. 2007.

URPI, T.; OLIVE, A. A method for change computation in deductive databases. In: INTERNATIONAL CONFERENCE ON VERY LARGE DATABASES, 1992, Vancouver. Anais San Francisco: Morgan Kaufmann, 1992. p.225-237.

VASSILIADIS, P., BOUZEGHOUB, M., QUIX, C. Towards quality-oriented Data Warehouse usage and evolution. Information Systems, v.25, n.2, p.89-115, 2000.

VASSILIADIS, P. et al. Data Warehouse process management. Information Systems, v.26, n.3, p.205-236, 2001. 
WARIGON, S. Data Warehouse Control and Security. Association of College and University Auditors LEDGER, v.41, n.2, p.3-7, 1997.

YANG, J.; KARLAPALEM, K.; LI, Q. A framework for designing materialized views in data warehousing environment. In: INTERNATIONAL CONFERENCE ON DISTRIBUTED COMPUTING SYSTEMS, 17, 1997. Anais Washington, D. C.: IEEE Computer Society, 1997. p. 458.

ZHUGE, Y.; GARCIA-MOLINA, H.; WIENER, J. Consistency Algorithms for MultiSource Warehouse View Maintenance. Distributed and Parallel Databases, v. 6, n. 1, p. 7-40, 1998.

ZHUGE, Y. et al. View Maintenance in a warehousing environment. In: INTERNATIONAL CONFERENCE ON MANAGEMENT OF DATA, San Jose, 1995. Anais New York: ACM Press, 1995. p.316-327. 


\section{APÊNDICE A - Classificação das alterações de esquema}

\section{ALTERACÕES DE ESQUEMA ESTRUTURAIS:}

As alterações de esquema estruturais são aquelas que causam uma mudança na definição de uma ou mais tabelas ou visões. Abaixo são analisadas as principais alterações de esquema deste tipo, relevantes para o escopo deste trabalho.

ADICIONAR COLUNA - inclui uma nova coluna de uma tabela existente.

- Características específicas: utilizada quando existe a necessidade de se ampliar o conjunto de colunas em uma tabela existente.

- Objetos possivelmente impactados: trigger, stored procedure, visão, tabela, programa de carga, programa de aplicação.

- Mecanismo de migração de dados: pode ser necessário popular o conteúdo da nova coluna, inicialmente.

- Estratégia para período de transição: não é necessário manter período de transição.

REMOVER COLUNA - remove uma coluna de uma tabela existente.

- Características específicas: utilizada quando a coluna não é mais utilizada. Pode ser executada como parte da alteração MOVER COLUNA.

- Objetos possivelmente impactados: controle de integridade, trigger, stored procedure, visão, tabela, programa de carga, programa de aplicação.

- Mecanismo de migração de dados: pode ser necessário preservar o conteúdo da coluna antes de realizar a operação.

- Estratégia para período de transição: manter a coluna durante o período de transição. Após o término do período de transição, a coluna pode ser removida, caso seja uma operação permitida pelo gerenciador de banco de dados. 
ADICIONAR TABELA - inclui uma nova tabela na base de dados.

- Características específicas: utilizada quando existe a necessidade de se criar uma nova tabela na base de dados.

- Objetos possivelmente impactados: controle de integridade, trigger, stored procedure, visão, programa de carga, programa de aplicação.

- Mecanismo de migração de dados: pode ser necessário popular o conteúdo da nova tabela, inicialmente.

- Estratégia para período de transição: não é necessário manter período de transição.

REMOVER TABELA - remove uma tabela existente da base de dados.

- Características específicas: utilizada quando uma tabela não é mais necessária.

- Objetos possivelmente impactados: controle de integridade, trigger, stored procedure, visão, programa de carga, programa de aplicação.

- Mecanismo de migração de dados: pode ser necessário preservar o conteúdo da tabela antes de sua remoção.

- Estratégia para período de transição: manter a tabela durante o período de transição. Após o término do período de transição, a tabela pode ser removida.

ADICIONAR VISÃO - inclui uma nova visão na base de dados.

- Características específicas: utilizada quando existe a necessidade de se criar uma nova visão na base de dados, possivelmente para sumariar dados para uma aplicação, reduzir duplicação de código SQL, entre outras.

- Objetos possivelmente impactados: trigger, stored procedure, programa de carga, programa de aplicação.

- Mecanismo de migração de dados: não é necessário.

- Estratégia para período de transição: não é necessário manter período de transição. 
REMOVER VISÃO - remove uma visão existente.

- Características específicas: utilizada quando uma visão não é mais necessária.

- Objetos possivelmente impactados: trigger, stored procedure, programa de carga, programa de aplicação.

- Mecanismo de migração de dados: não é necessário.

- Estratégia para período de transição: manter a visão durante o período de transição. Após o término do período de transição, a visão pode ser removida.

ADICIONAR SURROGATE KEY - substituir uma chave natural por uma surrogate key.

- Características específicas: as surrogate keys são amplamente utilizadas na modelagem multidimensional, em lugar das chaves primárias naturais das tabelas base. É um recurso importante pois favorece o desempenho e facilita a evolução do Data Warehouse (KIMBALL, 2002). Normalmente, a surrogate key é a chave primária da tabela.

- Objetos possivelmente impactados: controle de integridade, trigger, stored procedure, visão, tabela, programa de carga, programa de aplicação.

- Mecanismo de migração de dados: os valores da coluna devem ser inicialmente populados e, se for necessário, as chaves estrangeiras relacionadas à surrogate key (futura chave primária da tabela) também devem ser populadas, para garantir o controle de integridade referencial.

- Estratégia para período de transição: manter a surrogate key como uma chave alternativa na base de dados, sem eliminar chave primária original. Após o término do período de transição, a surrogate key passa a ser a chave primária da tabela. 
MOVER COLUNA - migrar uma coluna (e todo seu conteúdo) de uma tabela para outra tabela já existente.

- Características específicas: como o desempenho do Data Warehouse é favorecido pela denormalização do modelo de dados, pode ser necessário realizar esta operação e, em alguns casos a operação inversa (normalização) de tabelas. Nestas situações pode-se executar a movimentação de uma coluna para outra tabela.

- Objetos possivelmente impactados: controle de integridade, trigger, stored procedure, visão, tabela, programa de carga, programa de aplicação.

- Mecanismo de migração de dados: os valores da coluna movida devem ser, inicialmente, populados.

- Estratégia para período de transição: manter a coluna nas duas tabelas, tanto na tabela original quanto na tabela para onde a coluna será movida. É necessário também implementar procedimentos (triggers) que garantam a sincronização do conteúdo da coluna nas duas tabelas. Após o término do período de transição, a coluna pode ser removida da tabela original.

RENOMEAR COLUNA - altera o nome de uma coluna existente.

- Características específicas: pode ser necessária para atender a conformidade com padronização de nomes de objetos ou em caso de portar a tabela para outra base de dados.

- Objetos possivelmente impactados: controle de integridade, trigger, stored procedure, visão, tabela, programa de carga, programa de aplicação.

- Mecanismo de migração de dados: a nova coluna deve ser inicialmente populada.

- Estratégia para período de transição: Para garantir o período de transição desta alteração, é necessário criar uma nova coluna (com o novo nome) e mantê-la na tabela, com a coluna original. É necessário também implementar procedimentos (triggers) que garantam a 
sincronização do conteúdo das duas colunas. Após o término do período de transição, a coluna original pode ser removida da tabela.

RENOMEAR TABELA - altera o nome de uma tabela existente.

- Características específicas: pode ser necessária para atender a conformidade com padronização de nomes de objetos.

- Objetos possivelmente impactados: controle de integridade, trigger, stored procedure, visão, programa de carga, programa de aplicação.

- Mecanismo de migração de dados: caso seja criada uma nova tabela para atender o período de transição, a nova tabela deve ser inicialmente populada.

- Estratégia para período de transição: Para garantir o período de transição desta alteração existem duas alternativas. A primeir é criar uma nova tabela (com o novo nome) e procedimentos (triggers) que garantam a sincronização do conteúdo das duas tabelas. Após o término do período de transição, a tabela original pode ser removida. A segunda alternativa é renomear diretamente a tabela original e criar uma visão (atualizável) sobre esta tabela, com o nome da tabela original. Após o término do período de transição, a visão pode ser removida.

RENOMEAR VISÃO - altera o nome de uma visão existente.

- Características específicas: pode ser necessária para atender a conformidade com padronização de nomes de objetos.

- Objetos possivelmente impactados: controle de integridade, trigger, stored procedure, programa de carga, programa de aplicação.

- Mecanismo de migração de dados: não é necessário.

- Estratégia para período de transição: Esta operação é implementada por meio da criação de uma visão com o novo nome, com estrutura idêntica à visão original, assim, durante o período de transição, basta manter as duas visões, a original e a nova. Após o término do período de transição, a visão original deve ser removida. 


\section{ALTERACÕES DE ESQUEMA SOBRE QUALIDADE DE DADOS:}

As alterações de esquema sobre a qualidade dos dados são aquelas que melhoram a qualidade da informação armazenada na base de dados. Abaixo são analisadas as principais alterações de esquema deste tipo, relevantes para o escopo deste trabalho.

CRIAR TABELA DE LOUP - cria uma nova tabela que permite manter informações sobre uma coluna já existente.

- Características específicas: a criação de uma tabela de loup pode ser necessária para implentar controle de integridade referencial ou fornececer informações adicionais (como, por exemplo, descrição) sobre uma coluna que armazene um código, garantindo assim, a qualidade dos dados. Esta alteração pode ocorrer em virtude da evolução das aplicações analíticas, atendendo necessidades específicas do modelo de negócios.

- Objetos possivelmente impactados: controle de integridade, trigger, stored procedure, visão, tabela, programa de carga, programa de aplicação.

- Mecanismo de migração de dados: a nova tabela terá que ser carregada inicialmente. A manutenção períodica dos valores desta tabela, após a carga inicial, deve ser realizada pelos processos de carga existentes.

- Estratégia para período de transição: não existe necessidade de se manter um período de transição, já que foram apenas acrescentadas novas informações à base de dados.

REMOVER RESTRICCÃO DE COLUNA - remove uma restrição de controle de integridade de uma coluna existente em uma tabela.

- Características específicas: alteração utilizada quando uma regra de integridade não é mais aplicável à coluna. Pode ser necessário que, em determinados casos, a restrição seja controlada pelo programa de aplicação (no caso de sistemas de Data Warehouse, normalmente, pelos programas de carga). 
- Objetos possivelmente impactados: controle de integridade, tabela, coluna, programa de carga.

- Mecanismo de migração de dados: não é necessário.

- Estratégia para período de transição: manter a restrição até que o período de transição termine.

REMOVER VALOR DEFAULT - remove o valor default de uma coluna existente em uma tabela quando este valor é fornecido pelo gerenciador de banco de dados.

- Características específicas: quando não existe mais a necessidade de se preencher a coluna com um valor default, de forma automática, pelo gerenciador de banco de dados. Pode ser necessário que, em determinados casos, o preenchimento do valor default seja controlado pelo programa de aplicação (no caso de sistemas de Data Warehouse, normalmente, pelos programas de carga).

- Objetos possivelmente impactados: controle de integridade, tabela, coluna, programa de carga.

- Mecanismo de migração de dados: não é necessário.

- Estratégia para período de transição: manter o preenchimento automático do valor default, pelo gerenciador de banco de dados, até que o período de transição temine.

REMOVER RESTRICCÃO DE NÃO-NULO - remove a restrição de uma coluna existente em uma tabela, para que aceite valores nulos.

- Características específicas: quando o preenchimento de uma coluna passa a não ser mais obrigatório, permitindo que valores nulos sejam armazenados. Pode ser necessário um controle adicional de obrigatoriedade de preenchimento em determinados programas que acessam a coluna.

- Objetos possivelmente impactados: controle de integridade, trigger, stored procedure, tabela, coluna, programa de carga, programa de aplicação.

- Mecanismo de migração de dados: não é necessário. 
- Estratégia para período de transição: manter a restrição até que o período de transição termine.

ADICIONAR RESTRIÇÃO DE COLUNA - cria uma restrição de controle de integridade de uma coluna existente em uma tabela.

- Características específicas: alteração utilizada para garantir que o conteúdo da coluna seja sempre validado.

- Objetos possivelmente impactados: controle de integridade, tabela, coluna, programa de carga.

- Mecanismo de migração de dados: não existe migração de dados, porém, o conteúdo da coluna deve sofrer uma validação inicial, para garantir que seu domínio atende as restrições estabelecidas.

- Estratégia para período de transição: não é necessário manter período de transição.

ADICIONAR RESTRICCÃO DE VALOR DEFAULT - estabelece o preenchimento automático de um valor default, pelo gerenciador de banco de dados, para uma coluna existente em uma tabela.

- Características específicas: quando se quer que, nos casos de não serem fornecidos valores para a coluna, um valor default seja inserido automaticamente pelo gerenciador de banco de dados.

- Objetos possivelmente impactados: controle de integridade, tabela, coluna, programa de carga.

- Mecanismo de migração de dados: é necessário que os campos preenchidos com valores nulos recebam, inicialmente, um valor default.

- Estratégia para período de transição: não é necessário manter período de transição.

ADICIONAR RESTRIC̣ÃO DE NÃO-NULO - estabelece a restrição de conteúdo obrigatório (não-nulo) para uma coluna existente em uma tabela.

- Características específicas: esta alteração é utilizada quando se quer garantir que sempre seja fornecido um valor para a coluna, eliminando este controle dos programas de carga. 
- Objetos possivelmente impactados: controle de integridade, trigger, stored procedure, tabela, coluna, programa de carga, programa de aplicação.

- Mecanismo de migração de dados: caso o conteúdo da coluna tenha valores nulos, deve-se preenchê-los, inicialmente com valores apropriados.

- Estratégia para período de transição: não é necessário manter período de transição.

\section{ALTERACÕES DE ESQUEMA DE INTEGRIDADE REFERENCIAL:}

As alterações de esquema sobre integridade referencial são aquelas que garantem que os controles de integridade referencial em inserções, atualizações ou eliminações de linhas das tabelas. Abaixo são analisadas as principais alterações de esquema deste tipo, relevantes para o escopo deste trabalho.

ADICIONAR RESTRICCÃO DE CHAVE ESTRANGEIRA - adiciona um controle de integridade referencial para chave estrangeira.

- Características específicas: esta alteração é utilizada quando se deseja implementar os controles de integridade referencial para que não sejam inseridos valores inválidos em uma coluna chave estrangeira.

- Objetos possivelmente impactados: controle de integridade, trigger, stored procedure, tabela, programa de carga.

- Mecanismo de migração de dados: pode ser necessário preencher adequadamente os valores da coluna chave estrangeira, com base na chave primária referenciada.

- Estratégia para período de transição: não é necessário manter período de transição.

REMOVER RESTRICÃO DE CHAVE ESTRANGEIRA - remove o controle de integridade referencial para chave estrangeira.

- Características específicas: esta alteração é utilizada quando não existe mais a necessidade do controle de integridade referencial de uma coluna existente em uma tabela. 
- Objetos possivelmente impactados: controle de integridade, trigger, stored procedure, tabela, programa de carga.

- Mecanismo de migração de dados: não é necessário.

- Estratégia para período de transição: não é necessário manter período de transição.

\section{ALTERACÕES DE ESQUEMA NA ARQUITETURA:}

As alterações de esquema na arquitetura são aquelas que melhoram, de forma geral, a interação dos programas externos com a base de dados. Abaixo são analisadas as principais alterações de esquema deste tipo, relevantes para o escopo deste trabalho.

ADICIONAR CÓDIGO - inclui um programa ou rotina no banco de dados, normalmente implementada como uma stored procedure ou trigger.

- Características específicas: esta alteração é utilizada sempre que é necessário incluir no banco de dados código que permita executar uma função específica. Tipicamente, estas funções estão relacionadas a implementar uma rotina de cálculo ou algum tratamento que passe a ser executado diretamente pelo gerenciador de banco de dados, permitindo maior padronização no tratamento da informação.

- Objetos possivelmente impactados: tabela, programa de carga.

- Mecanismo de migração de dados: não é necessário.

- Estratégia para período de transição: não é necessário manter período de transição.

REMOVER CÓDIGO - remove um programa ou rotina no banco de dados, normalmente implementada como uma stored procedure ou trigger.

- Características específicas: esta alteração é utilizada sempre que é uma função implementada no banco de dados não é mais necessária.

- Objetos possivelmente impactados: tabela, programa de carga.

- Mecanismo de migração de dados: não é necessário.

- Estratégia para período de transição: não é necessário manter período de transição. 
ADICIONAR ÍNDICE - cria um índice em uma tabela existente.

- Características específicas: esta alteração é utilizada para melhorar o desempenho das consultas na base de dados.

- Objetos possivelmente impactados: tabela.

- Mecanismo de migração de dados: não é necessário.

- Estratégia para período de transição: não é necessário manter período de transição.

REMOVER ÍNDICE - remove um índice em uma tabela existente.

- Características específicas: esta alteração é utilizada quando não existe mais necessidade de se manter o índice na tabela.

- Objetos possivelmente impactados: tabela.

- Mecanismo de migração de dados: não é necessário.

- Estratégia para período de transição: não é necessário manter período de transição. 